\title{
The Impact Of Using Selected Art Therapy Approaches On Students Diagnosed On The Autism Spectrum (As) Or With Behavioral Disabilities (Bd) In An Elementary School Art Classroom.
}

Amie Dawn Perriello

aperriel@mix.wvu.edu

Follow this and additional works at: https://researchrepository.wvu.edu/etd

Part of the Art Education Commons, Elementary Education Commons, and the Special Education and Teaching Commons

\section{Recommended Citation}

Perriello, Amie Dawn, "The Impact Of Using Selected Art Therapy Approaches On Students Diagnosed On The Autism Spectrum (As) Or With Behavioral Disabilities (Bd) In An Elementary School Art Classroom." (2019). Graduate Theses, Dissertations, and Problem Reports. 3831.

https://researchrepository.wvu.edu/etd/3831

This Thesis is protected by copyright and/or related rights. It has been brought to you by the The Research Repository @ WVU with permission from the rights-holder(s). You are free to use this Thesis in any way that is permitted by the copyright and related rights legislation that applies to your use. For other uses you must obtain permission from the rights-holder(s) directly, unless additional rights are indicated by a Creative Commons license in the record and/ or on the work itself. This Thesis has been accepted for inclusion in WVU Graduate Theses, Dissertations, and Problem Reports collection by an authorized administrator of The Research Repository @ WVU. For more information, please contact researchrepository@mail.wvu.edu. 


\title{
THE IMPACT OF USING SELECTED ART THERAPY APPROACHES ON STUDENTS DIAGNOSED ON THE AUTISM SPECTRUM (AS) OR WITH BEHAVIORAL DISABILITIES (BD) IN AN ELEMENTARY SCHOOL ART CLASSROOM.
}

\author{
Amie Dawn Perriello \\ Thesis submitted \\ to the West Virginia University School of Art \& Design \\ at West Virginia University
}

In partial fulfillment of the requirements for the degree of

Master of Arts in

Art Education

Terese Giobbia, Ph.D., Chair
Joseph Lupo, MFA
Alison Helm, MFA
Department of Art Education

Morgantown, West Virginia

2019

Keywords: Art therapy approaches, Autism Spectrum, Behavioral Disorder Copyright 2019 Amie Dawn Perriello 


\begin{abstract}
The impact of using selected art therapy approaches on students diagnosed on the Autism Spectrum (AS) or with Behavioral Disabilities (BD) in an elementary school art classroom.
\end{abstract}

\title{
Amie Dawn Perriello
}

Students with autism and behavior disorders frequently have a difficult time communicating with their teachers and peers. Art can serve as a vehicle for communication while supporting strengths and encouraging self-esteem. Yet few art teachers have the specialized training needed to work with students on the spectrum, and we are often times left to our own intuition and devices on how to deal with these students. These students deserve greater individualized education, yet this can present a unique challenge to any classroom art teacher who does not have the training to deal with students who come from these special populations. With greater emphasis placed on core subjects such as math, science and reading, there is even less time to have students fully engage in art making activities that may help these students reach their full human potential. This proposal investigates the potential benefits of using selected art therapy approaches within art education classes, and its impact on students diagnosed on the Autism Spectrum (AS) or with Behavioral Disabilities (BD) in an elementary school setting. Through a multiple case study methodology, this proposal investigated the use of a variety of art therapy approaches being developed for use among the AS and BD population in an art classroom setting. Participants in this study were given an additional art class where art therapy approaches were implemented into the projects within the elementary art classrooms. Art therapy fundamentals included Color Psychology, Line Quality and Placement, all of which were used to help decode hidden messages that the artwork may have contained.The purpose of this paper was to discuss how art therapy, when integrated into an art education classroom, could benefit students diagnosed with Autism Spectrum or Behavioral Disabilities. The findings appear to suggest that when certain art therapy approaches are used with students with AS and BD, there is noticeable improvement in student behaviors, student learning outcomes and student creativity. 


\section{Acknowledgement}

I want to thank my committee members for their help throughout this process: my committee chair Dr. Terese Giobbia, as well as Joseph Lupo and Alison Helm for sitting on my committee. I would like to thank Dr. Terese Giobbia for challenging me and helping me throughout the writing process. I would also like to thank West Virginia University Art and Design Program for helping me further my education to reach my dreams. I would also like to thank everyone that I have had the honor of working with through the art therapy program in the last few years. I would also like to thank Dr. John Christey-Casson for sitting down with me at the beginning of my journey and giving me words of wisdom I will carry always.

I would also like to thank my entire family for their constant support throughout this process. Damian Christey for his constant love, editing skills and support throughout this process, cheering me along every step of the way. My grandparents; Mary Perriello and Charles F. Wilson who showed me that hard work can get you anywhere you want as long as you put your mind to it, I know they are watching me from heaven with smiling hearts. 


\section{Table of Contents}

Cover Page

Abstract

Acknowledgement iii

Table of Contents $\quad$ iv

List of Tables

List of Figures

Key terms $\quad$ ix

$\begin{array}{ll}\text { Chapter 1: Introduction } & 1\end{array}$

1.1 Statement of the Problem 1

1.2 Personal Perspective 1

1.3 Significance of the Research $\quad 2$

1.4 Methodology Used $\quad 4$

1.5 Participants $\quad 5$

$\begin{array}{ll}1.6 \text { Summary } & 6\end{array}$

$\begin{array}{ll}\text { Chapter 2: Literature Review } & 7\end{array}$

$\begin{array}{ll}2.1 \text { Art Therapy } & 7\end{array}$

$\begin{array}{ll}\text { The Origins of the Art Therapy Movement. } & 7\end{array}$

The Use of Color Psychology.

Symbolism and Icons. $\quad 10$

Human Potential. $\quad 10$

Robert Ault and Grandma Layton.

$\begin{array}{ll}2.2 \text { Education } & 14\end{array}$

A Brief History of Education in the United States. 14

STEM vs. STEAM. $\quad 16$

Benefits of a Combined Art Education and Art Therapy Curriculum. 18

2.3 Autism Spectrum 20

2.4 Behavioral Disability 24

Gross Motor Activities. 24

$\begin{array}{ll}2.5 \text { Closing } & 25\end{array}$ 
Chapter 3: Methodology $\quad 26$

3.1 Participants and Sites 26

3.2 Contour Line Drawing - Grandma Layton 27

3.3 Journals $\quad 29$

3.4 Observational Notes $\quad 30$

3.5 Art Therapy Fundamentals

3.6 Art History 33

Vincent Van Gogh.

Frida Kahlo. $\quad 34$

3.7 Introspective Self-Portrait 36

$\begin{array}{lr}\text { Chapter } 4 \text { Data Collection and Analysis } & \mathbf{3 8}\end{array}$

4.1 Introduction 38

4.2 Contour Drawing $\quad 40$

4.3 Journals $\quad 50$

4.4 Pizza Box $\quad 50$

4.5 Pizza Pie Chart $\quad 57$

Joy. $\quad 58$

Sadness. $\quad 59$

Fear. $\quad 59$

$\begin{array}{ll}\text { Anger. } & 60\end{array}$

4.6 Van Gogh Portrait $\quad 69$

4.7 Frida Self-Portrait Collage $\quad 83$

$\begin{array}{ll}4.8 \text { Materials } & 92\end{array}$

4.9 Teacher Responses 100

Chapter 5: Discussions and Findings $\quad 105$

$\begin{array}{ll}5.1 \text { Introduction } & 105\end{array}$

5.2 Suggestions for Future Implementation 107

$\begin{array}{ll}5.3 \text { Closing } & 110\end{array}$

$\begin{array}{ll}\text { Conclusion } & 112\end{array}$

Bibliography 113

$\begin{array}{ll}\text { Additional Library (reference books for the students to use) } & 121\end{array}$ 


\section{List of Tables}

Table 1. Instructional strategies, Student activities and Learning outcomes 


\section{List Of Figures}

Figure 1. Human Potential Pyramid, Mcleod, 2018.

Figure 2. Shultis, 2018

Figure 3. Teacher Example Contour Outline

Figure 4. Finished Teacher Example Contour Drawing

Figure 5. Grandma Elizabeth Layton PowerPoint

Figure 6. Student Example Contour Drawing Sketch

Figure 7. Student A Example Contour Drawing

Figure 8. Pizza Box Portfolio Class Set-up

Figure 9. Student A Example Pizza Box Portfolio

Figure 10. Teacher Example Pizza Box

Figure 11. Teacher Example Close up detail of Pizza Box

Figure 12. Teacher Example Pizza Pie Chart

Figure 13. Teacher Example Finished Pizza Pie Chart

Figure 14. Student A Example Pizza Pie Chart

Figure 15. Student B Example Pizza Pie Chart

Figure 16. Student A Example Pizza Pie Chart Completed

Figure 17. Teacher Example sketched Van Gogh Portrait

Figure 18. Teachers Example Van Gogh Portrait

Figure 19. Student A Van Gogh canvas portrait sketch- in process 76

Figure 20. Student A Van Gogh canvas sketch- completed sketch 
Figure 21. Van Gogh Canvas self portrait- Fingerpainting aftermath

Figure 22. Fifth grade Self- Portraits

Figure 23. Student A painting process

Figure 24. Student A completed Van Gogh Self Portrait

Figure 25. Student C Van Gogh Self- Portrait completed

Figure 26. Teacher Example Frida Kahlo Collage

Figure 27. Student A Frida Kahlo Collage working image

Figure 28. Student A Frida Kahlo Collage completed

Figure 29. Twin A Frida Kahlo Collage working image

Figure 30. Twin A completed

Figure 31. Twin B completed

Figure 32. Journal Reflection

Figure 33. Vincent Reflection Sheet

Figure 34. Face Handout \#1

Figure 35. Face Handout \#2

Figure 36. Face Handout \#3

Figure 37. Frida Reflection Sheet

Figure 38. Student D Test page \#1

102

Figure 39. Student D Test page \#2

Figure 40. Student D Test page \#3

104 


\section{Key terms}

Art therapy primarily aims to help individuals experiencing emotional and psychological challenges achieve personal well-being and improved levels of function.

Autism Spectrum (AS) is a developmental disorder that affects communication and behavior. Although autism can be diagnosed at any age, it is said to be a "developmental disorder" because symptoms generally appear in the first two years of life.

Autism spectrum is a condition related to brain development that impacts how a person perceives and socializes with others, causing problems in social interaction and communication. The disorder also includes limited and repetitive patterns of behavior. The term "spectrum" in autism spectrum disorder refers to the wide range of symptoms and severity.

Behavioral disorders, also known as disruptive behavioral disorders, are the most common reasons that parents are told to take their kids for mental health assessments and treatment. ... If left untreated in childhood, these disorders can negatively affect a person's ability to hold a job and maintain relationships.

An emotional and behavioral disorder is an emotional disability characterized by the following: An inability to build or maintain satisfactory interpersonal relationships with peers and/or teachers. ... Consistent or chronic inappropriate type of behavior or feelings under normal conditions.

Cognitive analytic therapy, or CAT, is a short form of talk therapy that allows people to really understand their current difficulties, and develop new methods they can use to keep the issue at bay in the future.

Contour drawing is an artistic technique used in the field of art in which the artist sketches the contour of a subject by drawing lines that result in a drawing that is essentially an outline; the French word contour meaning, "outline.

Color Psychology is the study of hues as a determinant of human behavior.

Echolalia is a meaningless repetition of another person's spoken words. 
Emotional Behavioral Disorder affects a person's ability to be happy, control their emotions and pay attention in school. According to Gallaudet University, symptoms of an emotional behavioral disorder include: Inappropriate actions or emotions under normal circumstances.

Expressionism a style of painting, music, or drama in which the artist or writer seeks to express emotional experience rather than impressions of the external world.

Gestalt therapists and their clients use creative and experiential techniques to enhance awareness, freedom, and self-direction. The word gestalt comes from the German word meaning shape or form, and it references the character or essence of something.

Human Potential Movement (HPM) arose out of the counterculture milieu of the 1960s and formed around the concept of cultivating extraordinary potential that its advocates believe to lie largely untapped in all people

Icon a person or thing regarded as a representative symbol or as worthy of veneration

Introspection is the examination or observation of one's own mental and emotional processes.

Line quality is the thickness or thinness of a line. By varying the line quality an artist can show form in a drawing with just the use of line.

Placement in art therapy references to the size of the main figure in relation to other objects around it, how ones sees themselves on a scale of importance.

Psychoeducation refers to the process of providing education and information to those seeking or receiving mental health services, such as people diagnosed with mental health conditions (or life-threatening/terminal illnesses) and their family members

Self-Portrait is a representation of an artist that is drawn, painted, photographed, or sculpted by that artist

Self-stimulatory behavior, also known as stimming and self-stimulation, is the repetition of physical movements, sounds, or words, or the repetitive movement of objects common in individuals with developmental disabilities and most prevalent in people on the autism spectrum. These actions include flapping, rocking, spinning, or repetition of words and phrases.

STEAM is an educational approach to learning that uses Science, Technology, Engineering, the Arts and Mathematics as access points for guiding student inquiry, dialogue, and critical thinking 
STEM is a curriculum based on the idea of educating students in four specific disciplines science, technology, engineering and mathematics - in an interdisciplinary and applied approach.

Sublimation is one of these ways that the ego reduces the anxiety that can be created by unacceptable urges or feelings. Sublimation works by channeling negative and unacceptable impulses into behaviors that are positive and socially acceptable.

Symbolism is the use of symbols to represent ideas or qualities. 


\section{Chapter 1: Introduction}

\subsection{Statement of the Problem}

Art is known to benefit students and improve cognitive social skills. With an increased emphasis on core education subjects, such as math, science and reading, and the increased populations our statewide school system has experienced, students throughout West Virginia are getting less, if any, art education. Rather than increasing the staff of art and design teachers, in

response to overpopulation, administrators have merely added to the workload of the current staff or simply eliminated positions altogether, shortening the time art teachers have in the classroom with their students. Art education teachers don't see students on a timely basis. This in turn has made it all the more difficult for students to get the attention they deserve and has especially deterred those students affected by behavior disorders or autism from reaching their human potential. One out of fifty-nine students in the US are diagnosed on the Autism Spectrum. This proposal investigates the benefits of using selected art therapy approaches within art education classes, and its impact on students diagnosed on the Autism Spectrum (AS) or with Behavioral Disabilities (BD) in an elementary school setting in rural West Virginia. The research may provide new instruction strategies and art activities for art educators to use that will improve students learning outcomes for students with AS and BD.

\subsection{Personal Perspective}

Throughout my tenure as a classroom art teacher for over ten years at an elementary school in rural West Virginia, I have seen the student population almost double. As a result, I now teach 
almost eight hundred students on a five or six day rotation, with an increasingly higher percentage of students who are on the spectrum diagnosed with either behavioral disorders and/or autism. These students get art every 5-6 days, which in some cases means once every two weeks. Students in kindergarten through second grade rotate every six days, while third through fifth grade have art on a once a week basis. Within this rotating schedule students receive art class for a total of only 40 minutes on a weekly basis.

In the beginning of my teaching career I was able to provide additional class time to students diagnosed with Autism Spectrum (AS) within my weekly schedule. A small group consisting of 5 students usually came accompanied by their classroom teacher and assistant. Ranging in ages from 7-10, I aided students from the second, third and fourth grades that were identified as AS. This was due to having an additional planning period that has since been consumed by the larger population. Additional time, like this, is now being used to teach additional art education classes. The students met once a week for additional art classes, for approximately forty minutes, and were given lessons tailored to meet their specific skills and abilities. Within this time frame, I was able to create art lessons that aligned with the curriculum focus in each of their regular education classroom. The art they created reinforced the other academic content they were studying at the same time. We were able to paint, build and create artwork that reinforced ideas on the weather and seasons. We drew using letters to practice writing while creating animals and pictures. All of these things together created an environment that added to these students being able to fulfil their own personal human potential. 


\subsection{Significance of the Research}

The current focus on unequal learning outcomes, especially among students with AS or BD, raises questions about whether these students are being afforded the opportunity to realize their full human and creative potential (Katz-Buonincontro, 2018). Allowing for students to reach their full human potential should be the goal of any organized system of education specifically within the art classrooms. Human Potential Theory summarizes ways humans can experience an exceptional quality of life filled with happiness, creativity and fulfillment. A visual arts education allows for this by allowing for creativity to flourish. As art education programs have been reduced, devalued, or eliminated, this potential for creativity in the classroom is decreased as a whole. This lack of creativity in turn decreases problem solving skills and the ability to think using abstract thoughts skills that are necessary for these students in particular to succeed in an academic classroom setting. While the current education system in the United States encourages science, technology, engineering, and math courses within its curriculum, the arts, which holds many benefits for students on the spectrum, should also be incorporated. The art education classroom offers a perfect setting for AS and BD students to flourish. The environment in an art classroom is usually less restricted than other academic core classes can be. The focus, in art education, is more towards seeing and interpreting ideas than memorizing information. Both AS and BD students might lack the communication skills needed to communicate feelings that they may have in any given situation. This can lead to outbursts of anger and frustration when they feel they are not being understood. The arts can give them the visual communication tools to be able to express these ideas and emotions, in a more positive outlet. These new communication skills will help them move 
forward in their lives by building a more solid cognitive base to grow from. A higher cognitive development base will help them with peer to peer relationships, social acceptance, social development, and learning how to interact with others in a positive way.

The visual arts curriculum is intended to help students develop their creativity, as well as the ability to communicate with other people through visual images.Visual Art therapy adds an additional layer to this by looking at why and what the patient is adding into the artwork that they are creating, to achieve a deeper understanding of themselves. The students learn from one another through visual observations, mimicry and spoken communication, while in the peer group. When these two ideas are combined the students has the potential to grow socially within their group of peers and personal within themselves.

This proposal investigates the impact of using art therapy approaches on students diagnosed with Autism Spectrum(AS) and Behavioral Disability (BD) within 2 separate art education classes in a rural elementary school setting. When all the arts, including humanities, language arts, dance, drama, music, visual arts, design, and new media are incorporated into the curriculum, human potential has a higher possibility of increasing (Gale,2008).

\subsection{Methodology Used}

Through a multiple case study methodology, this proposal investigated the use of a variety of art therapy approaches being developed for use among the AS and BD populations in an art classroom setting. The process of making artwork as a whole can benefit all elementary school age students and specifically those diagnosed as AS and BD. The participants in this study were given an additional art class where art therapy approaches were implemented into the projects. Art 
therapy fundamentals including Color Psychology, Line Quality and Placement were used to help decode hidden messages that the artwork may contain.

The students studied artwork and completed projects based on Vincent Van Gogh and Frida Kahlo. As they look at the artists' artwork the students were given additional age appropriate information on the artists' personal lives and struggles. By adding this art history element in, the students were able to see that the artist flourished within a negative situation. They then discussed the use of icons and symbols in these two specific artists' artwork and how it can be translated into their own work. Now imagine if these ideas were placed in the public school system alongside art education. How could the students who struggle to speak and communicate benefit from tools that would make these tasks easier to do? What are the possibilities to a student who has behavioral problems when he has the tools to express his or her anger in a positive way? Art gives them the tools needed to function in everyday life.

\subsection{Participants}

The participants in this study were divided into two groups of children; one group was made up of fourth grade students and the other group consisted of fifth grade students. The two groups were divided evenly between girls and boys with 13 boys and 12 girls in each of the two grades. The participation groups contained three students diagnosed with either AS or BD, matching the statistical average. The two groups met over an eight week course. The students differed in their academic levels, skills and abilities.

In Group I, the fourth grade class was made up of 24 students and met on Thursday mornings. In Group II, there were 26 students in the fifth grade group, who met on Tuesday 
mornings. Topics taught during these sessions were not included during regular art education. The goal in doing that was to create a safe and controlled setting for the students to express inner thoughts and feelings within their peer group. All participants were students within the rural elementary school and had been in the school for at least one year prior to this group meeting. The use of the familiar space and teacher lessened the time needed for the participants to become comfortable and relaxed in the situation. This provided them with a familiar environment to express feelings and emotions while creating their artwork.

\subsection{Summary}

Art education gives students tools they need to communicate and process information on a higher level while gaining skills that will personally benefit them. Changes in the West Virginia Education System should include the incorporation of the Visual Arts as a key component to helping students achieve their full potential, especially among the AS And BD student populations. Through the visual arts, students have greater possibilities for reaching their true human potential. Valuable skills could be gained by the incorporation of these art therapy ideas in collaboration with art education. This idea could not only benefit the student population of West Virginia but specifically the Autism Spectrum and Behavioral Disability special education community. 


\section{Chapter 2: Literature Review}

\subsection{Art Therapy}

\section{The Origins of the Art Therapy Movement.}

The Art Therapy movement was founded during the 1940s. One of its leading founders was Margaret Naumburg, who was not only a psychologist in the field but also an educator, artist and author. Naumburg was influenced by the teachings of Sigmund Freud and that dreams could contain deeper meanings. She believed that students could not only learn knowledge through art therapy, but also use that knowledge as long as they also knew themselves (Naumburg, 1966). By adding psychology and a new concept known as sublimation within the education system, something that had not been done up before, Naumburg was able to see that behaviors students were displaying stemmed from a deeper problem, and that these internal problems manifested themselves as actions (Naumburg, 1996).

Reimagining how new art therapy tools could be used to benefit students that struggled in different areas of education gained momentum in the 1960s. Up to this point in education, these negative behaviors were seen as isolated events that were never truly dealt with. Naumburg incorporated the use of sublimation into art therapy. Sublimation is defined as one of the ways the ego reduces the anxiety that can be created by unacceptable urges or feelings. Sublimation works by channeling negative and unacceptable impulses into behaviors that are positive and socially acceptable (Rubin, 1999). 
British schools were the first to begin adding additional art therapy sessions, counseling and services in their budgets due to the fact that they have seen a positive outcome to the services previously being offered (Keating, 2007). In Keating's study conducted on one class of 14 year-olds, Keating exposed how art therapy was seen to be a less invasive process than talk therapy where participants may feel threatened to speak out, noting how images and artwork could expose what the students were feeling more than words alone (Keating, 2007). Having this time of "self-expression and release" the brain was allowed to focus more intently when asked to do more structured subjects (Keating, 2007). Keating's study revealed that behaviors improved when inner emotions were released versus being bottled up (Keating, 2007).

In a study done by the Georgetown Behavioral Health Institute ("Benefits of expressive art therapy for children,” 2016), the findings seemed to show that expressive arts could positively affect function, mood, cognition and behavior. This was particularly evident in children with special needs, such as those with autism, speech impairments, PTSD, developmental disabilities, ADD/ADHD or other mental and behavioral health conditions ("Benefits of expressive art therapy for children," 2016). Expression through art became a way to help children feel a sense of normalcy without judgment, while allowing them to show their individual personality and bring attention to their strengths.

The Georgetown Behavioral Health Institute study focused on many different benefits to art therapy and the different ways that it can help the individual ("Benefits of expressive art therapy for children," 2016). The study showed that when dealing with not only autism patients but patients with behavioral health conditions and other disabilities, art therapy was not only beneficial to the 
person's conditions but also has benefits from normality, a sense of pride and building on strengths they may not see on a everyday bases.

In the article published in the American Art Therapy Association journal in 2017, An expert on School-Based Art Therapy explains how art therapy helps children make sense of the insensible, the author, Keane (2018), goes through the important role a school has in today's society.

Schools are usually the first to see a student struggle cognitively, emotionally or behaviorally (Keane, 2018). In this school setting, it is not only helpful to students with special needs but for all students involved. Keane's article goes on to explain that schools are beginning to become the first, sometimes only, to assist with mental health care. This is due partly to the long and diligent task to get a child identified with a problem, but then the cost to receive services becomes too much for the family to handle (Keane, 2018).

Keane goes on to explain how artmaking can help students express and explain emotions they internally cannot make sense of, creating a visual record to return back to later. By identifying and process of the internal self, the students become more aware of how to comprehend and gain perspective. Keane refers to art therapy as a bridge connecting the student, teacher and parents.

\section{The Use of Color Psychology.}

Describing not only the history behind color psychology and how it is used in art therapy can vary greatly depending upon other cultural influences (Cherry, 2018). Color psychology is linked not only the art world but in every aspect of life and culture. In some cultures black and red have different meanings and can often connotate positive or negative feelings. Cherry defines each color and discusses what each is typically associated with. While color can have an influence on how we feel and act, these influences are also subject to personal, cultural, and situational factors. 
Because of this, color psychology is not an exact science, and more research needs to be done. (Cherry, 2018).

\section{Symbolism and Icons.}

Symbols and icons have been used in artwork by many different cultures throughout the world. There is a strong link between the arts and language (Morrell, 2011). In Morrell's study on symbolism, the author discusses the uses and differences of icons and symbols, how they can be used in art and last the importance of their uses. It goes into the use of bilingual therapy that can also be seen during this process. The words that a client can say while in session can vary greatly from the icons and symbols being used, which creates two different languages; the spoken and the drawn, and "art in art therapy can function as sign, symbol, and intermediary, and thoughtful switching between art and language modes may affect positive change in art therapy clients" (Morrell, 2011, p. 31) With AS students, who may not be verbal, or who have limited verbal skills, being able to express oneself through art becomes a critical component of showing their inner feelings and/or fears.

\section{Human Potential.}

During the 1940s and 50s, psychologist Abraham Maslow introduced the movement of human motivation, which was based on the idea that people seek fulfillment and personal growth (Mcleod, 2018). Maslow created system based on the hierarchy of needs, a pyramid that listed the basic human needs and in what specific order one should achieve all the steps. The figure below shows the five steps, from the base to the top, of the pyramid are as follows; physiological needs, safety needs, love and belonging needs, esteem needs and last self-actualization needs. 
Hierarchy of Needs- Psychologist Abraham Maslow

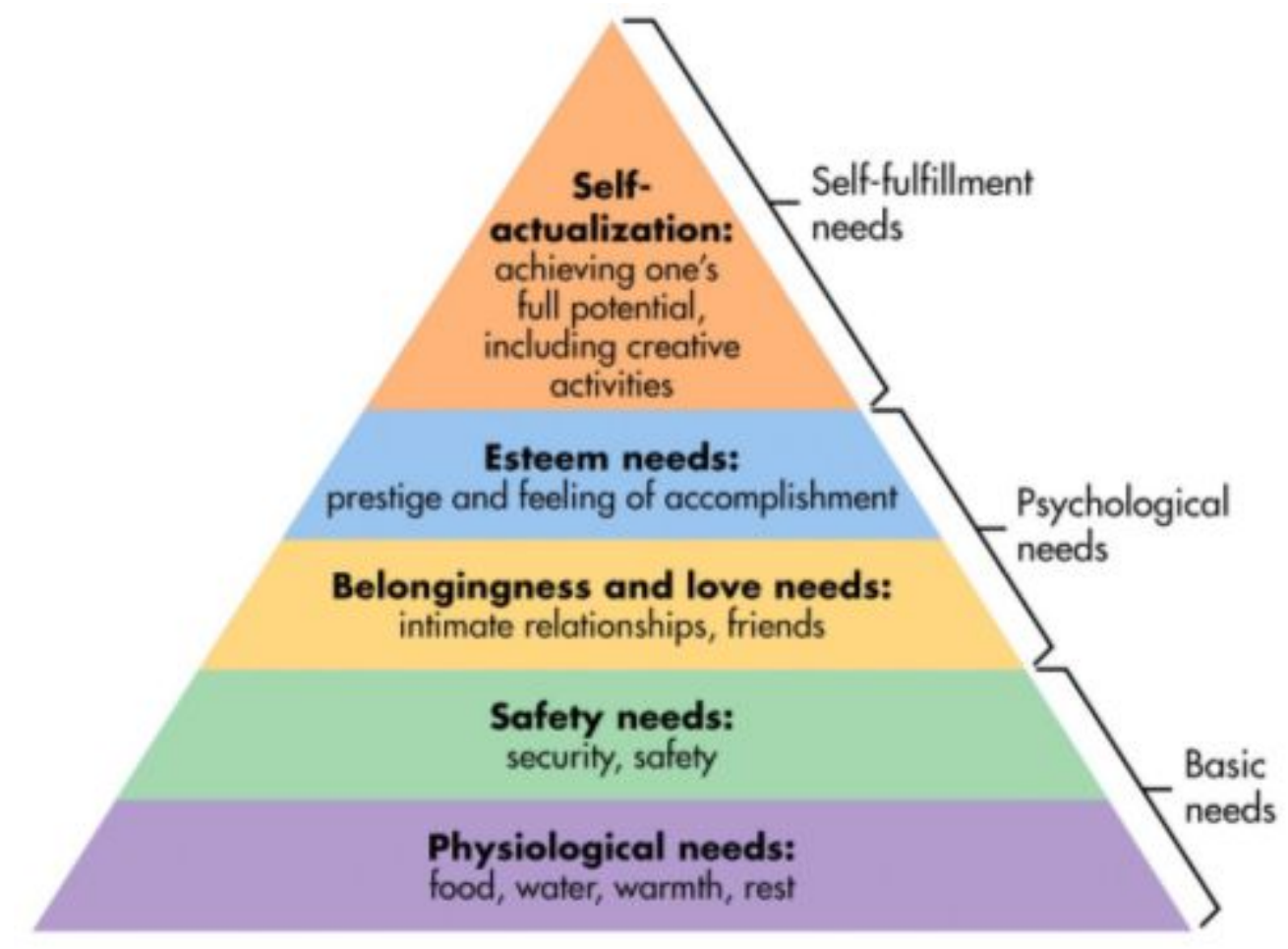

Figure 1. Human Potential Pyramid, Mcleod, 2018.

In the 1980s, Maslow changed his original idea by saying that the order that one pursues to reach the top of the pyramid does not need to be in this specific order. This was due to the fact that individuals have different cultural and social values. People can value one level more over another level, while some people may not need or desire one level at all. This change allowed for individual growth based on one's own personal values and allowed for the pyramid to fit the needs of specific individual.

Throughout the 1960s and 1970s, the human potential movement was very popular. Human Potential Theory lists the purpose, description, risks and typical results one would experience when using these specific type of therapies (Gale Encyclopedia of Medicine, 2008). The early human 
potential movement placed greater emphasis on the development of the human self through such techniques as encounter groups, sensitivity training, and primal therapy. In a paper presented at the 42nd Annual Conference of the California Association for Health, Physical Education, and Recreation, author Stratton Caldwell listed the positive benefits of the use of the human potential in relation to the minority classes to obtain a more equal share of the American dream, noting how there was a "rediscovery, renaissance, resurrection of the body as central, integral, valued in one's unified being and becoming" (Caldwell, 1975, p. 1). Caldwell showed that non-verbal movement and motions made through physical activity and dance therapy could improve a person's whole self.

The idea of the human potential movement associated with art therapy does not seem as far stretched. The use of dance therapy versus art therapy does not vary as much as one may think. Both are creative outlets allowing the participants to search internally for inspiration. The nonverbal element that Caldwell speaks of in his paper ties into my idea of AS, where students could have limited or no verbal communication skills, and thus art therapy would give the students a way to communicate nonverbally with adults and peers.

Within psychology and education, there is heightened interest in how the arts, broadly defined, contribute to diverse aspects of well-being. Contemporary educators now claim that the promotion of well-being, rather than economic gain, should be the primary goal of higher education (Ryff, 2018). Ryff looked at the importance of a renewed interest in the idea of the human potential movement for use across multiple fields in modern society. Ryff included this specific statement on education and the importance of the idea of a human's potential as a more beneficial avenue across multiple disciplines, including medicine where medical professionals are now looking at the arts as a healing tool for patients. 
These articles signal a return to insights from Dewey (1934) whose writings on how we experience art and how it matters in our lives. These studies show how the use of art therapy approaches can have positive benefits and direct us to look at how they can specifically benefit those students who have been labeled as AS and BD. The students are able to reference the ideas and levels from the hierarchy of needs to create their own path to achieve their own full human potential.

\section{Robert Ault and Grandma Layton.}

Robert Ault could see that the use of art therapy was not just for the individuals with clinical diagnoses but for anyone seeking help. In 1961, Ault found a new friend and colleague in Don Jones. Jones and Aule "would sit in the office after hours and talk about dream of the idea of using art to work with patients" (Feen-Calligan, 2008). Ault looked at Jones as his mentor and as a father figure to him in the field. Jones referred to their work as "soul language," or a language without words but letting their soul be heard. In 1986, Ault and the Menninger Foundation created a video on how art therapy could be used at their clinic and Ault became a driving force to show viewers how art therapy could be used to benefit people of all ages. He studied Freud and illuminated ways to show how dreams, symbols and images influenced all aspects of culture, specifically looking at Naumburg use of sublimation as a tool. This brought about the inclusion of the human potential movement, which brought together the use of art, music, therapy and drama as ways to express directly to art therapy (Rubin, 1999).

The use of the gesture drawing technique was first introduced into art therapy by Kimon Nicolaides as a way to make rapid drawings in a short amount of time. This action of moving and creating the drawings were later used to form of contour line drawing techniques (Rubin, 1999). 
Ault used the specific technique of contour line drawings to help Grandma Layton who had dealt with depression for many years. This quick action was able to relieve stress and cause the person to relax and Ault showed how doing these quick contour line drawings had an antidepressant effect on participants.

Layton had suffered for years from bipolar disorder and had tried many different therapies, including being placed in a facility, over the years, with no success. Introducing art therapy into Layton's life became a turning point for her. A YouTube video created by the Topeka Library in Kansas gives a brief history of the personal struggles of Grandma Elizabeth Layton and her importance on the art community and her artwork (TopekaLibrary, 2010). The video describes Layton's use of art making to describe personal and political views, and also revealed her use of contour drawing, even demonstrating how to draw using this style.

\subsection{Education}

\section{A Brief History of Education in the United States.}

The current U.S. educational system was created at the beginning of an industrial revolution that occurred slightly over a century ago and has changed little since that time. Robinson (2006) looks at how that educational system is broken. Robinson's idea-- that the system is focused more on one side of the brain rather than the individual as a whole. Students are encouraged to be a one sided brain thinker and in turn are punished for expressing creativity or individualism. Students are taught that being creative or unique are not as important as the Math and Language Arts students. The school system has created an unbalanced hierarchy of importance where the Arts are always at the bottom. Robinson reinforces the notion that the education revolution has started to form whose 
focus has moved away from the outdated notion of a hierarchy of subjects and more toward technology and uniqueness, including creativity (Robinson, 2006).

The visual arts has the ability to be incorporated into all areas of education and in turn create more rounded people. During the 1870s, the Massachusetts Board of Education recognized the importance of art in the many different areas of their growing economy (Bolin, 1990). They realized that due to a lack of drawing skills, the areas of manufacturing and mechanical designs of the new cities and commonwealths were suffering. They saw the importance that drawings skills could have on their economy and created the Massachusetts Drawing Act of 1870. The Drawing Act was adopted to accommodate a variety of purposes, including drawing education classes in the graded public schools of Massachusetts. The Drawing Act enforced that drawing was required in all schools as a core education class. This included not only teaching drawing skills to school age students but also anyone over the age of fifteen when the population of the city was over ten thousand.

Blumberg (n.d.) writes about the life of Arthur Wesley Dow who was a American artist and teacher. Dow used his studies in Japan and Japanese art to create a guide for art classes and art teachers. His study, entitled Composition: A Series of Exercises in Art Structure for the Use of Students and Teachers, was first printed in 1899. This became a staple in art education stressing the importance of line, color, not an (Japanese concept of light and shade, or mass), and value. According to Dow, art making was a way to express oneself, personally, by using these few simple elements.

In West Virginia, Policy 2419 was created in 2017 as a supplement to the Regulations for the Education of Students with Exceptionalities, giving clear instructions of the expectations of 
students within our state (West Virginia Department of Education [WVDE], 2017). The policy goes

through all student rights while in the public school system. The document has many sections

dividing the different classifications of gifted through special education students. Listed in 1.1 the

scope, it states the following;

"These policies and procedures apply to preschool, early childhood, middle childhood, adolescent and adult students whose educational programs require special education and related services. These apply to three year-olds, as of their third birth date, through five year-olds with disabilities, students with disabilities ages five through twenty-one, all exceptional gifted students in grades nine through twelve and to all gifted students in grades one through eight as specified. Rights under these regulations cease to apply at the end of the school year in which the student turns twenty-one years of age, that is, the year in which the student is twenty-one years of age prior to September 1 or the student has met graduation requirements for a standard high school diploma" (WVDE, 2017)

Within the state of West Virginia it is required for all school age students to participate from elementary through middle school within the visual arts, yet that is not always the case in many of the schools throughout the state. High school varies between the arts, only requiring one area between music and art verses requiring both. The law includes the importance of the visual arts as a requirement for elementary thru middle school but leaves a potential gap within the high school years. The lack in required visual arts, during the high school years, lessons the potential and creative outlet needed for students with a disability.

\section{STEM vS. STEAM.}

The connections between developing concepts and solving problems is listed as being one of the positives for using STEAM over STEM (Wade-Leeuwen, Vovers, Silk, \& Chemical, 2018). Historical examples show how the arts have been incorporated with science to invent new and exciting creations (Wade-Leeuwen, Vovers, Silk and Chemical, 2018). 
The STEAM approach is not a new concept. People throughout history have shown the importance of combining the arts with other core academic subjects. Leonardo Da Vinci is the perfect representation on how the arts can be integrated across the curriculum. Da Vinci's own artwork has shown us the importance of combining science and art to make important human discoveries (Wade-Leeuwen, Vovers, Silk and Chemical, 2018). Leonardo Da Vinci showed how combining the arts, technology and sciences can help to make new discoveries; including the human form, functions of the human brain, optics, perspective and color. Da Vinci also created blueprint drawings that were later be used to help create the flying machine, tanks, and parachutes, to just name a few. When including the STEAM approach into an academic setting the possibilities are endless (Wade-Leeuwen, Vovers, Silk, \& Chemical, 2018).

The argument between STEM vs. STEAM is an ongoing one. With STEAM the individual has the ability to create a visual representation of the concepts they are discussing, enabling them to not only think abstractly about new ideas, but also the ability to visually work through any problems that may arise. The arts and humanities that STEAM incorporates give them additional tools that employers are looking for in new employees. The last paragraph in the article is a list of practical applications of STEAM, listing individuals that have combined two fields together to form a career.

STEM supporters argue that the arts should be kept separate from the core focus of science, technology, engineering, and math (Cox, 2016). This idea could be linked to the United States' concern of essential skills needing to be up to date with other developing nations. STEAM supporters think that the arts being incorporated into the STEM subjects strengthens the core subjects and act as a way to fill in the education gaps that may exist (Cox, 2016). Lectures focusing 
on the divide between two classes of people, scientists and the literature world, to examines the importance of arts and humanities being taught in college of science and college of technology courses have been ongoing (Lachman, 2018; Snows, 1959). Lachman (2018) promotes the use of STEAM over STEM explaining the benefits set in real world situations. His study showed how graduating professionals lack the social and real world applications to the science and technologies that they develop. New professions also could lack some of the socially acceptable interaction skills that the humanities give teams when working with co-workers. Issues of ethics and responsibility in science and technology could also play a factor in their career developments as they progress forward (Lachman, 2018). These individuals also have another class working against them, the populists, and how the real world can stereotype the science and technology community as intellectuals.

When incorporating arts into mainstream studies, the results and test scores speak for themselves. Students who were given additional art into their core classes scored higher on SAT tests than students who were not given the additional resources (Edudemic, 2015). Students who have arts within their curricula will develop additional coping skills and be able to problem solve in a different way to address new issues as they arise, expand and improve behavior and learning skills. Art allows the individual to create freely and express emotions that would, in other situations, not be allowed to release or express.

\section{Benefits of a Combined Art Education and Art Therapy Curriculum.}

A good art therapist has to know his art and his materials well; art education therefore serves as a framework for art therapy—Drachnik 
The combination of art education and art therapy within special education can result in positive outcomes among the special population (Malley, 2017). Art Education implores teachers to have examples of the artwork students will be creating to allow them to see what it is they will be making. The process of making art also allows the teacher to work through any difficulties that may arise during the process (Wiste, 2016). Malley states that the combination can give the students full participation, increase their own personal independence, convey upper level thinking, development of artistic and personal competencies and advance their personal social and emotional skills. The two departments working together can give the students a positive outcome for the students to learn in.

Art therapy primarily aims to help individuals experiencing emotional and psychological challenges achieve personal well-being and improved levels of function. Cognitive analytic therapy, or CAT, is a short form of talk therapy that allows people to really understand their current difficulties, and develop new methods they can use to keep the issue at bay in the future. Gestalt therapists and their clients use creative and experiential techniques to enhance awareness, freedom, and self-direction. The word gestalt comes from the German word meaning shape or form, and it references the character or essence of something. Psychoeducation refers to the process of providing education and information to those seeking or receiving mental health services, such as people diagnosed with mental health conditions (or life-threatening/terminal illnesses) and their family members. Knowing the different types of therapies that are available and when to use what form of therapy is important because it allows the viewer to understand the vast abilities and variations that art therapy has the ability to take on. 
Art therapists have used new approaches to benefit these students specifically. Robert Ault grouped art therapy into four main categories; analytic therapy, functional art therapy, Gestalt art therapy and psycho-educational art therapy, and all of these categories of art therapy can tie directly into art education (Rubin, 1999). Stout (1995) looked at how art, specifically visual arts; drawing, painting, printmaking, fiber arts, pottery, metalsmithing, glasswork, computer graphics, and mixed-media, can act as a gap between what thoughts exist in the mind and ability to express verses what the outside world sees. In other words the act of art making can be the piece of the puzzle that can

bring the picture together. Academics like math, reading and writing are important factors of the developmental process but without the creativity that art provides the other areas lack.

Art has the ability to act as the link from the heart to what the eyes can see being outwardly expressed. Ault drew with his patients when he conducted art therapy sessions, similar to the way an art education teacher draws with his or her students. By doing this, art teachers and art therapist can create a safe environment for his patients to share thoughts and emotions (Rubin, 1999).

\subsection{Autism Spectrum}

Autism Spectrum is a developmental disorder that affects communication and behavior. ${ }^{1}$ It is a condition related to brain development that impacts how a person perceives and socializes with others, causing problems in social interaction and communication. The disorder could also include

\footnotetext{
${ }^{1}$ In 2018 the CDC determined that approximately 1 in 59 children is diagnosed with an autism spectrum disorder (Autism Facts and Figures, 2019) The site then goes on to show the different statistics, challenges that an individual diagnosed can face along with ideas on support. The website goes on to list problems that an individual could possibly face throughout their life.
} 
involuntary repetitive patterns of behavior. The term "spectrum" refers to the wide range of symptoms and severity (Mayo, 2018). Behavioral Disability is a condition exhibiting one or more of the following characteristics over a long period of time and then begins to affect a child's educational performance:

1. An inability to learn that cannot be explained by intellectual, sensory, or health factors;

2. Difficulty building or maintaining satisfactory interpersonal relationships with peers and teachers;

3. Inappropriate types of behavior or feelings under normal circumstances;

4. A general pervading mood of unhappiness or depression;

5. A tendency to develop physical symptoms or fears towards personal or school problems (Loveless, 2019).

Students with an AS or BD diagnosis need additional tools to function on a typical level. These students, that when given these additional tools, will be able to have a higher human potential when in an academic classroom setting. Students with AS and BD diagnoses tend to have trouble focusing on the tasks. This can cause them to become a distraction in class due to their lack of tools available to them. These distractions are not just to the student themselves but also to the teacher and the other students in the room. By incorporating the concepts and fundamentals of art therapy into an additional art education class, my proposal attempts to determine what student learning outcomes will emerge from providing students with greater focus on art and art therapy.

One idea is to decrease the amount of excess energy that can accumulate in the body, which in turn then can cause behavioral issues. This can be done by incorporating gross motor activities 
into the students personal schedule; specifically activities that use the large muscle groups and get the body moving more freely. By adding these activities the stress hormone Cortisol is then released (Bergland, 2013). By adding art alongside gross motor activities, specifically large muscle activities, the student will move more and gain skills that will potentially help them focus in an academic classroom setting. This will then cause less distractions, for not only them personally, but for others as well.

Art therapy encourages learners to explore and express themselves using art materials even though crafting attractive artwork is not the goal (though it may be a happy by-product) (Lacour, 2018). Studies show the different positive outcomes from incorporating art therapy among students with Autism, including developing interpersonal/social skills, increases in self-esteem. As an expressive creative outlet (especially among non-verbal students), art therapy helps to develop fine motor skills, relieve stress and anxiety while creating art and develop oneself (Valentin, 2018).

Self-Stimulatory Behavior is a repetitive physical action or object movement that is common in many different disabilities, especially Autism. The actions vary between the different senses including; hand flapping, eye blinking, scratching, smelling of other people or objects, rocking back and forth, auditory noises including tapping of ears, snapping fingers and vocalization also known as echolalia. These are all considered behaviors to self-stimulate an individual's senses. This behavior is caused by a lack in the brain that makes the body crave additional stimulation to excite or arouse the nervous system. These actions were considered, in the past, to be a educational distraction, but in fact are not. If the individual is allowed to express these actions after a set learning time, the actions then act as a positive reinforcement to the learning (Edelson, n.d.). 
The benefits of art therapy with clients diagnosed AS are huge. People that have AS usually have problems with abstract thinking. AS clients respond well to visual clues and nonverbal communication prompts. Art therapy has a unique ability to address several specific and difficult treatment goals by capitalizing on the desirable use of art materials that are compatible with ASD symptoms (Martin, 2009). The ideas of abstract thinking paired with visual clues and nonverbal communication prompts ties completely into the idea of art therapy and Art therapy has the ability to help clients with AS immensely, benefiting from the materials and free-feeling associated to art making. In a study on children with ASD showed how art therapy positively contributes to becoming more flexible and expressive, more relaxed, and more able to talk about their problems in the therapeutic setting as well as in their home situation (Schweizer, Spreen, \& Knorth, 2017). Yet, the field of art therapy with a specialization in Autism Spectrum is a very small and specific field, with many available benefits (Martin, 2009). Add to that an already small pool of art therapists that specialize in assisting clients diagnosed as AS. Within the AS community art therapy is seem as an added expense to an already pulled thin family budget. Families with children that are diagnosed with AS usually have a massive amount of out of pocket expenses. Art therapists that specialize with clients with AS are usually too expensive to consider, this may partly be because the specialization is too specific.

In a study on eight experienced art therapists and their experiences with their AS clients - children diagnosed with AS between the ages of 8-12, research showed that not all AS clients can deal and understand symbolic based projects completely, some can only respond to projects through body movements and expressions. Art therapy could have an effect on reducing behavioral problems of children with autism in specific problem areas, including social 
communicative behavior, flexibility, and self-image (Schweizer, Spreen, \& Knorth, 2017). Art therapy does not always work the exact same way from one AS client to another. Some art therapy projects are about the end result were others are focused more on the process one takes to create the end project. This study ties into my own research of students in the fourth and fifth grade and while more research is needed on the topic, the study shows the benefits of using art therapy with children diagnosed with AS can greatly improve.

\subsection{Behavioral Disability}

In a pilot program conducted at the Andy Warhol Museum, called Warhol Art, created to help emotional and behavioral challenged students, the program showed the benefits of using art with AS and BD students. The program was a collaboration with the art teacher at Friendship Academy. Friendship Academy is a private elementary school focusing on mental health services for students who may need them, located in Pennsylvania. The school is a licensed through the state and provides many different services and is a training site for special education, social work, psychology and counseling (Falk, 2017).

The program focused on having students use art to connect their feelings into a positive and productive art making outlet. The first step was to tour and introduce the students to artwork in the Warhol Museum. Staff from the Warhol encouraged the students to express emotions and ambitions. Student artwork was later displayed at The Andy Warhol Museum during a sensory-friendly "Silent Disco" event hosted at the museum in celebration of Autism Awareness and Acceptance Month. The exhibit showed how student artists were encouraged by seeing their artwork prominently displayed in a renowned art museum. 


\section{Gross Motor Activities.}

Behavioral issues usually respond well to gross motor activities, specifically the use of large muscle groups and getting the body moving more (Bergland, 2013). The movement releases Cortisol, the stress hormone. The body builds up Cortisol and needs the release for the body to keep functioning. Once the body has too much Cortisol the body becomes stressed and needs a place to release, in turn causing outbursts of anger.

At Drexel University, a study conducted to see if adding art making classes, around 45 minutes, would reduce participants Cortisol levels. The study was conducted with participants between the ages of 18- 59 years old and results showed that among $75 \%$ of the participants Cortisol levels were lowered after one 45 minute session. Originally Drexel University thought that the materials and age could affect the outcome of the study; Clay and marker projects vs. a collage project, however, in the end the results did not support this initial idea (Kaimal, Ray, \& Muniz, 2016).

\subsection{Closing}

Imagine an art program that incorporates all these ideas incorporating art therapy approaches into art education into one place, specifically tailor made for students to participate and flourish in. Imagine the benefits of such a program and the growth an individual could achieve. All students no matter what their diagnosis or label, ability or academic achievements could come together and learn and grow as individuals in a peer group setting. 


\section{Chapter 3: Methodology}

\subsection{Participants and Sites}

The research may provide new instruction strategies and art activities for art educators to use that will improve students learning outcomes for students with AS and BD. For this proposal, I used two sets of participants: one group made up of fourth grade students and the other group of fifth grade students. Observations were done while the students were participating in multiple art therapy based art projects. The participants reflected before and after about the process using journal entries. Teacher interviews were conducted following this process to see the impact on the students core education classes. The two groups were evenly divided between girls and boys. Each group includes a classroom set of no more than 30 students. The two groups met separately from one another over a eight week period, each session lasted 30 minutes.

The session space was set up with eight separate tables pushed together to create on large rectangle. The participants were given plenty of space to spread out materials as they work. The room is divided into multiple sections that serve different functions and spaces. The drying racks have been placed in two different areas. The back left corner holds a table top rack that holds multiple flat pieces, the space in the right corner is an area of $10 \times 25$ foot that hold multiple different styles of drying features. There is a matching rack as featured in left hand side, a large three tiered rolling cart to hold three dimensional art and a double sided mobile two dimensional cart. The space provides both storage and drying capability for multiple artwork of any size.

All materials that were needed for the daily projects were set up ahead of time in separate 
divided spaces. If multiple materials were needed for a project on the same day they were divided and organized into separate bins. The bins were filled with similar materials based on the different steps involved in each project. Materials that were used on multiple steps were placed in a more permanent container and brought out during all the steps it was required. The students retrieved the materials as needed as they went through the different project process. All materials were set in the center of a table placed in front of the large multiple table rectangle they will be working on. The students were given back their projects at the beginning when they first walked in. Once all the students were in the classroom I reintroduced the materials we had previously worked on then released them to work on projects independently. While they worked I observed their mood and attitude towards the project and materials. Are they showing signs of anger or dismay? Does that coincide with the journal entry for the day? Or is it the project causing the new negative attitude being displayed? Is anyone showing signs of joy? Will the journal change from the beginning of class to the end? After the project has been done?

The students participated in multiple different styles and media based art activities over the eight week time span. The activities dealt with looking internally into themselves and then were asked to reflect on the activities at the end of each session.

\subsection{Contour Line Drawing - Grandma Layton}

As a pre assessment project the students were introduced to contour line drawing and the artwork of Grandma Layton. The reason for doing this was a direct relation to what Robert Ault did with Grandma Elizabeth Layton during her art therapy sessions. Ault said that to use it correctly 
would be to look at three areas of the patient: person, the process, and the product. Ault used the contour line drawing technique to release stress and anxiety emotions.

Influenced by Freud, Ault examined and how dreams, symbols, images and influences certain aspects of culture. He looked at Naumburg and the use of sublimation as a tool. (Tobin, 2015) This brought about the inclusion of the human potential movement. This movement brought together the use of art, music, therapy and drama as ways to express directly to art therapy.

Ault looked at the process for key elements and symbolism to identify a problem or work through an issue that the patient may be having. Ault was not as worried about the art making elements and techniques but more on the process that the patient went through while creating the piece. An art educator looks more at the technique that are being demonstrated in the lesson and the end result. The underlying issues that the student has may become seen during the process of creating, but were not the focus in this setting.

The end result would be to look at the information that was left in the picture, as clues into the person's life. The three together would tell a lot about the person and create a platform to gain trust and other services. He argued that the use of art in any form would provide healing growth even if it was not labeled as "therapy."

Ault also looked at dreams like Freud. Using art as a tool to express the thoughts and feeling in the person's minds, somethings that they may or may not want to say out loud but could process and cope with in terms of images in their art, Ault was able to incorporated the use of sublimation from Naumburg and ask the client questions during the process stage. He was an influential part of the 'marriage' of all these different elements and bringing about modern art therapy, which in turn helping heal thousands of patients. 
Ault was not just an art therapist but an artist also. Ault was known to draw with the patients during their time together, this action helped in gaining their trust, allowing them to beginning opening up during sessions. Ault's small act could be tied to how an art educator creates examples of projects and draws with their students.

Ault ties into both of the artists I am using for a few different reason. Van Gogh created his artwork using expression and looked at the workings of the inner mind just as Freud did. Art was a release for Van Gogh and a way to cope with the inner feelings he held inside. Frida Kahlo used symbolism and images in her collages to represent ideas and convey emotions that she wanted the viewer to feel and see when looking at her artwork. She uses representation of the objects, what they mean to her specifically, verses what others see and feel, making the artwork and symbolism specific to her.

\subsection{Journals}

Journals were kept to allow the students to reflect on emotions at the beginning and end of each session. The allotted journal time was five minutes, twice during the session, at the beginning and end of class totaling ten minutes. The journal entries were pre printed sheets that will have placed in their individual binders (Figure 32). The pre printed sheet includes a place for them to write their name, date and project title. On the right hand side of the sheet is a rectangle square that four emojis were placed inside of. The emojis included are happy face, a shy face, a slightly annoyed sad face and last a mad face with angled eyebrows. This will allow the students a range of emotions to choose from. The bottom of the page was left blank, to allow them space to write and 
draw freely about their emotions. All folders, containing the journals, were kept inside of the pizza boxes when not being used.

The beginning journals were used to assess mood prior to the project. How they are feeling that day? By doing this I created a baseline for the students emotions and overall wellbeing for that day. The ending journal was a way for the student to reflect not only on the project or activity they just participated in but also as a physical action. The visual of seeing the beginning sheet and the emotions that they felt at the beginning of session, but also the physical action of turning the page and placing the emotions in the past could show some growth. Grammar and spelling were not be a main focus during this time. If a student specifically asked me how to spell a particular word I would provide assistance.

After the initial two artists and artwork were shown and the projects explained I allowed the students to do their second reflection differently that day. The students were given a pre printed sheet of the artist face, Van Gogh (Figure 33) and Frida Kahlo (Figure 37), instead of the normal journal entry page. This was only done on during the time we introduce these two artists. The students reflected over the image using words, images and color of what they thought and felt towards the artist initially.

\subsection{Observational Notes}

As the students worked on journals I made visual observations and notes about their overall reactions to the process but also any distress, emotions or struggles they may be showing. The notes were divided with dates, group being seen and project title on the top. The students were listed in 
the notebook by initials only. My notes were kept in a separate notebook that only I have access to. All of these steps were to insure the students are kept as anonymous as possible.

\subsection{Art Therapy Fundamentals}

Color psychology is not a perfectly defined science, allotting for many variations including age, cultural influence, race and personal preferences (Cherry 2018). Line quality is the thickness or thinness of a line. By varying the line quality an artist can show form in a drawing with just the use of line. Placement in art therapy refers to the size of the main figure in relation to other objects around it, how ones sees themselves on a scale of importance. 

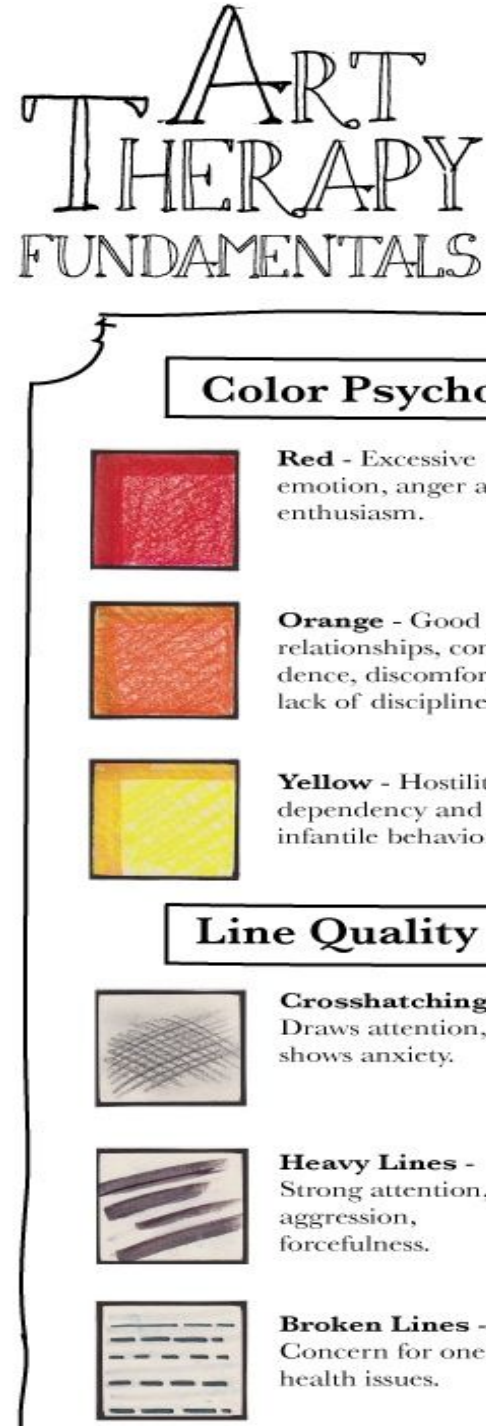

Red - Excessive enthusiasm.

Orange - Good lack of discipline. dependency and infantile behavior.

Heavy Lines Strong attention, aggression, forcefulness.

Broken Lines health issues.

\section{Color Psychology} emotion, anger and

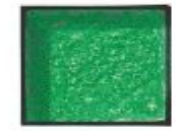
trolled behavior, cycles of renewal and overprotectiveness. relationships, confidence, discomfort,

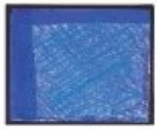

Blue - Conmolled reactions, selfrestraint, distance and sadness.

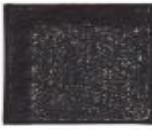

Black - Controlled reactions, compulsive behavior, unconsciousness, depression and loss.

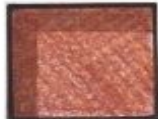

Brown - Timidity and shyness, worthlessness and new beginnings.

Yellow - Hostility

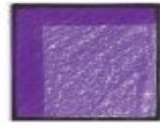

Violet/Purple Paranoia, persecution and quietness.

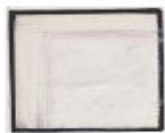

White - Timelessness and concealing, clarity and synthesis.

The Ast Therapy Sourceboolk Cathy Malchioxil

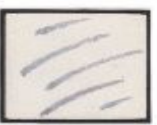

Faint Lines Lack of energy, depression, insecurity, inhibition, shyness.

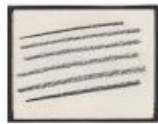

Straight Lines Determination, aggression, need for added struc ture.

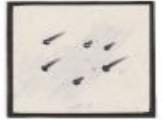

Jabbing Marks Inward or outward anger.

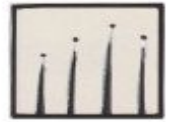

Pointed Lines Intelligence. Concern for oneself,

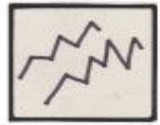

Jagged Lines -

High energy, anger, frustration.

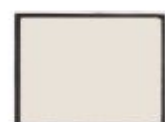

Excessive Erasing - Draws attention, shows anxiety

Signals from the Child

\section{Page Placement}

Base Lining Placing figure at very bottom of page or running off page suggests drawer requires need for added security.

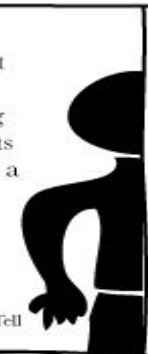

Underlining Placing figure on top of patch of grass or

other object or drawing heavy lines under-

neath figure is suggestive of lack of security or structure.
Very Top - Difficulty in reaching goals.

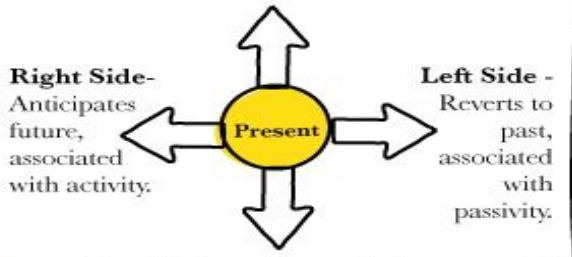

Very Bottom - Insecurity issucs.

Figure 2. Shultis, 2018 


\subsection{Art History}

The students then looked at artwork by Frida Kahlo and Vincent Van Gogh. The students learned about these two artists; trials they faced personally and how their artwork reflected their lives. The information and artwork shown, the artists' lives and trials they each faced were kept age appropriate. The students learned about how Van Gogh fought with depression and visions but limited information about the extreme measures that the artist suffered. Due to Frida Kahlo's' subjects and nudity in her artwork, the amount of pieces able to be shown was be limited. Frida Kahlo's images that were used show an overview of collage and symbolism. The two artists were chosen for this project to show not only a disability causing oneself to become an artists but also the idea that a action or event can changes one's life. The students were also reference these artist in their own artwork and projects. The projects for both artists were to create a self portrait done in two very different style with two very different processes of creating.

\section{Vincent Van Gogh.}

Van Gogh used paint as his own personal tool to create brush strokes, textures and feeling. The students studied the different brush strokes of Van Gogh and described the chaotic paint mixing textures he created with each stroke. The students watched a virtual three-dimensional tour inside Starry Night and Van Gogh's Bedroom in Arles. The tour is a visual field trip that is animated (MotionMagic, 2016). I choose these specific images to begin with because the students are familiar with Starry Night and have previously studied this painting with me in art education class. This additional prior knowledge helped them add new information to an existing artist. The students then listened to music written about Vincent's life. Ellie Goulding redid a Don Mclean 
song titled, "Vincent" (Goulding, 2018). Both versions were listened to while working on the projects. Don Mclean's music video showed multiple Van Gogh artworks in the video (Wysty67, 2009). Ellie Goulding video has more easy to read lyrics, but no artwork by the artist. All these videos were projected on the classroom smart board, this way the students were able to watch and listen. The combination of the two videos allowed for visual images and written words to be shown. By adding different media about the artists the students were able to relate better with the subject and artist. The more information they are given the more of a personal association they will be able to have towards the project. How do the colors mix? What does it make you feel? Do the colors that Van Gogh uses tell you anything about what he may of been feeling? Does knowing more about the artist change your thoughts and feelings about the artwork?

\section{Frida Kahlo.}

\section{"Passion is the bridge that takes you from pain to change."}

\section{-Frida Kahlo}

Definitions for both symbolism and icons were given to the students at the beginning of this lesson, prior to the background on Kahlo. What other types of images represent an idea? What images give a visual representation that does not need words to express an idea? Think of the projects we have done so far; Do any of the items you used in any other projects fit into that idea? The goal in these questions is have the students connect with the use of emojis from the pizza pie chart project. Students were given some background information about Frida Kahlo; Frida was going to become a doctor when her life changed due to a bus accident. She lost one of her legs and was restricted in motion and mobility. People thought that this event would limit her abilities. She began painting while in the hospital and soon realized that she had a talent for it. People then began 
to realize that her disability did not limit her in any way. This was an opening to talk to both groups about how others view you and whether their preconceived ideas ever held you back from achieving or going for a goal.

The students talked about symbolism and how Frida Kahlo used it in her artwork.

Symbolism is the use of symbols to represent ideas or qualities and an artistic and poetic movement or style using symbolic images and indirect suggestion to express mystical ideas, emotions, and states of mind. The first image that the students will look at is Self-Portrait with Thorn Necklace and Hummingbird. This piece specifically is a self portrait that incorporated a wire necklace with a hummingbird pendant. The background contains a monkey and a black panther, one is seen lurking over each of her shoulders. The second artwork we will be looking at is Memory, the Heart. The painting shows a full body portrait of Frida Kahlo. To the left of her is a short dress with a white top, reminiscent of a school uniform. On the far right hand side hangs a traditional mexican dress that were a familiar fashion for Frida to wear. After looking at Kahlos' work they picked symbols that they will then be able to incorporate into their own self portrait. The students could pick symbols out of the artist's work as well as create and use new ones more personal to themselves. Does a portrait have to include a face to be a portrait? Can a portrait be made up of objects that represent the person? Would that be possible? These were the questions when looking at the last image, My Dress Hangs There. This specific painting does not include an actual portrait of Frida Kahlo but is made up solely of images and symbolic ideas that spoke to the artists during her time in America. The painting was created because she was homesick for her beloved Mexico. The painting was created depicting icons and landmarks that were close to her but also the icons of her homeland. The dress in the center is the first image that most focus on. It is a traditional Tehuana 
Mexican dress, Frida was known to fashion. The background contains images and icons including; the Statue of Liberty, Modern industrial society and difference between the upper and lower class. This painting was specifically created to express Kahlos' discontentment in America due to its lack of human values and dim overview of the states. (Freedman, 2019) There are many elements to this painting that are a bit above the fourth and fifth grade level of thinking. I focused on the above list of symbols and icons for this reason.

\subsection{Introspective Self-Portrait}

Throughout history artists have used self-portrait as a way to not only portray themself, but also for other more personal reasons. Vincent Van Gogh painted over 30 self-portraits between the years 1886 and 1889. His collection of self-portraits places him among the most prolific self-portraitists of all time. Van Gogh used portrait painting as a method of introspection, a method to make money and a method of developing his skills as an artist. Introspection is the examination or observation of one's own mental and emotional processes. Vincent Van Gogh saw creating self portrait paintings as a important personal element to his ongoing battle with mental illness. Van Gogh's artwork is considered a form of expressionism, a style of painting, music, or drama in which the artist or writer seeks to express emotional experience rather than impressions of the external world. This connects completely with the project associated to Van Gogh. The students were given canvas that they were to paint their inner self, not the person that everyone sees but the version of you that you see yourself as. They were able to use different painting techniques and materials on their canvas including brush, palette knife and finger painting. 
When starting on the Kahlo portrait using symbols the students were encouraged to draw out all parts and pieces on their paper prior to applying any color, on a $8 \times 10$ sheet of cardstock. This will allow, the artwork to be stored in the portfolio box with the other artwork. The students must include one symbol that they found from the Frida Kahlo piece and at least one new symbol that represents something to them. What specific symbol did you picked out of Kahlos artwork and why did you pick it? The reason and object chosen must also be reflected in the journal entry.

The students penciled out all the outlines to the piece. They then were given a choice of materials to color: color pencils, markers, crayons. They have prior knowledge of using these materials together and what order they can be used in. Markers never on top of crayon. Crayons over markers. This was reviewed to prevent any major disasters. This is a recurring statement that the students are used to hearing from art class. Due to the material and details that these pieces could contain I allowed two sessions for this project. Some of the students made additional pieces outside of the session times and want to bring in those pieces to add to their collage, which was allowed. Only flat materials were allowed be collaged into this piece. This could include; scrapbooking paper, magazine clippings, stickers etc. The students had multiple pieces that they were able to collage onto one set background paper. 


\section{Chapter 4 Data Collection and Analysis}

\subsection{Introduction}

The purpose of this paper was to combine art therapy ideas within an art education classroom to see the potential benefits among students diagnosed with Autism Spectrum or Behavioral Disability. The research may provide new instruction strategies and art activities for art educators to use that will improve students learning outcomes for students with AS and BD. This chapter reflects on the data collection tools used throughout this proposal and the individuals' reactions and experiences towards each of those tools. Teacher examples and student examples are included. 


\begin{tabular}{|l|l|l|}
\hline Instructional Strategies & Student Activities & Learning Outcomes \\
\hline $\begin{array}{l}\text { PowerPoint; Modeling, Open } \\
\text { dialogue; } \\
\text { Guided practice }\end{array}$ & Pizza box & Project completion, etc. \\
\hline Open discussion & Journals & $\begin{array}{l}\text { Emotions pre / post art } \\
\text { assessment }\end{array}$ \\
\hline $\begin{array}{l}\text { PowerPoint, Art History, } \\
\text { Artmaking demonstration }\end{array}$ & $\begin{array}{l}\text { Grandma Layton- Continuous } \\
\text { Contour Line Drawing; } \\
\text { Self-Portrait }\end{array}$ & $\begin{array}{l}\text { Large muscle group- } \\
\text { Cortisol } \\
\text { De-stressing activity }\end{array}$ \\
\hline $\begin{array}{l}\text { Open dialogue, peer to peer } \\
\text { discussions, group station } \\
\text { painting }\end{array}$ & $\begin{array}{l}\text { Pizza Box Portfolio- Exterior } \\
\text { Self - Portrait }\end{array}$ & $\begin{array}{l}\text { Color association to } \\
\text { external emotion self, } \\
\text { Color Psychology- Outer } \\
\text { emotions as color }\end{array}$ \\
\hline $\begin{array}{l}\text { Inner Emotions as icons demo, } \\
\text { open dialogue, modeling }\end{array}$ & Mixed media collage & $\begin{array}{l}\text { Symbolism- Iconography } \\
\text { internal emotions }\end{array}$ \\
\hline $\begin{array}{l}\text { Art History, Demonstration, } \\
\text { pallet knife technique demo }\end{array}$ & $\begin{array}{l}\text { Vanvas Painting; Pallet knife, } \\
\text { brush, finger }\end{array}$ & $\begin{array}{l}\text { Introspection- Emotional } \\
\text { color based self-portrait }\end{array}$ \\
\hline $\begin{array}{l}\text { Art History, Demonstration, } \\
\text { vollaging demonstration, }\end{array}$ & $\begin{array}{l}\text { Frida Self- Portrait Collage } \\
\text { Symbolic and Iconic self }\end{array}$ & $\begin{array}{l}\text { Abstract thinking } \\
\text { abilities }\end{array}$ \\
\hline
\end{tabular}

Table 1 


\subsection{Contour Drawing}

Day one began with introducing the new concept, contour line drawing. Contour line drawing can be described as an outline of a shape. As I introduced the idea, I showed the students my example. I then demonstrated how to use and prop the mirror in front of them while they drew. Students were then allowed to move around the room collecting the materials they would need. The students started creating their contour line drawing self portrait using mirrors, $8 \times 11$ paper and pencils. Mirrors were placed in a separate drawer, easily labeled for the students to find. Students then used the remaining time to work on the contour line self portrait. I walked around assisting anyone who had difficulties or questions.

Due to the students, in the fifth grade group, concerns towards contour drawing from Day 1 I added a short powerpoint to the beginning to day 2 . This allowed the students to see a few pieces of Grandma Elizabeth Layton artwork and a photograph of Grandma Layton herself. This showed the students what she looked like in real life. The second slide was the definition of a contour line drawing. I included this to reinforce the definitions that I had introduced the previous class. We then looked at four different pieces of artwork that Grandma Layton created in her life. We discussed the fact that the pieces were drawn out then colored using colored pencils, the same materials that they would be using. The powerpoint took around 5 minute class time. Once the powerpoint was complete the students were sent back to their tables. Artwork was passed out along with buckets of colored pencil. The students were then given colored pencil and blenders to help blend the different layers and colors together. This was demoed using an elmo camera on the 
whiteboard. All remaining time in the second class session was used for finishing any remaining parts, not finished on day one, and adding color and detail using the colored pencils. Due to this being a prior knowledge projects I did not have the students do any journalling element for this project.

When I introduced this concept to the class I was met with a bit of hesitation and unsureness. Most of the students were excited to practice a new idea and concept. There was a small group of around four students that were more opposed to the idea. They voiced their concern with messing up, not being able to erase and that the portrait would look strange and not "perfect". The students that voiced their concerns I would label more as a perfectionist type, struggled and drew slowly when working in this style. These students on average take longer on projects and work slower, being more meticulous on each step. Lines were drawn slowly and lots of additional thought was placed into where and how lines were added, caring more on the end result. The majority of the participants in the group made carefree lines and focused on the journey to get to the final image, not stressing over the additional lines, looking at it as the process and part of the end result. This process took about two weeks of time. The first 30 minutes was used to explain the process and to draw out the lines and creating the features and details of the self portrait.

My example was shown during the introduction process (Figure 3-4). The students asked questions about the materials we would be using during the project during this time. What materials did you use to color yours with? How did you get the color so smooth? All these questions were answered as a group. Some of the students had used blender pencils before in my classroom and were familiar with their process. Other students needed to be shown, how to use the blenders, in small group settings. 
By adding the PowerPoint images of Grandma Layton's artwork it clarified a lot for the students (Figure 5). They were able to see how a professional does contour line drawings. The introduction slide also included a photo of Elizabeth Layton. This way they were able to see, not only her artwork, but what she actually looked like in real life. Once they were shown the artwork the students responded more positively to the idea of this drawing style. I think by adding this short five minutes into the plan the students responded faster and in a positive way to an idea of contour line drawings that they had previously seen as a negative project. They saw that "perfect" in this style is not as important as the process of making the artwork itself.

The student example I have attached is a student from my fourth grade participation group, the individual will be referred to as Student A. Student A is a student participating in my fourth grade group who is diagnosed AS. Student A has a autism mentor assistant that accompanies her to all of her classes, including this group. During the contour drawing project she loved getting to use the mirror and being able to look at herself (Figure 6). This probably played a part in her constant attention and consistency of the artwork, adding to her own personal success. The mentor assistant did not assist Student A during this project. The mentor assistant remained in the art classroom with her, but watched from afar to allow her to work through the new concept on her own. Student A did struggle a bit with the idea of a continuous contour line drawing, instead she created a wonderful contour drawing self-portrait. Student A was very consistent, staying in all the lines she created, while coloring with the colored pencil (Figure 7).

One male student, in the fourth grade group, moved away right after this project was completed. This student moving away changed my number of participants by one. 


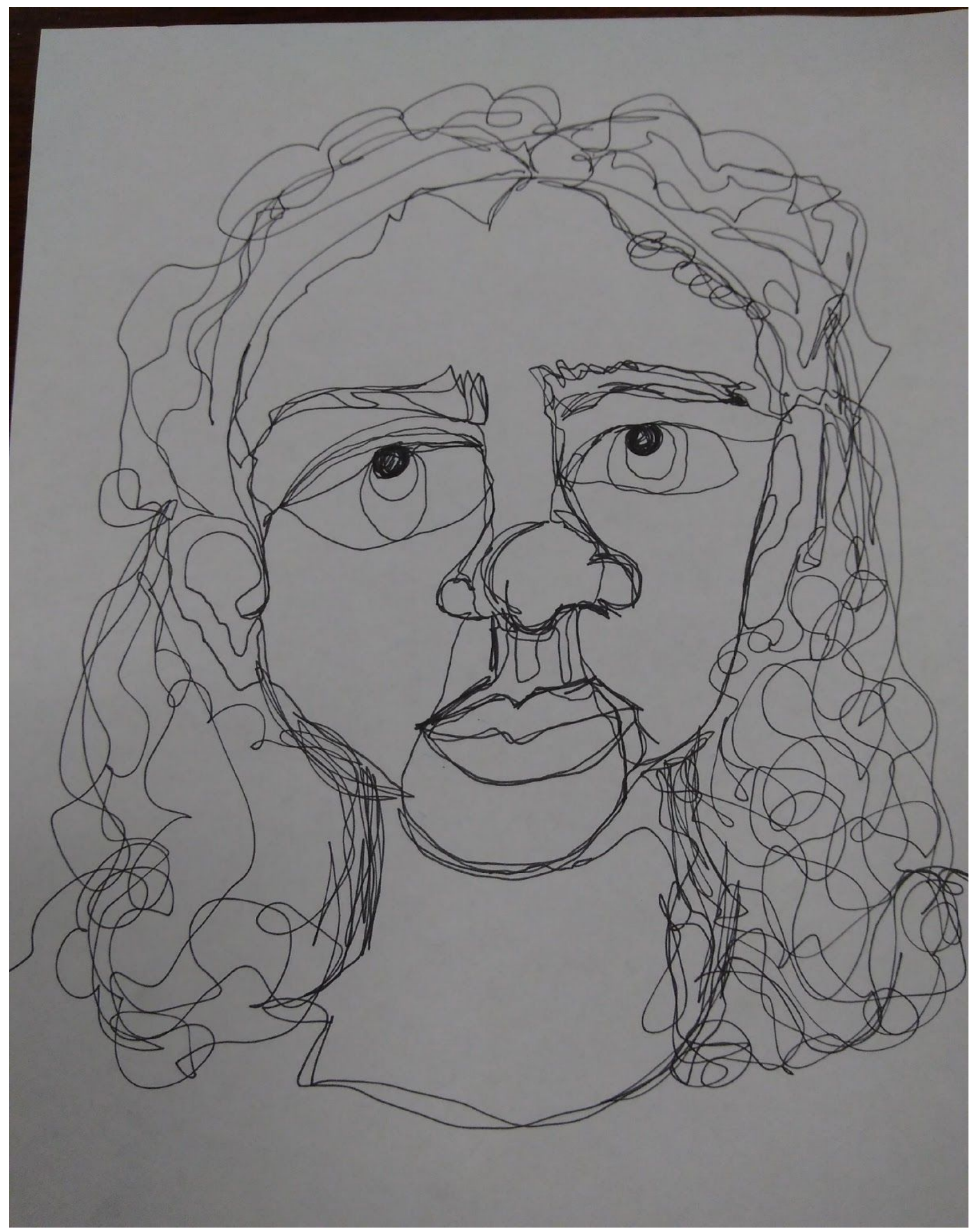

Figure 3. Teacher Example Contour Outline 


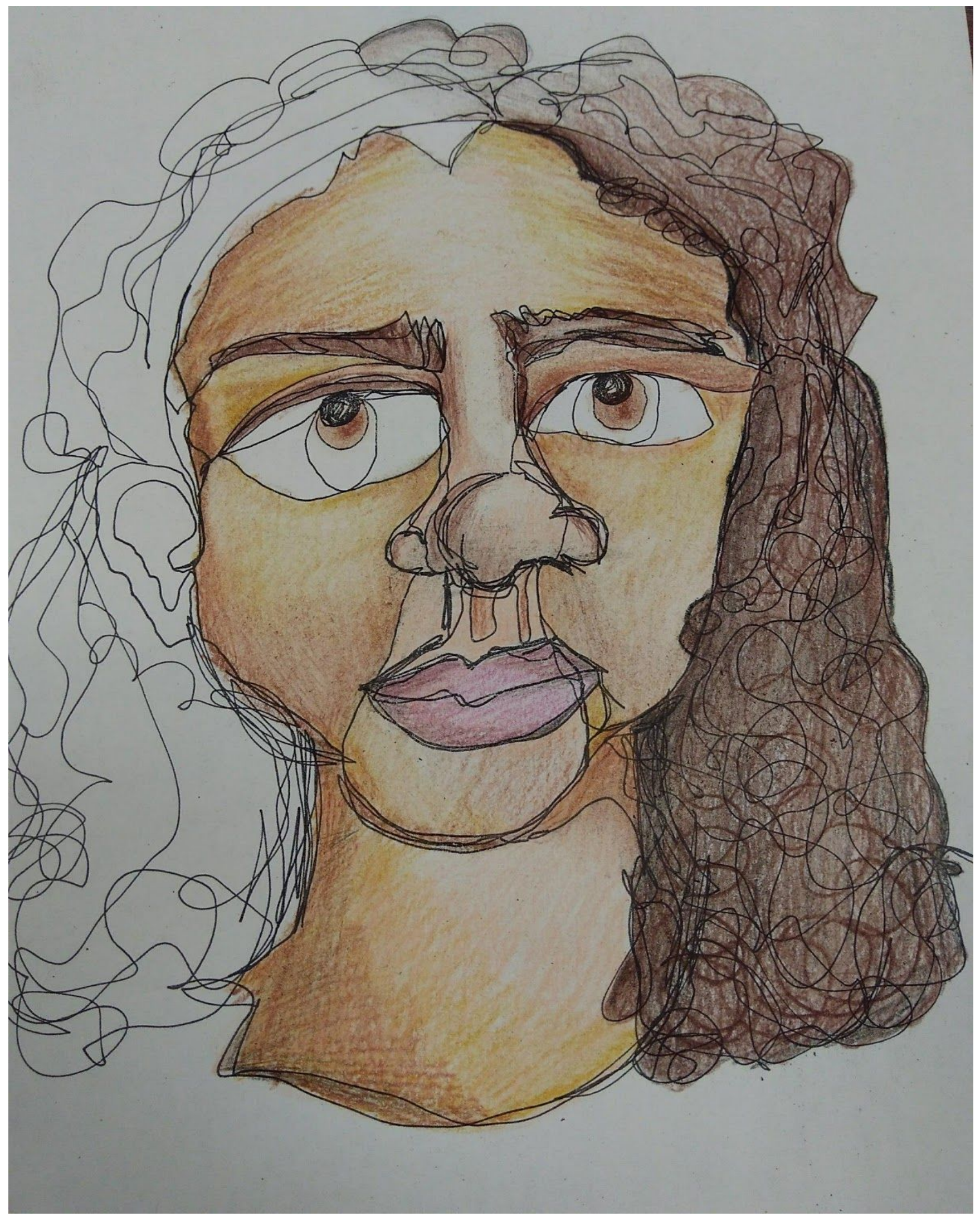

Figure 4. Finished Teacher Example Contour Drawing 


\section{Grandma}

Layton

CONTOUR LINE DRAWING

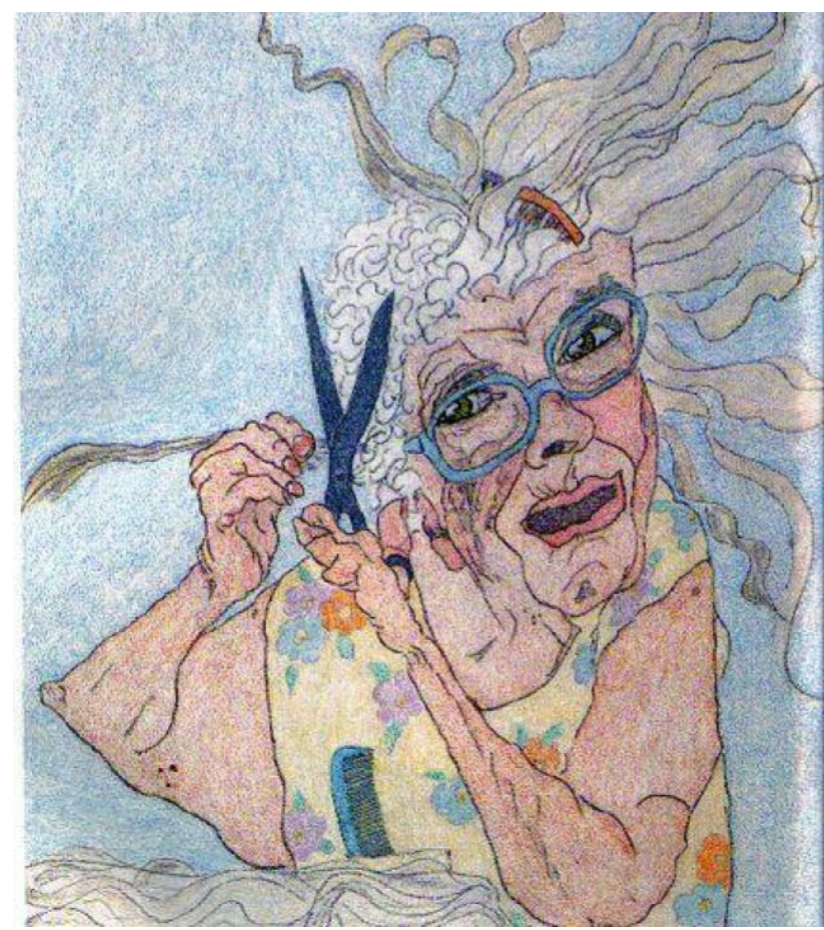

Contour drawing, is an artistic technique used in the field of art in which the artist sketches

the contour of a subject by drawing lines that result in a drawing that is essentially an outline; the French word contour meaning, "outline." 

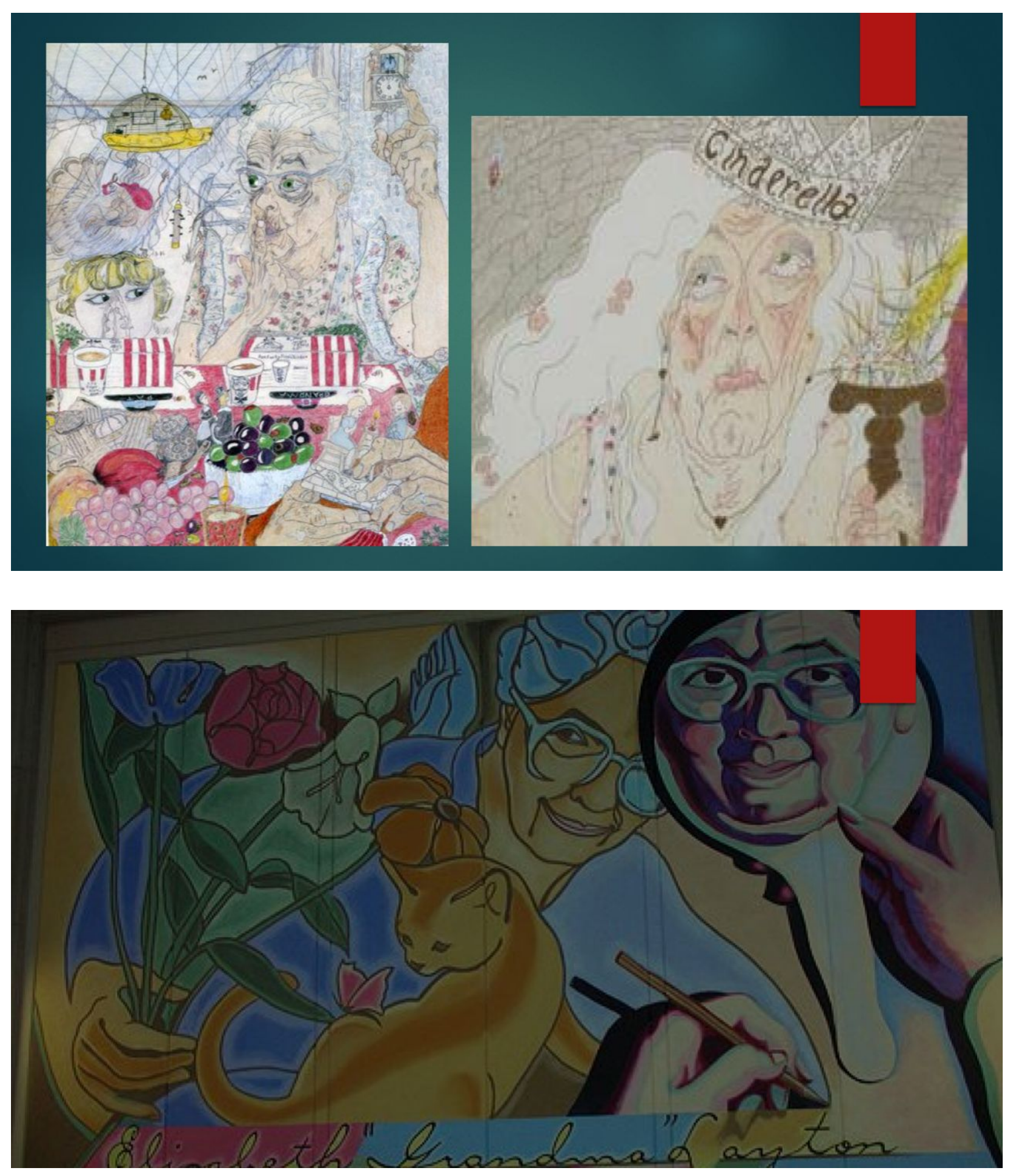


\section{Sources}

- https://www.picswe.com/pics/layton-contour-bb.html

- http://kansascityartistscoalition.org/artists/tag/art/page/35/

- http://www.liveauctioneers.com/item/8279087

- http://arttherapydirectives.blogspot.com/2012/07/self-portrait-contourdra wings-this.html

Figure 5. Grandma Elizabeth Layton PowerPoint 


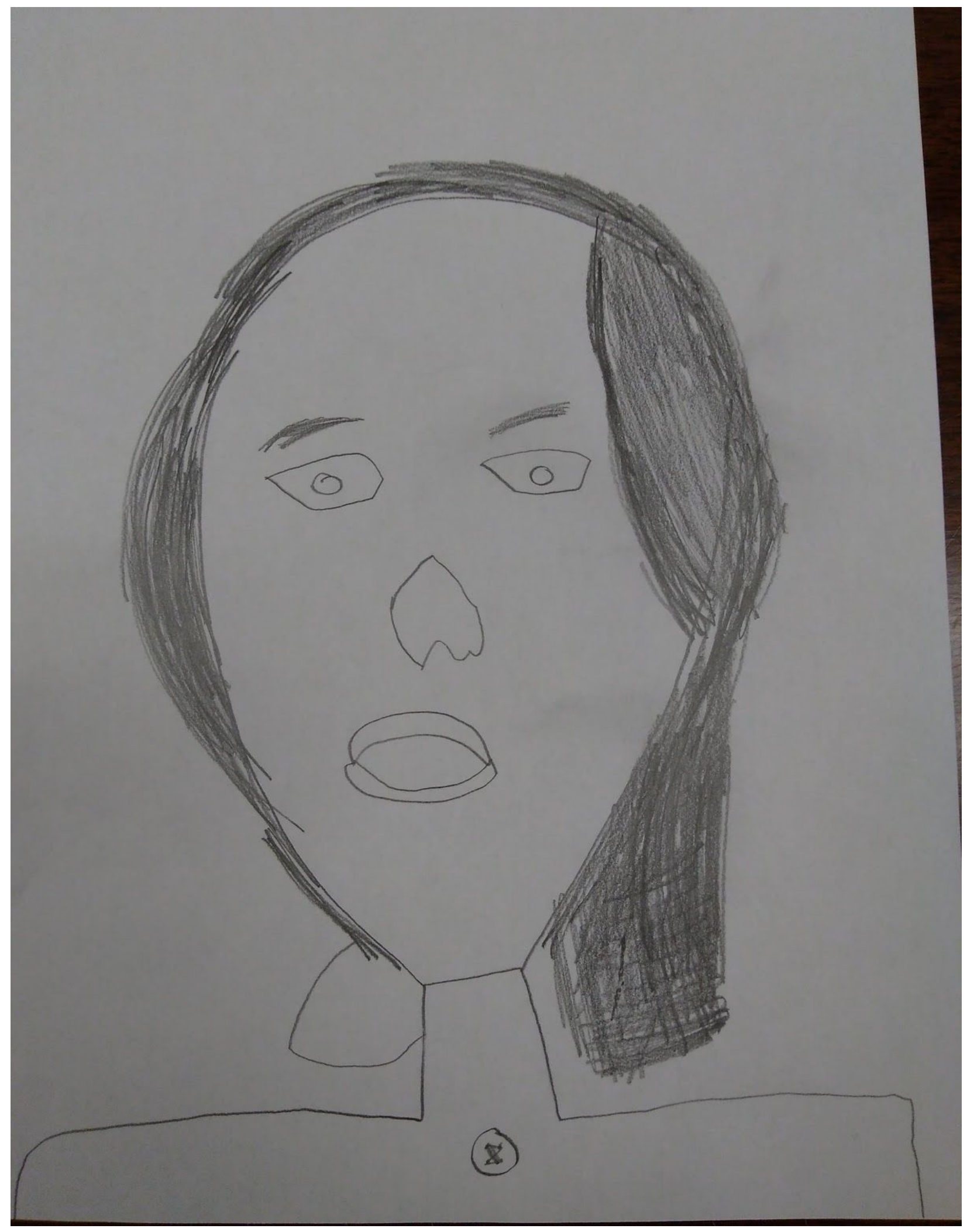

Figure 6. Student Example Contour Drawing Sketch 


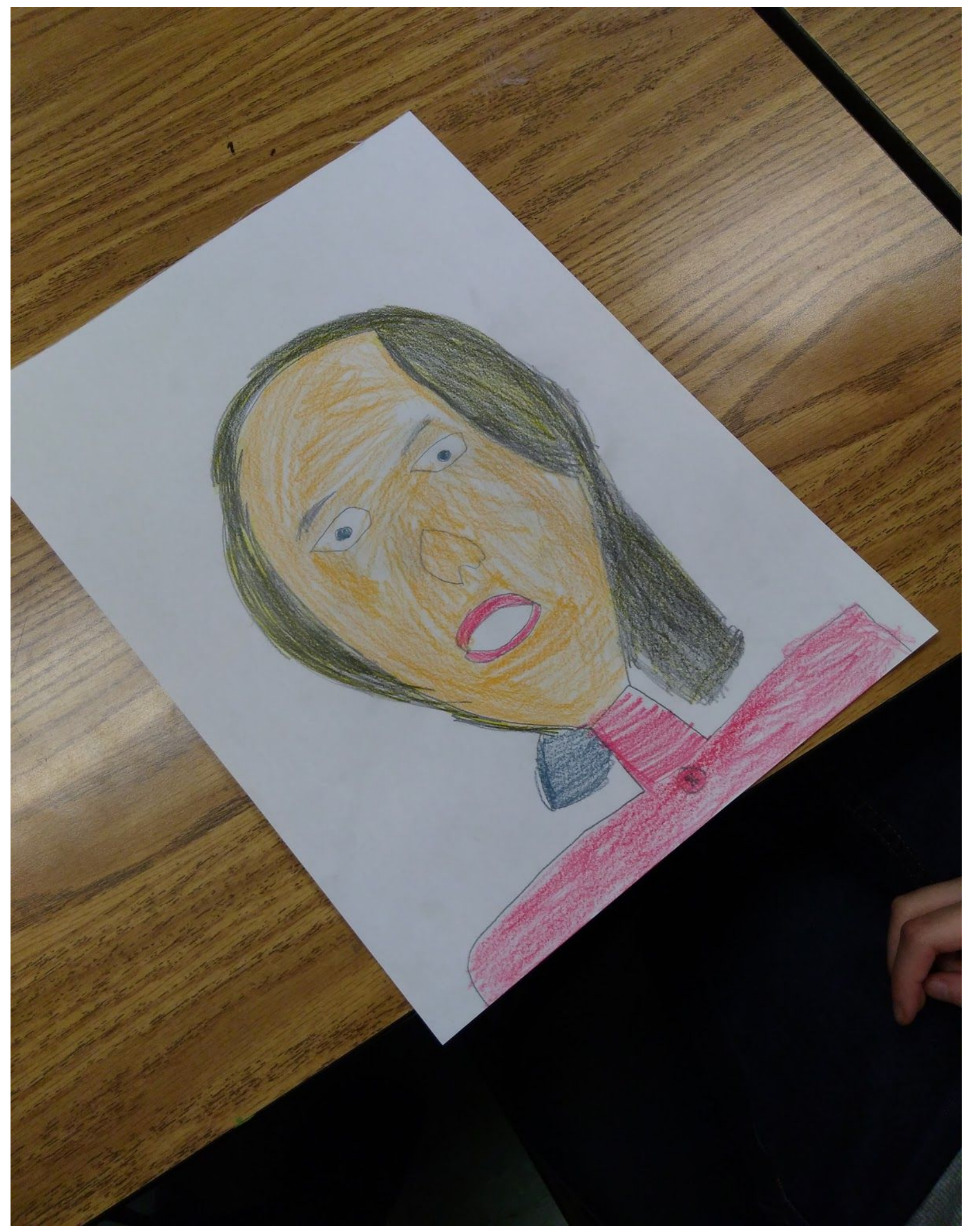

Figure 7. Student A Example Contour Drawing 


\subsection{Journals}

I loved having the journal element, for the students, during all these projects. The journals added an element of consistency between all the different projects. The students responded to the emojis at the top of the journal page the most. They could easily identify the emotions they were feeling and easily circle or color in the shape. The students began to remember to do the journal reflection entries around week two-three. I still gave prompts at the beginning and end of each class but as the weeks progressed on the number of prompts needed decreased sufficiently.

\subsection{Pizza Box}

Each student created a medium size, 14 inch, pizza box at the beginning introduction session to act as a portfolio to keep all their artwork inside including the journal element. The outside of the pizza box will be painted using colors that represent their outer self. How others see you? Not the warm squishy parts that are inside, but your hard outer shell. What does that look like? I then showed the students my example. Does this look like Ms. Perriello? Why do you say it does or doesn't? Why do the colors make you think that? Do you associate this colors with me?

The students then were allowed to grab the pizza boxes that were stacked in the middle of the tables along with brushes, also in the middle of the table. No name were added anywhere on the outside of the box. The students then used the paint and brushes to represent their outer self. What color would describe you best? More than one color? Why did you pick the colors you choose? What do these colors mean to you specifically? These questions will be answered in the journal entry that they complete that day. The paints were placed in the middle of the large tables on multiple trays. Colors were organized in similar shades of color. The students moved around the 
room accessing the different colors that they wanted to use. This step took around 20 minutes of class time. The pizza boxes were then left on the floor to dry completely until they could be stacked.

The pizza boxes were kept in a separate closet when not in session. The closet was locked preventing anyone from seeing the boxes or accessing the materials inside. The space has multiple closed door shelving and additional open drying shelves if needed. This insured that the materials including the journals will be preserved for the students in session only. The two groups of boxes were kept in the same locations of the closet when not in use but will be set up and brought out for each session prior to students coming in the room. The goal in doing that was to create a safe and controlled setting for the students to express inner thoughts and feelings within their small group peers.

The students in both groups responded positively to the pizza box portfolio projects. The class walked into the room with everything set up for the project (Figure 8). The students, in both groups, were respectful of all the materials as they painted. They moved around the art room with their pizza boxes in hand, sharing paints and paint pallets. The fact that I set up the paints in palettes based on color similarity and shades, across multiple tables, benefited the students for a few reasons. One of the focuses of these projects is the ability for gross motor skills and the benefit that can occur from adding in these motions. The students were able to experience the release of any stress hormones they may have been feeling, this was reflected in their journal entries, while they painted their pizza box portfolios.

Student A painted her pizza box using a few different colors (Figure 9). She began by painting the outside parmator using a bright red color. She applied the color thinner than some of 
the other students did, causing the image underneath to peek through, adding again to my desire to change the pizza box underneath to a solid white, blank canvas, if I did this again. She then moved into the center point painting a large pink dot in the middle. Student A left the letters Pizza alone, not adding any color over top of them. When asked she left them there because she likes to eat pizza. Student A assistant sat outside the main paint area and prompted her whenever she needed additional cues. The only prompt that the autism mentor assistant did need to give during this process was during clean up. The prompt she was given was to leave her paintbrush on the paint pallet for me to clean up after session, Student A had already placed her brush in the sink. Student A then walked back to the sink and carefully examined each brush until she found her exact brush she had painted with. She then removed it from the sink and placed it back on th paint pallet as she had been instructed.

My personal pizza box (Figure 10-11) was decorated using using many different colors of acrylic paint. I started with solid black. I painted the top, bottom and sides of the box first solid black leaving the center top section open. Once I had it painted the solid black I choose bold bright colors to make up the center area. I choose; blue, a few shades of green, turquoise, purple and pink. I choose these colors because they reference not only colors that I like and wear but colors that I use in my artwork. Pink and green are my two favorite colors. I added small sections of yellow and orange to balance against the darker green and black areas. The purple blends well into the dark black areas creating texture and depth. My color choices also reference my own artwork. In my personal artwork I tend to do bold black sharpie lines, creating a color book page style, as outlines then color using bold intense shades of color. I then ran the colors from the top side over onto the left and right sides, slightly. I feel like the pizza box represented me and my BOLD personality very 
well. The black paint, on both sides, balances the intense color making you focus on the center area that contains the color. 


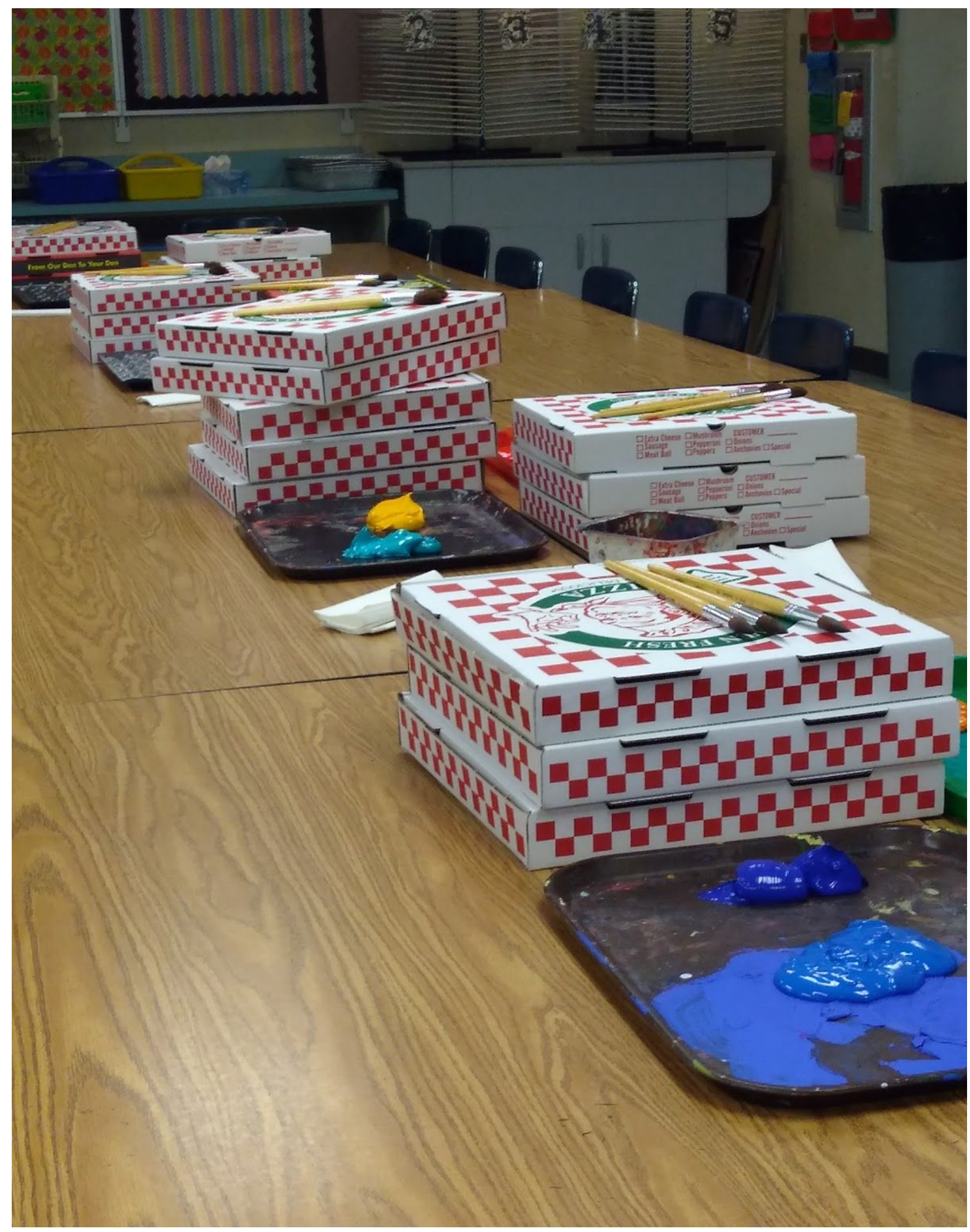

Figure 8. Pizza Box Portfolio class Set-up 


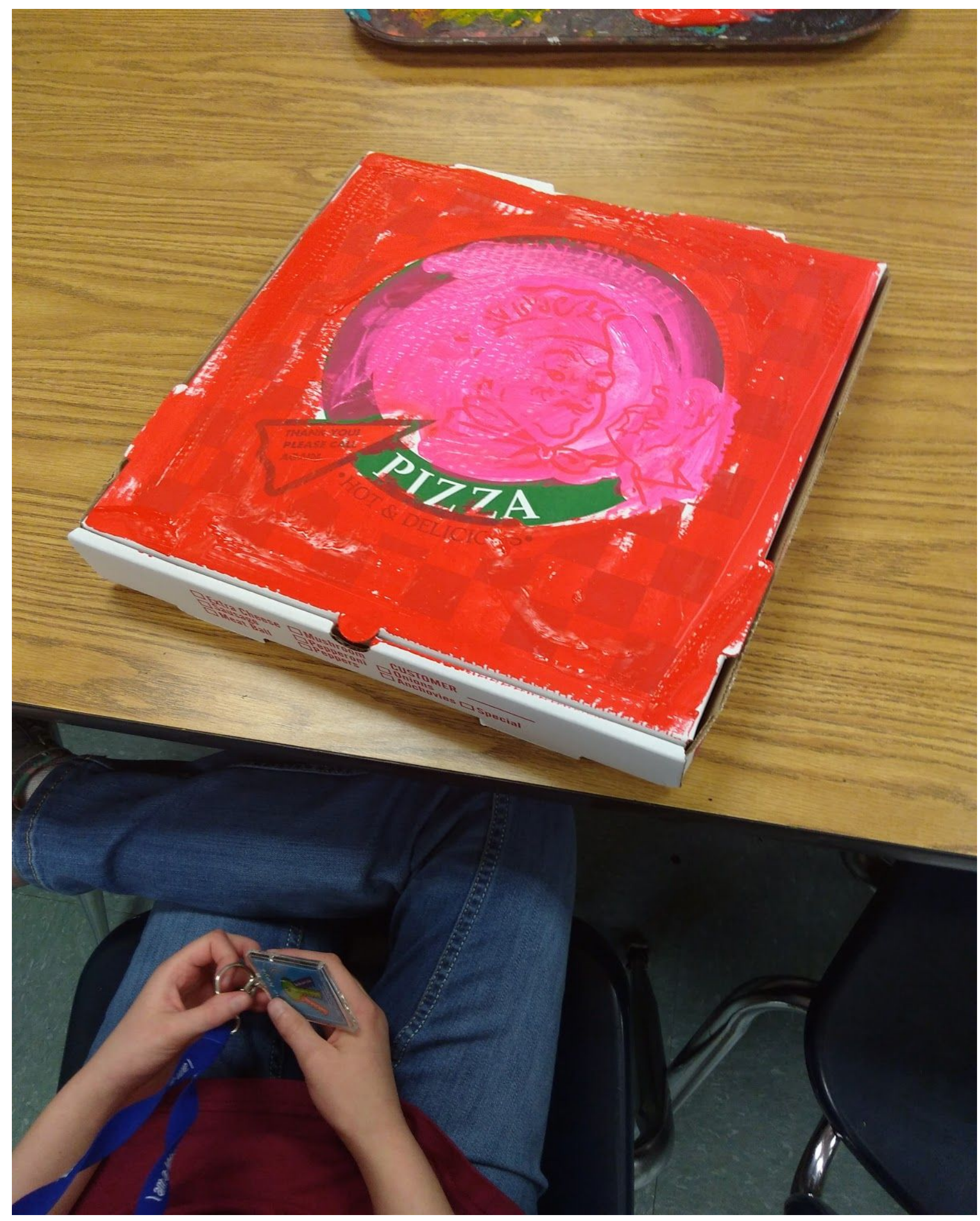

Figure 9. Student A Example Pizza Box Portfolio 


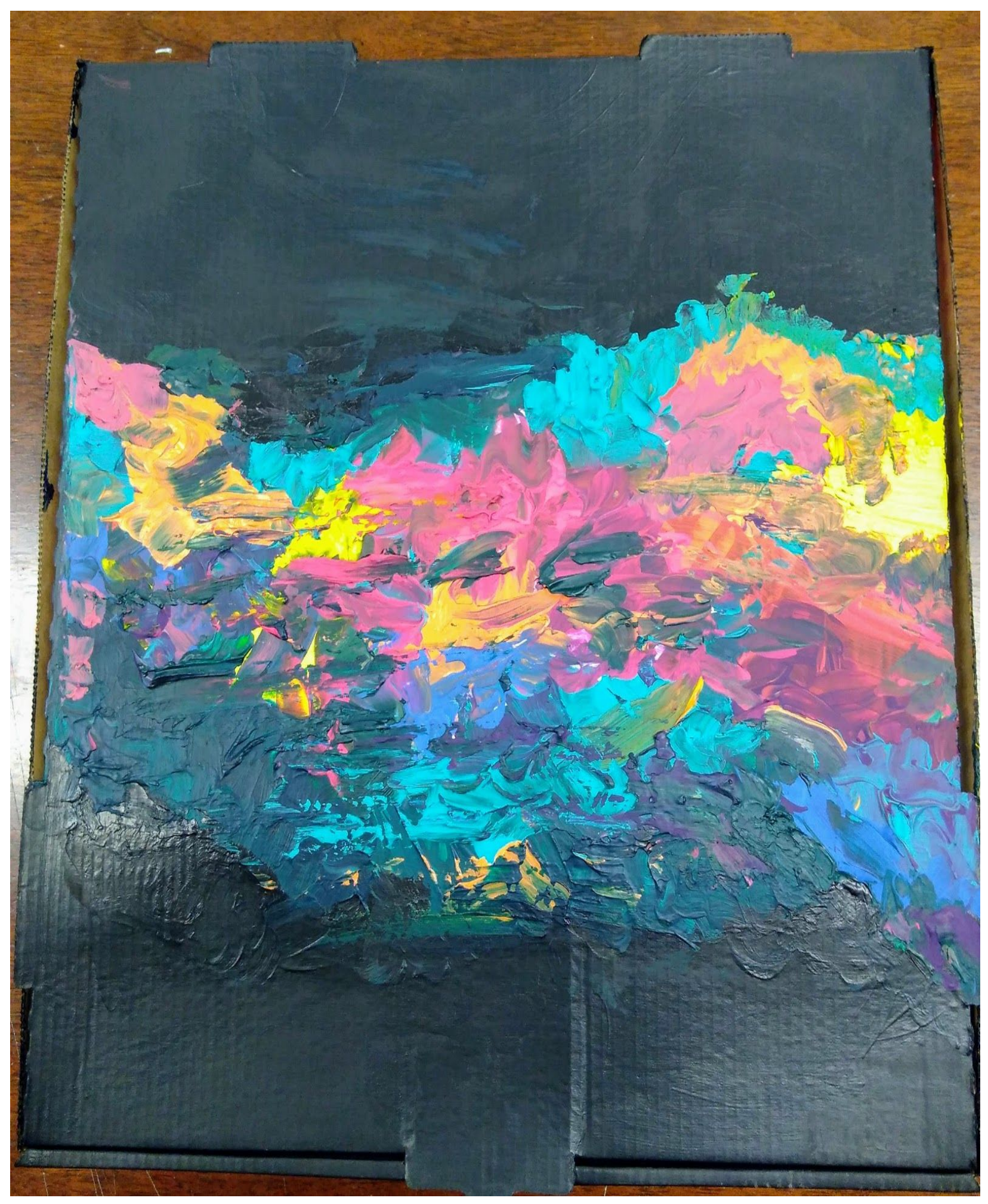

Figure 10. Teacher Example Pizza Box 


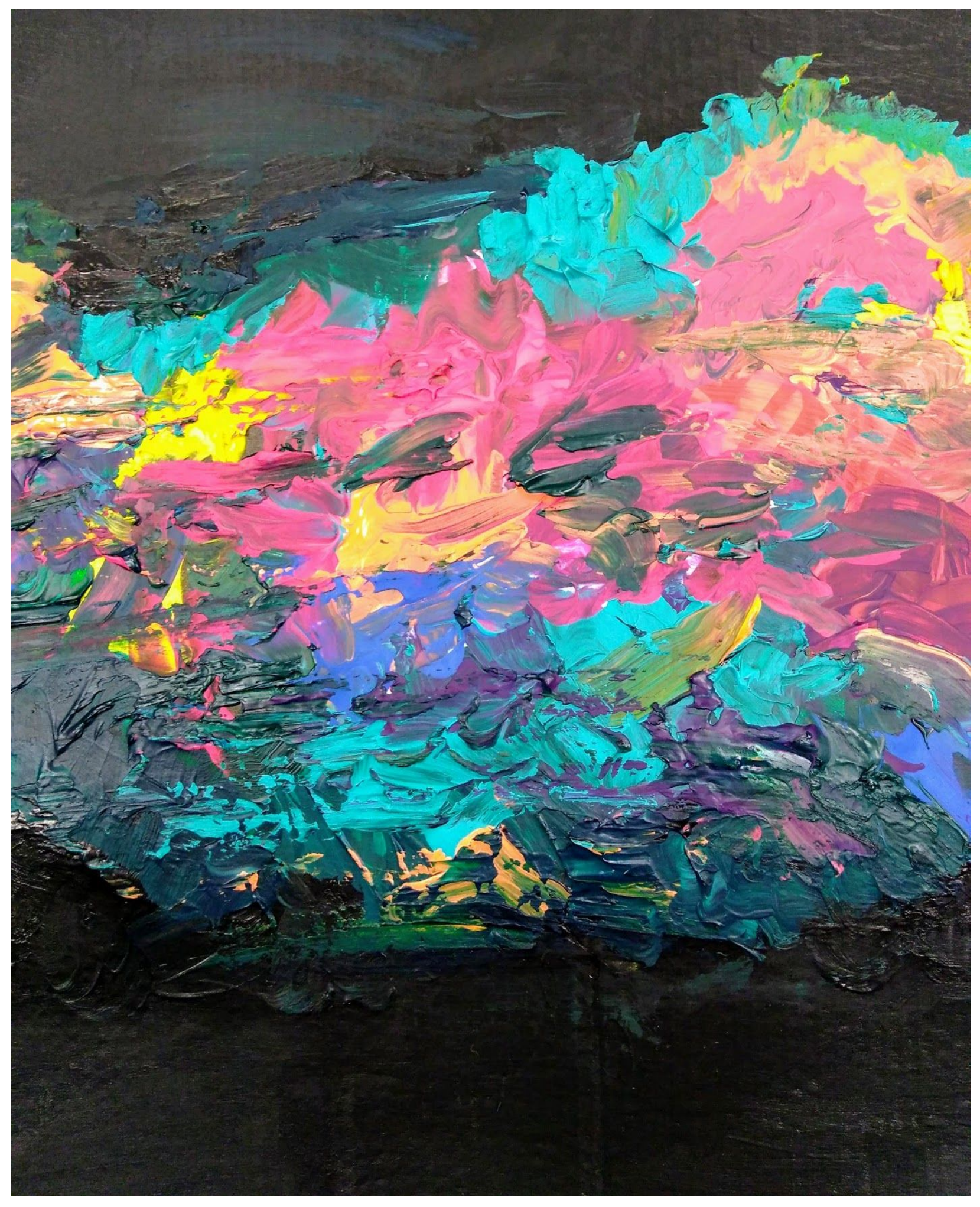

Figure 11. Teacher Example Close up detail of Pizza Box 


\subsection{Pizza Pie Chart}

The pizza boxes were decorated on the the inside using a 9 inch circle cut out of construction paper. The circle will be divided into slices, similar to a pizza. The different slices represent the different pieces of their self. This was the inner "pizza yourself", as I described it to the students. The pizza was divided to represent the inner emotions that you feel. For example, I gave the students a list of emotions (these emotions were indirectly based on the movie Inside Out) that they will be able to divide the pizza into. IE; Joy, Sadness, Anger, Fear and Disgust. They then picked four emotions for the pizza. If the student comes up with an additional emotion they would like to use, not found on the list, that was allowed. The list that was provided was just a jumping off point. The pizza was divided into four equal slices, creating a pie chart. The students used pencil, color pencils, markers and crayons to draw quick pictures in each section to show their emotion they are trying to convey. The emotion word was placed on the back of the each slice. Additional objects were added to the top of the drawn images. These objects were found objects either out of the collected box or brought in by the individuals to convey the emotion they are trying to show. The 3-D objects were attached using hot glue to the finished color images. The pizza pie chart was placed into the bottom of the pizza box portfolio. They were then attached to the pizza box using a brad placed in the center allowing the pizza pie chart to move and still be lifted to read the emotions on the underside.

During Day 1 of the Pizza Pie Chart I noticed a few interesting and exciting details while the students worked. All the students throughout the two groups had many in depth discussions 
about objects that could be drawn and what emotion they tied into. The fourth graders had more meaningful conversations, about all the emotions and pictures they were including in their chart, over the fifth grade participants.

My pizza of myself consists of four emotions. I had two example at this point in the process. I showed the students the drawn out images that I had included in my pizza pie chart (Figure 12). I then went on to show the students my completed example; drawn out, colored completely and 3D images attached (Figure 13). By having both for the participants to see they could see the difference and importance of the use of color in these charts. The first image shown is plain and lacks depth one expects to see with the emotions listed. The color enhances, and plays off the idea of color psychology, to add depth and additional understanding to the emotions being shown. The emotions that I choose from the list were; Joy, Sadness, Fear and Anger. I divided the 9 inch circle into four equal slices. I will now list what I included in each section and why I choose each image.

Joy.

For the Joy slice I started by drawing in a paint pallet, pencil and paintbrush. I added an emoji smiley face to mimic the use of emojis that I am using on my data collection sheets. I thought by including a element into both it would tie the two together. The last thing I added was the word ART. After the entire slice was sharpied I then went into adding color. I kept with bright happy colors focusing on pink, green and turquoise. After coloring in the area I added my three dimensional found objects. Iris button to represent gardening, cupcake to show my love of baking, the spoon was attached to the pallet to represent baking and broken vintage jewelry to show I like old vintage objects. 


\section{Sadness.}

The Sadness slice was the hardest of all four slices for me to do. I added another two emojis a yellow sad face crying and a blue green sad face. I added a lightning bug to represent my Pap who passed away at the beginning of last summer. The hummingbird represents my grandmother who has also passed away. The last image I added was the eyeball crying in the corner. For this slice $\mathrm{i}$ kept the colors more muted using browns and blues. The hummingbird was colored purple because it was my grandmothers favorite color. The only three dimensional objects that were added into this slice was a broken crayon and a small hummingbird in gold. Connecting my personal and professional worlds together gives the students a more well rounded view of what I want them to achieve during this project.

\section{Fear.}

For the fear slice I placed a large Earth in the center of the piece. I added simple stick people onto the edge ( the crust side of the pizza) in front of the Earth. Before coloring the piece I added a light curved line in the center of the slice. This line was only added to act as a barrier for how I was planning on coloring a guideline. The colors used in my fear slice was to represent my fear of a black and white, no color, world. Being an art teacher this would be a horrible thing, indeed. I then colored one half of the slice black, gray and white. The other side of the curve, guideline, was colored using bold blues, purples and greens. I chose to stay in the cool color palette to reinforce the coldness and fear associated to the idea, a world that lacks color. I then added in stick letters spelling out no color on one side and a clay bead face on one of the stick peoples faces. 
Anger.

Anger started for me with the words "Talking over me" as being places in the middle of the slice. Another emoji was added this time a mad face with steam shooting out its ears. A nintendo controller was added to represent anger that is felt when playing video games. The word silent was added to show that when I am mad I become quiet. Last was the eye scowling to mimic the eye on the slice across from it on the pizza. I colored this slice using only red, black and gray leaving small spaces of white. I think by limiting the colors used in anger it added to the drama that is associated with the word. The only thing that was glued into this section was a stiff broken paintbrush.

After finishing all the entire pizza slices I noticed that some of the drawn objects had overlapped into different areas. The paintbrush is in the center of the circle and had started in Joy. But the use of art and painting specifically for me can incomposs all the emotions that I used in my circle. I think that by having parts and pieces overlap into other slices and emotions is good to show in an example. Sometimes students at this age, pre teens, can struggle with the idea of emotions and how to explain them. For students to be able to see that emotions can be categorized into more than one feeling, even as an adult, can be a strong tool for them to see. Images and icons can overlap different emotions on different days and can constantly change. This could be used to show growth over time as the icon and images could change and have different meanings.

Student A started her pizza pie chart (Figure 14) by picking the four emotions she wanted to include. The mentor assistant wrote the four emotions on the back of her pizza pie chart circle for her. She first began working on the Joy, "Happy," slice. I noticed that she colored the entire back of the slice a solid yellow color. When asked about the color choice and she responded with, “" Yellow is happy." Student A then began drawing on top of the solid yellow color creating two 
figures with a ball in between them. I thought this was an interesting way to start the association to the emotions, by using color psychology as the background. Color psychology ties directly into the art therapy fundamentals that I was looking at. For her to add this, without any prompts or clues to the idea, was an exciting and wonderful development.

Student A talked to the other students around her, and her assistant, about the emotions and things that made her happy as she drew. She then began to fall a little off the emotion conversation and began talking about pizza and what they all liked as toppings on their pizza. This literal interpretation of the idea of a pizza pie connected her to the food, which she does love, seemed like a great way for her to connect more to the project. Between this literal connection along the pizza and the searching for her exact paintbrush reinforced the idea that Autism students see in a black and white world, not all the grey in between.

During Day 2 of the pizza pie charts with fourth grade the students participants seemed to be more engaged with the idea of how to show icons and symbols as emotions and how those emotions can relate to more that one feeling. As the students worked I observed many different ideas than I had with the participants in the fifth grade group. The students began to incorporate icons and symbols that encompassed more than one slice on the pie chart. I noticed students using the divided lines, the lines put in place to show the separation of the four feelings, as a way to separate icons into different areas of feeling.

One student was not here on day 1 and started working on her pizza pie chart on day 2. Student B (Figure 15) example shows the idea of using the slice dividing lines by placing a hot chocolate mug, directly between the happy and the sad slices. When asked why she had done this she responded by saying, " Hot chocolate makes me happy because it is delicious but sad when it is 
to hot to drink." Student B then went on to ask if coloring the entire fear slice black was allowed, showing the darkness associated to the emotion of fear. Student B would be labeled as a gifted students, above average intelligence. Student B saying this reinforces the idea colors are connected to emotions, that until this point only Student A had mentioned or incorporated into her pizza pie chart.

Student A was able to then complete the pizza pie chart (Figure 16) after Student B had started hers. The two individuals were sitting on opposite sides of the room from each other when Student A was working. Student A then went on to complete the entire pizza pie chart using colors associated to the emotions she was asked to express, tying completely into the color psychology element I was looking for.

Overall I think that the fourth grade participant group were more successful than fifth grade students, on this project as a whole. The fourth grade participants were able to understand the ideas and concepts of icons and symbols; connecting the emotions and feelings to the idea of an image icon. The fourth grade students were able to engage with one another to form meaningful conversation within their peer social group during this specific project.

While fifth grade participants were successful, I felt that the group's struggle occurred more with the distractions happening internally and within their social peer group. These social peer distractions are more associated with the age of the group, being between elementary and middle school. Fifth grade participant fall into the category of pre teen, when social peer opinions are valued highly and peer influences can cause participants to not want to share internal emotions out loud within a social peer group. With this all being said I noticed that within the fifth grade participant group the female participants were more successful than the male participants. This 
difference between male and female being displayed could be interpreted as the females being more in touch with their emotional internal self, or as the males responding to social pressure to repress their feelings. 


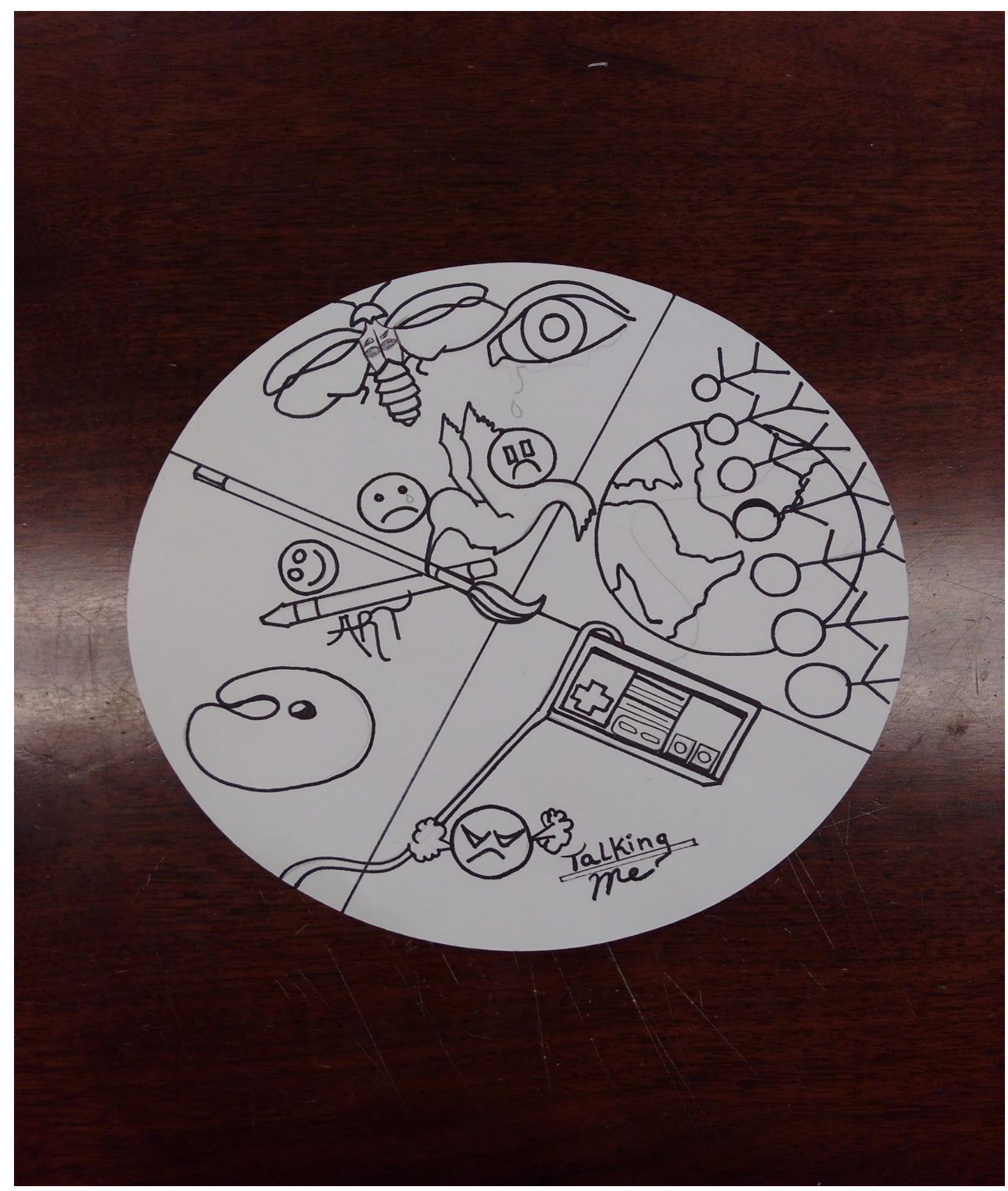

Figure 12. Teacher Example Pizza Pie Chart 


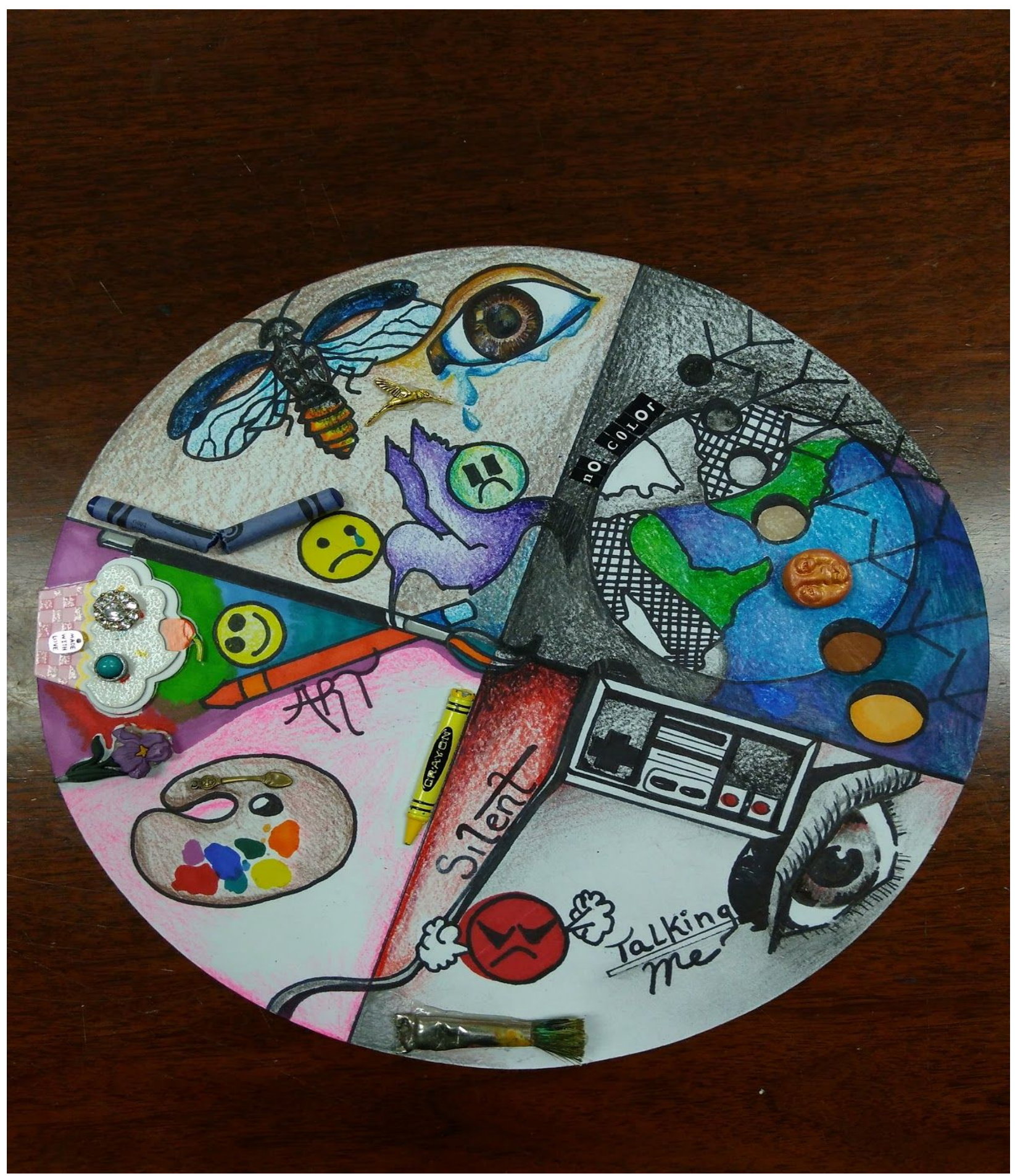

Figure 13. Teacher Example Finished Pizza Pie Chart 


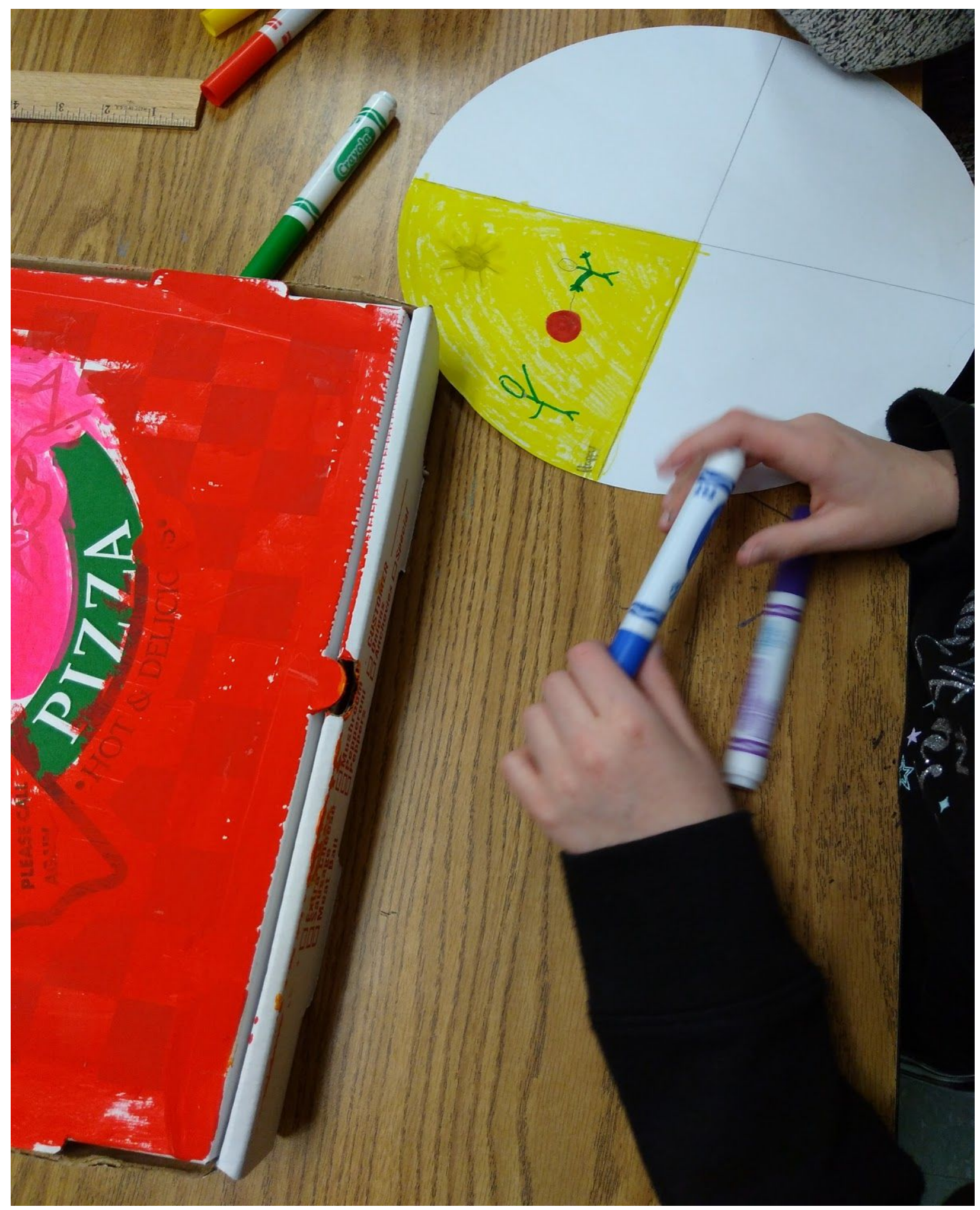

Figure 14. Student A Example Pizza Pie Chart 


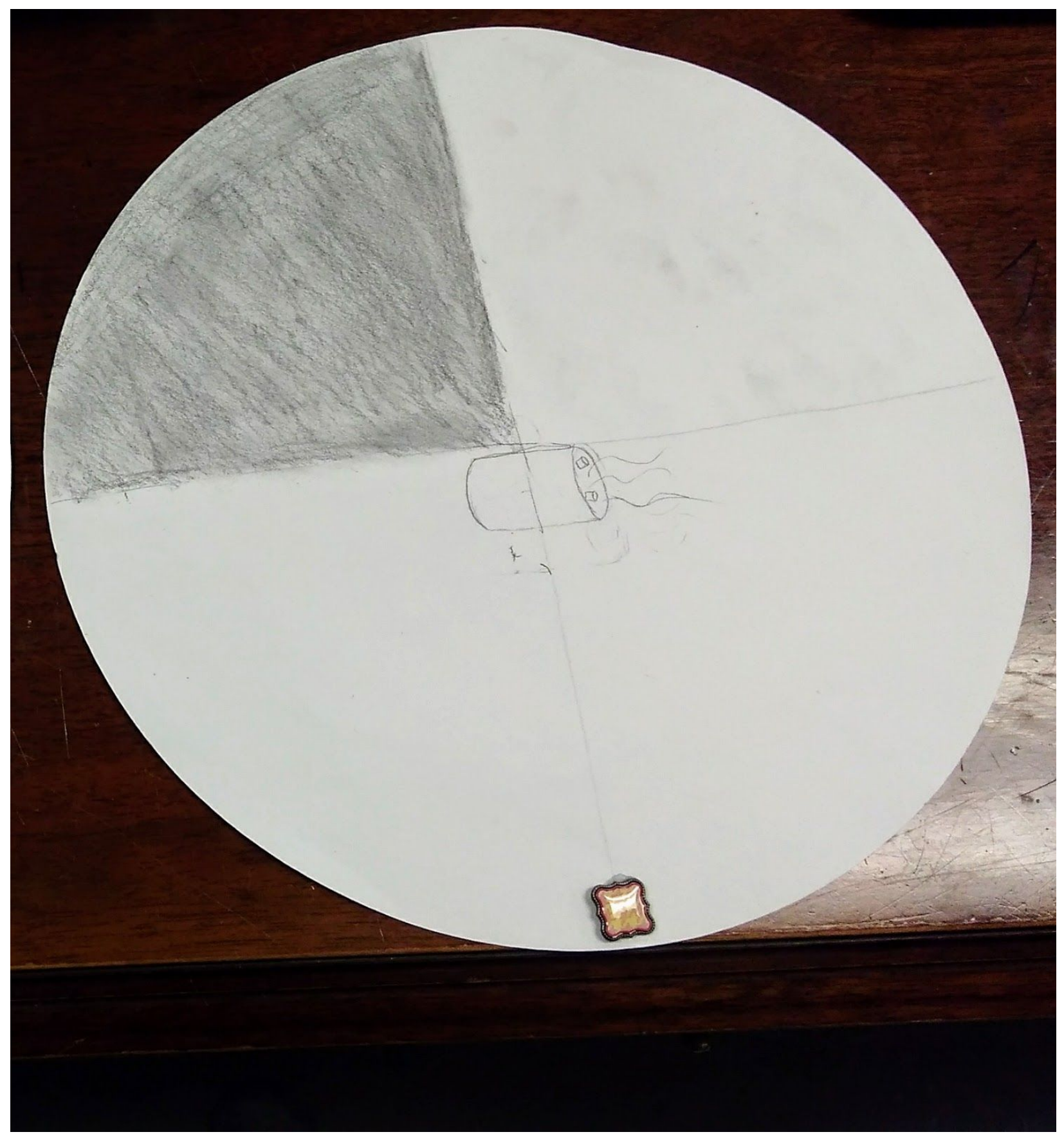

Figure 15. Student B Pizza Pie Chart 


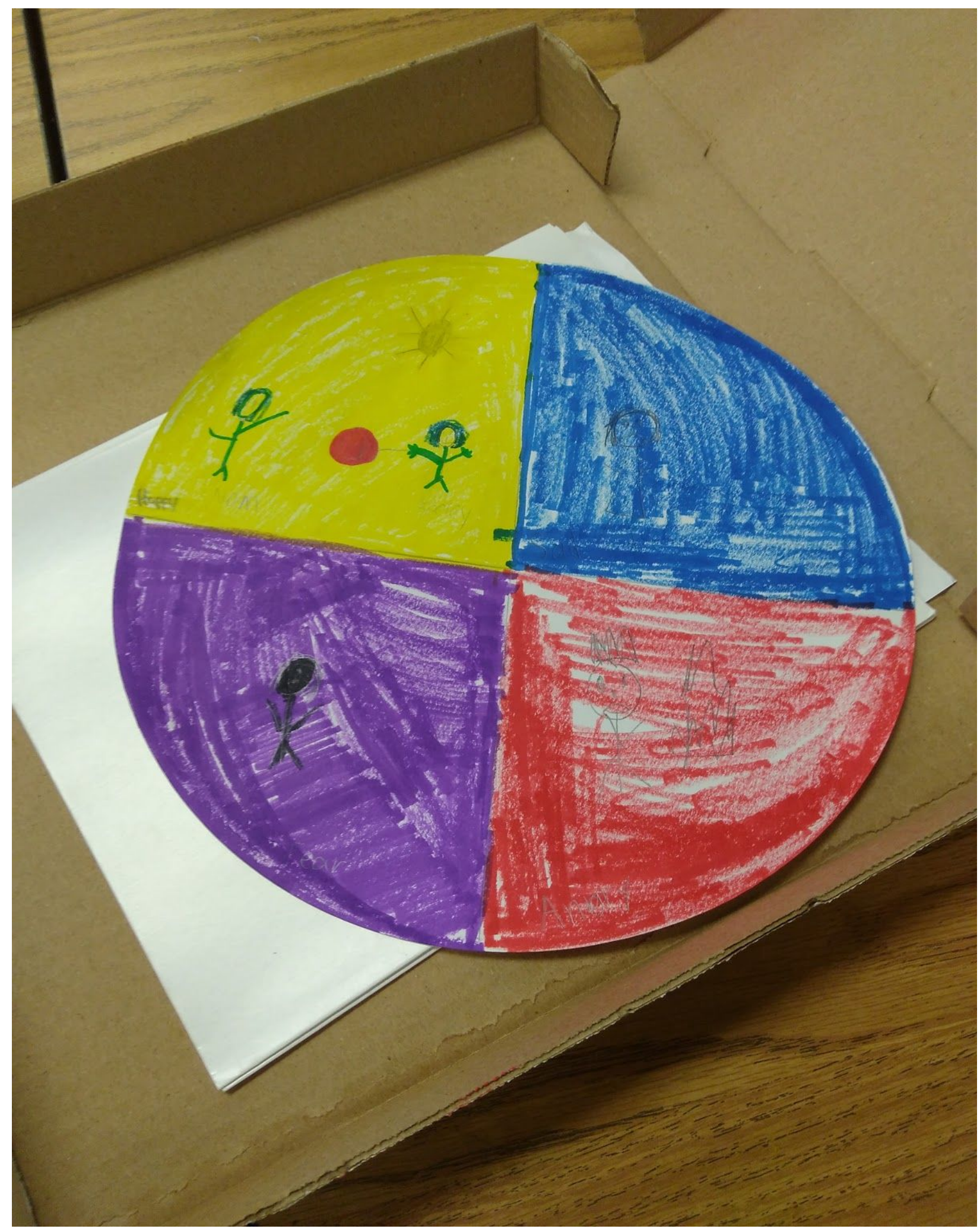

Figure 16. Student A Example Pizza Pie Chart Completed 


\subsection{Van Gogh Portrait}

During the introduction for the fifth grade class, they responded in a positive way towards the video. The students loved being able to move the camera around inside the video painting and explore the different angles within. The fifth grade students had some hesitation in drawing another portrait of themselves. The additional handouts that the students had available to them helped immensely for drawing out the outline and base image on the canvas. Some students chose to use the handouts in conjunction with the mirrors they had used prior. The students drew out the ovals and then began drawing the lines to help assist with facial feature placement and spacing. A few students struggled with the outline on the eye shape being to large, turning out more anime style, verses looking more proportioned. The students were overall more excited that they did not have to draw in contour style, as they had done before with Grandma Layton. As far as materials go, they seemed excited and interested in the idea of using the combination of brush, pallet knife and fingers to paint their canvas with.

The main thing that I noticed from the contour drawing project to the beginning of the sketch for the Van Gogh portrait was that the students responded and succeeded so much more by having the handouts in front of them. The students were able to work through the process of where to place all the facial features on their own. This could be a combination of the two different elements coming together, worksheets that were available and the fact this was the second attempt of a portrait.

At the beginning of Day 1 for this project I showed the students a copy of my painting prior to adding the paint (Figure 17). This allowed them to see both the beginning sketch step, that they 
were beginning, but then also the completed canvas. For my Van Gogh style self portrait (Figure 18) I decided to keep in the yellow and blue color pallet that Van Gogh used throughout his paintings. I added purple and a small amount of red into my paint pallet before I began to paint. I began by applying the paint, to the face, using a small paintbrush with a thin oval tip. As I worked outwards I switched to a beveled pallet knife as I began to apply the thick paint to the hair area. Once the entire piece was covered in paint I went back into add the piece adding smaller details with the original brush and my fingertips. The students used the same process and materials.

The students were first given a small canvas, 8 x 10, for their personal Van Gogh style self portrait. The students used pencils and mirrors to lay out the outline and proportions of their faces. Additional face handouts were placed on my desk for students to come and grab if desired. The last remaining five minutes of class were withheld for the students to journal about the artists, thoughts and feelings.

Day 2 began with the students completing any outline not finished on the first day. Once the outline was complete they were then given acrylic paint, pallet knives and brushes. I provided multiple different sizes and shapes of brushes and knives during this time. I used an additional canvas to demonstrate the different techniques with which paint could be applied to the canvas. I demonstrated the different ways to apply paint using palette knives, a tool that none of the students have used with me in the past. The students then applied the thick paint to the canvas to create a portrait of themselves. The students were allowed to apply some paint with their fingers if they wished. This will not be required of them due to some labels or disabilities can not stand the feeling or texture of paint on skin. I asked them: How do the colors mix as you apply them? If you over mix what do you think will happen? I told them to make sure you are making a portrait of yourself 
and not over mixing the colors. Due to the thickness of the paint the paintings will need a few days to dry completely.

Student A worked very diligently as she used the mirror to admire herself. By using this tool she was able to draw a portrait with even more success that she had when asked to use it on continuous line. Student A ( Figure 19 ) shows her using the mirror as a tool to sketch on her canvas. The sketch was done using pencil. As Student A worked she was focused on the task at hand and put all of her effort into the drawing out her self portrait (Figure 20).

During Day 2 the students were apprehensive and hesitant at the idea of applying the paint to the canvas. The hesitation was focused more on the idea of painting a self portrait then towards the canvas itself. The fifth grade students dived right into the idea of painting and mixing with the colors, creating movement and texture. Students mixed paint with their fingers to create movement and left fingerprints in the paint, leaving a personal mark into the piece. The fifth grade participants were excited to get to use the materials in a less constrained way (Figure 21). This photo shows a pair of hands, out of the fifth grade group, after the session had ended. The hands alone show the amount of colors and color mixing that occurred during the process, and in a way form a piece of art in themselves.

After the Fifth grade class had completed the portraits the students seemed to be overall pleased with the outcome of the project. The students were excited to try out new tools and techniques, palette knives and the use of finger painting combined with brushes seemed to give them different types of textures and styles (Figure 22). In figure 22, I have shown the top most successful uses of materials and use of a portrait in the Van Gogh style. The students seemed to be more cautious of the process until I reiterated that the portrait was not based on the realistic self but 
more on the internal self that you see yourself as. I showed my example again pointing out the differences between the me, in person, and the self that I was portraying on the canvas. Notice the differences, "Do i have blue and red hair? No, but my inner self would." Once that was explained the students seemed to grasp the idea and how to create a successful portrait in the Van Gogh style.

Student A responded to the idea of painting her self portrait using all three tools that were allowed. She also grabbed a mirror to look at herself while painting as seen in the photo ( Figure 23). At first she tried the pallet knife, a new tool for her to use. After a few attempts of the knife she was not pleased with the attempts and laid it down on the table. The next tool that she used was her fingers covered in paint. I was personally a bit shocked at the fact the she even attempted this. Usually, Student A does not like materials, like paint, on her fingers and hands. After completing her eyes and eyebrows using her fingers to paint she was done trying the finger painting idea. She washed her hands quickly and then moved on to the idea of the paintbrushes. Student A used a paintbrush to complete the remainder of her self portrait (Figure 24). Student A final pieces has a over amount of yellow and tan colors being used. This color pallet is very reminiscent of her use of yellow associated with joy from our pizza pie chart from before. When asked about her color choices and why she choose as she had it was because to her that was the closest colors to her true visual self. Student A also expressed happiness and joy towards the project to not only me but also her mentor assistant.

Overall I think that Student A did beyond my expectations on this project. She was open to new tools and tried out finger painting even though in the past she has had sensory issues with it. This paired with her verbal and facial cues about her painting's outcome to not just me, but also her assistant, reassured me of the end results' impact. 
During the painting of the Van Gogh portrait there was another participant that nailed the idea and process more that anyone throughout the two groups. Student $\mathrm{C}$ was able to use not only use shape but color to show how her inner self portrait would look (Figure 25). Student C was able to use multiple techniques, using all three painting tools, to create a mix of painted color and depth. Student C's face has less paint layered on it leaving space for the under drawing to peek through. Overall Student $\mathrm{C}$ was able to use all the tools, material and artists background concepts to create a very successful Van Gogh self portrait. 


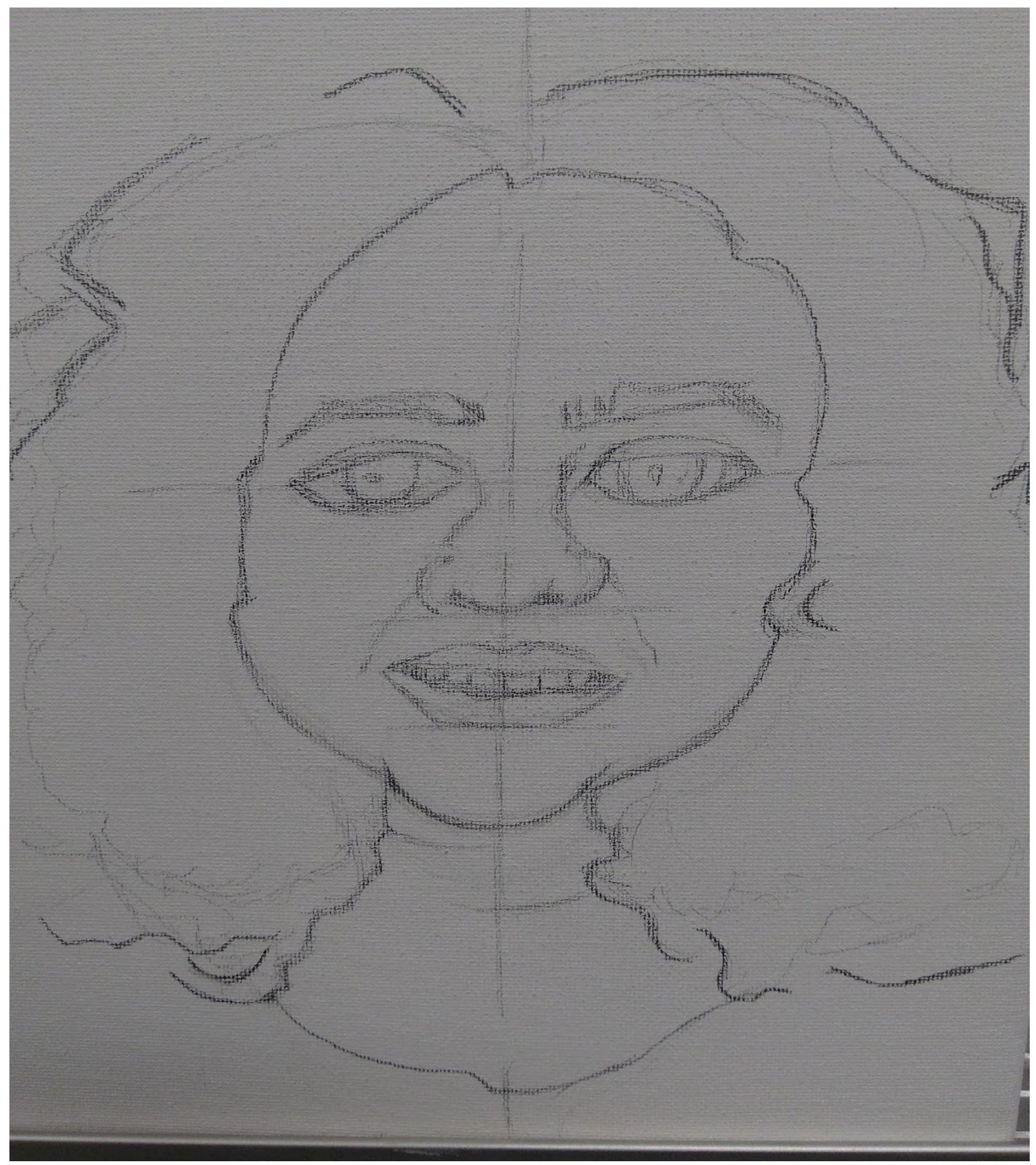

Figure 17. Teacher Example sketched Van Gogh Portrait 


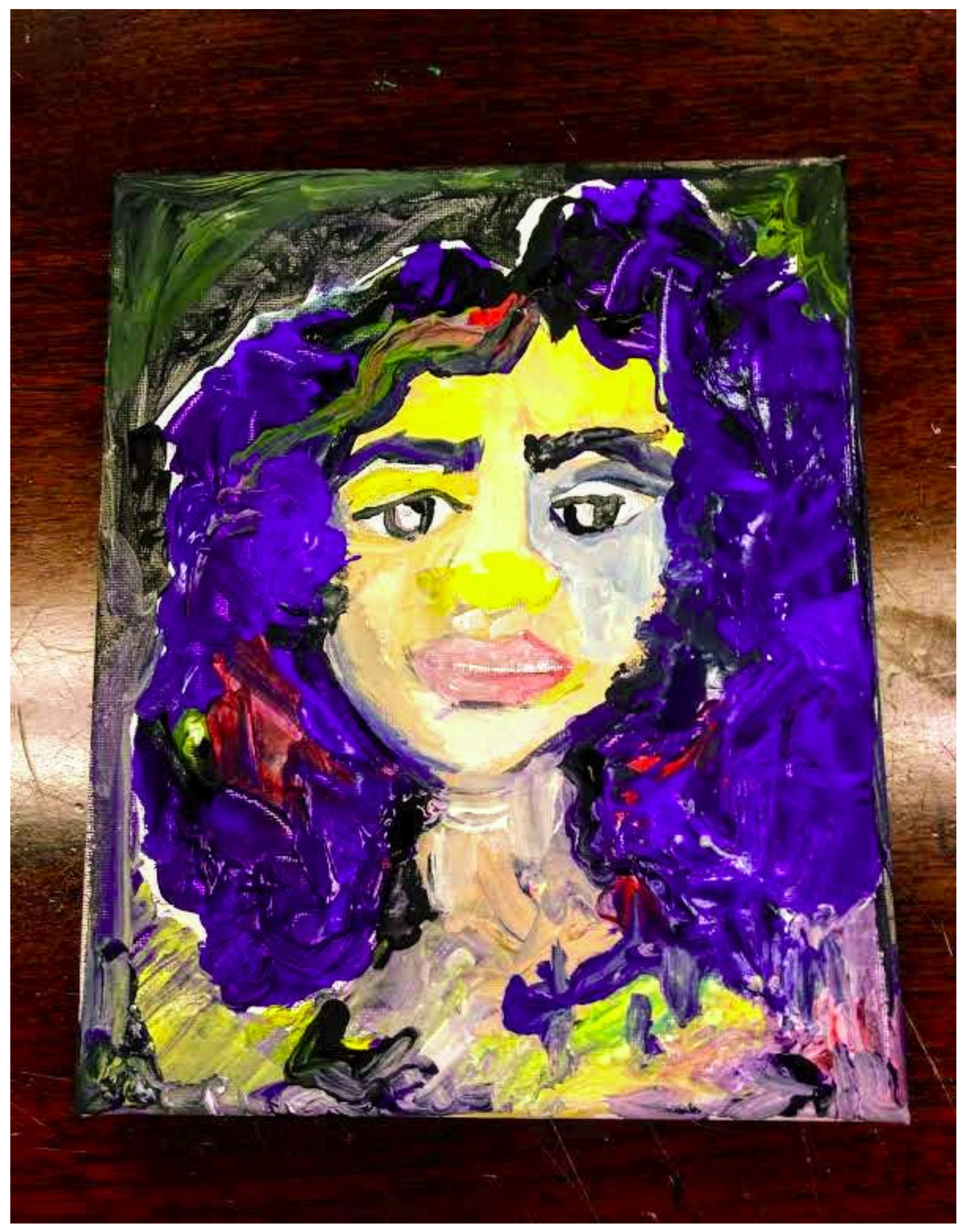

Figure 18. Teachers Example Van Gogh Portrait 


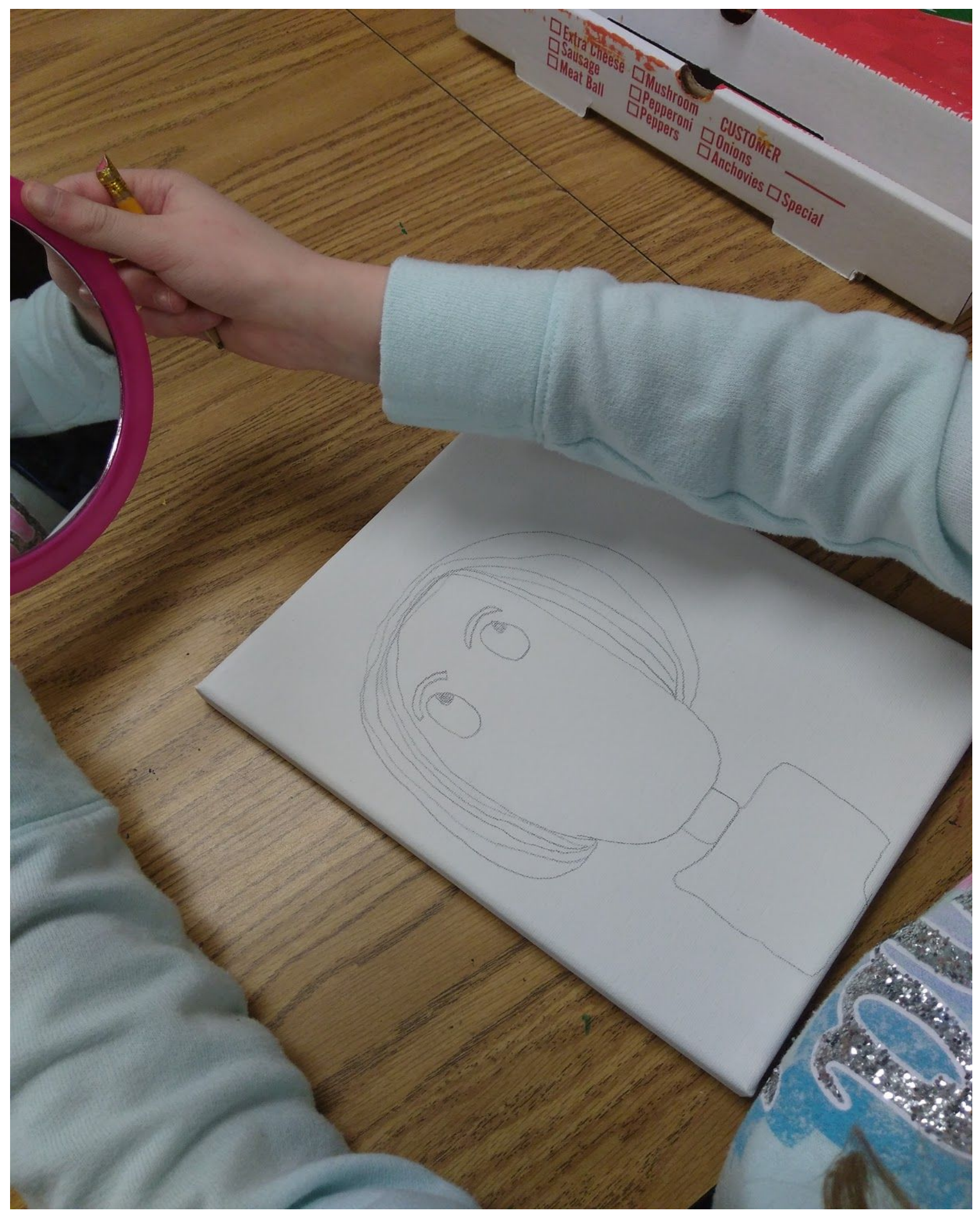

Figure 19. Student A Van Gogh canvas portrait sketch- in process 


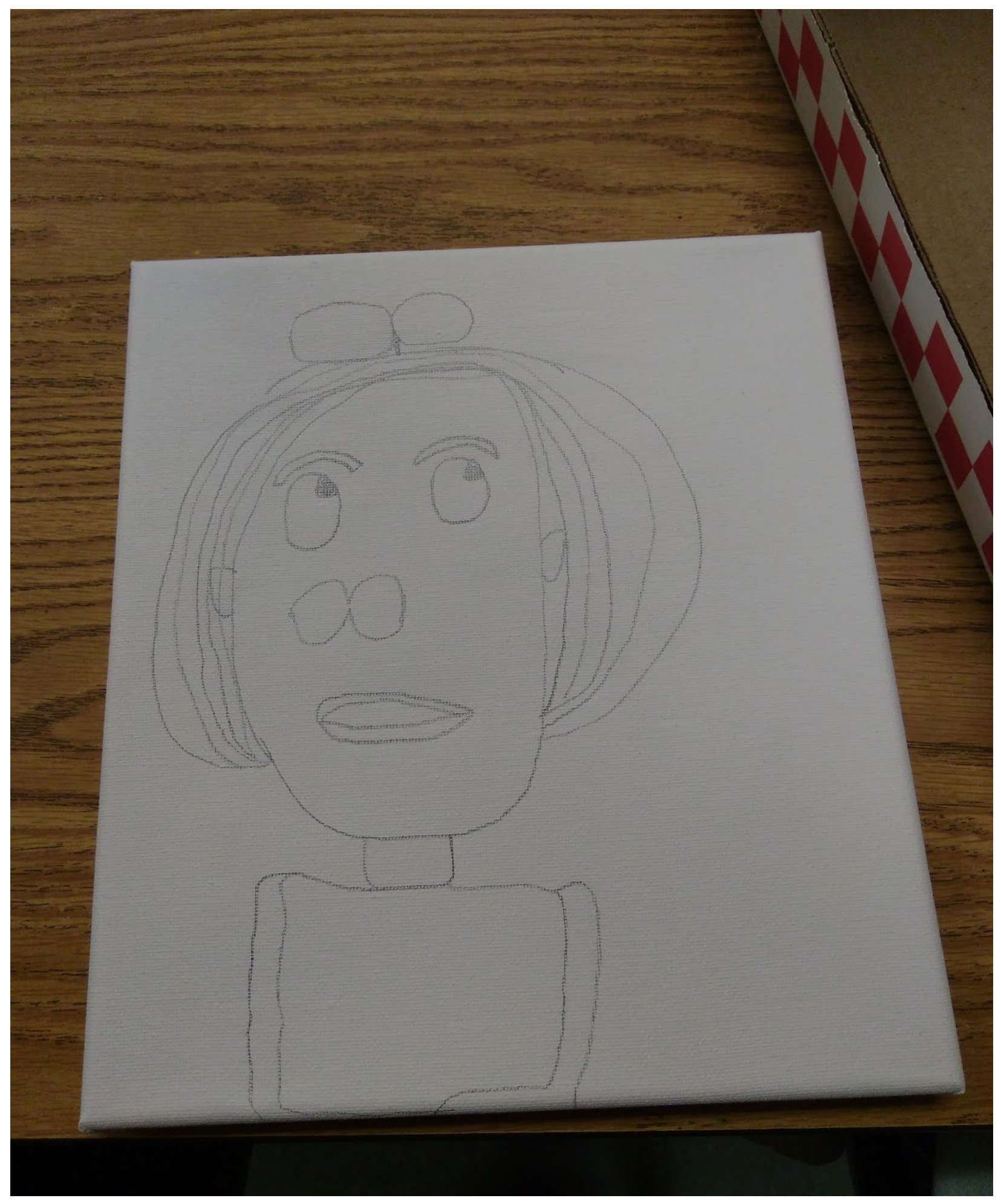

Figure 20. Student A Van Gogh canvas sketch- completed sketch 


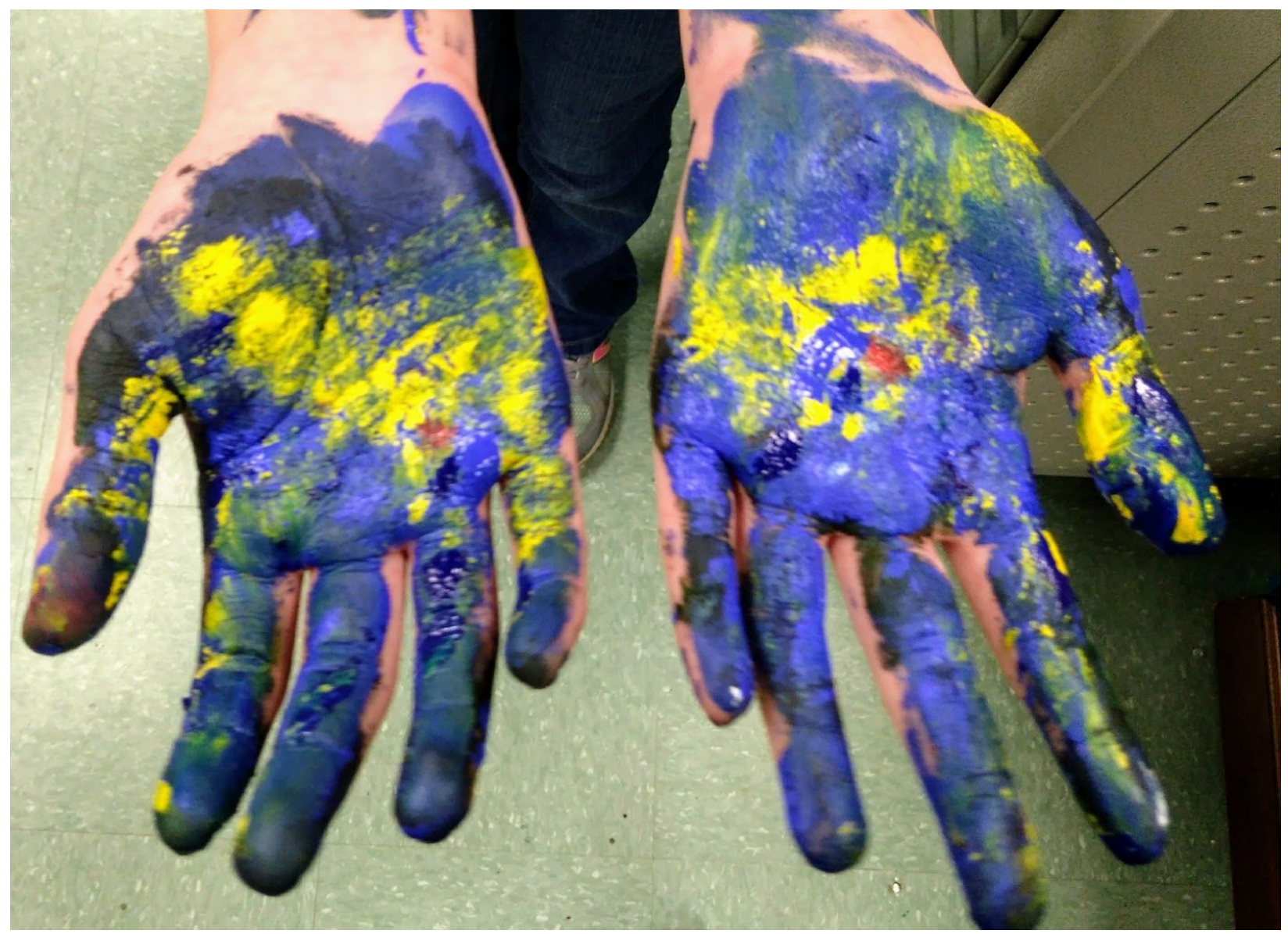

Figure 21. Van Gogh Canvas self portrait- Fingerpainting aftermath 


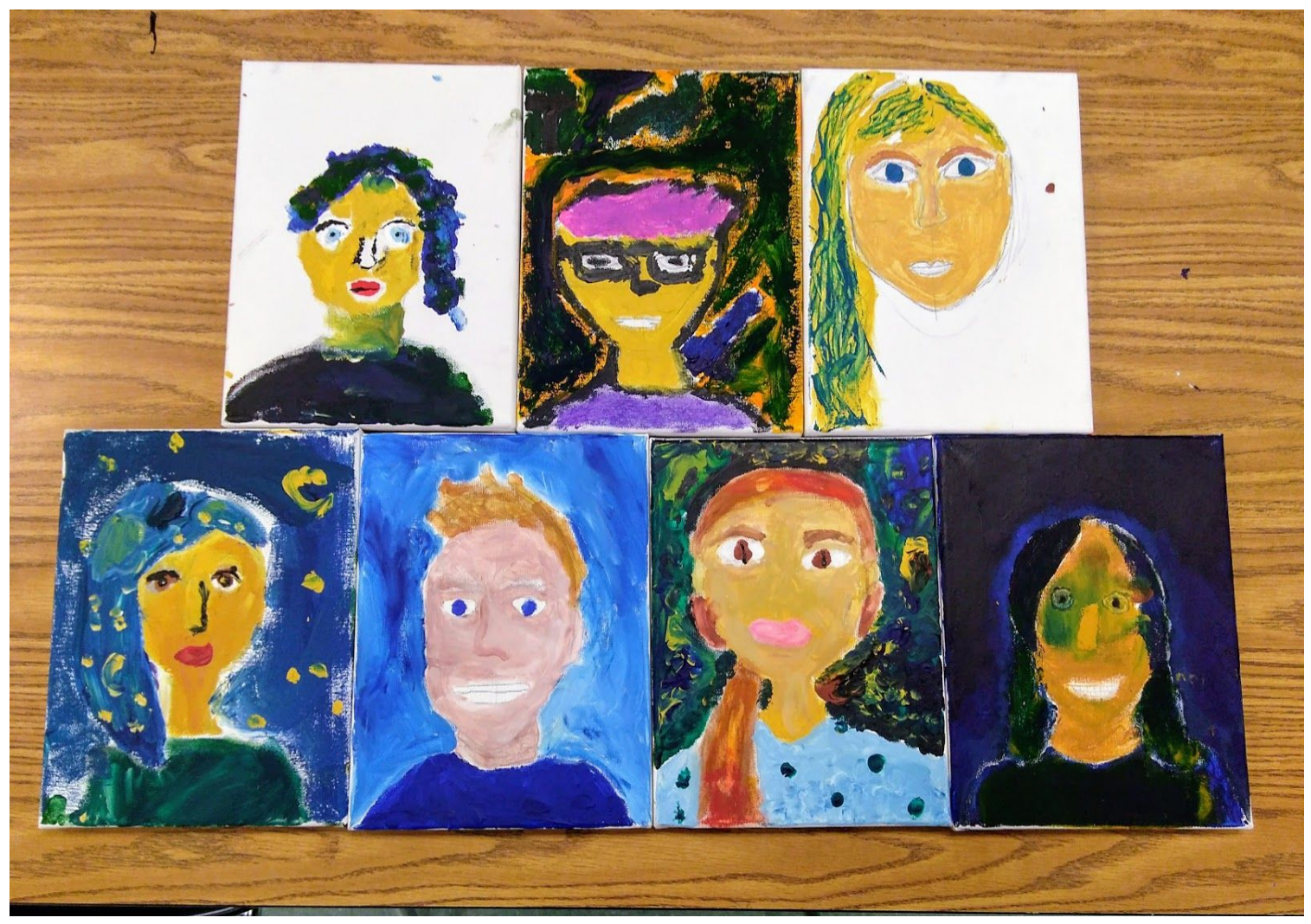

Figure 22. Fifth grade Self- Portraits 


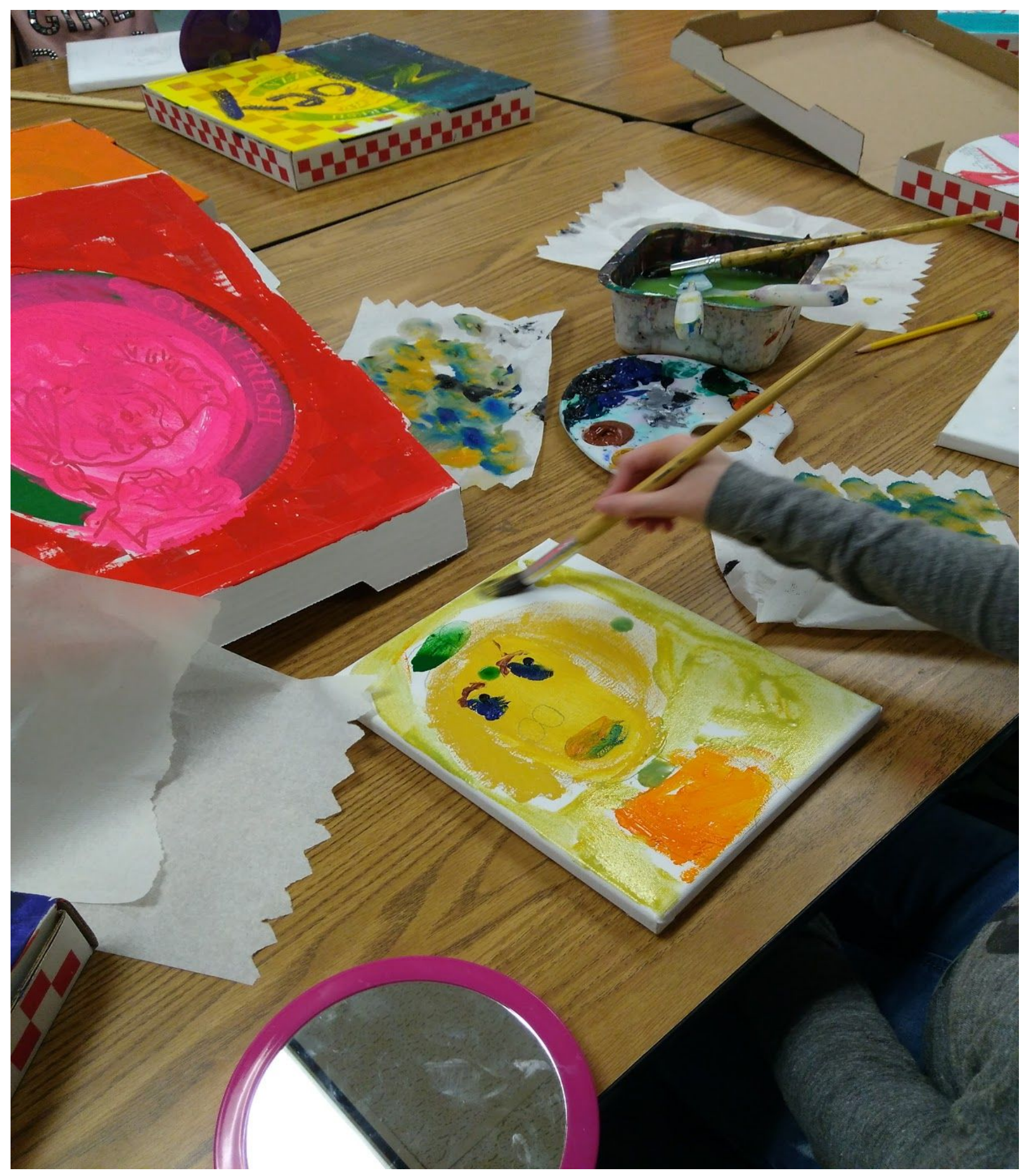

Figure 23. Student A painting process 


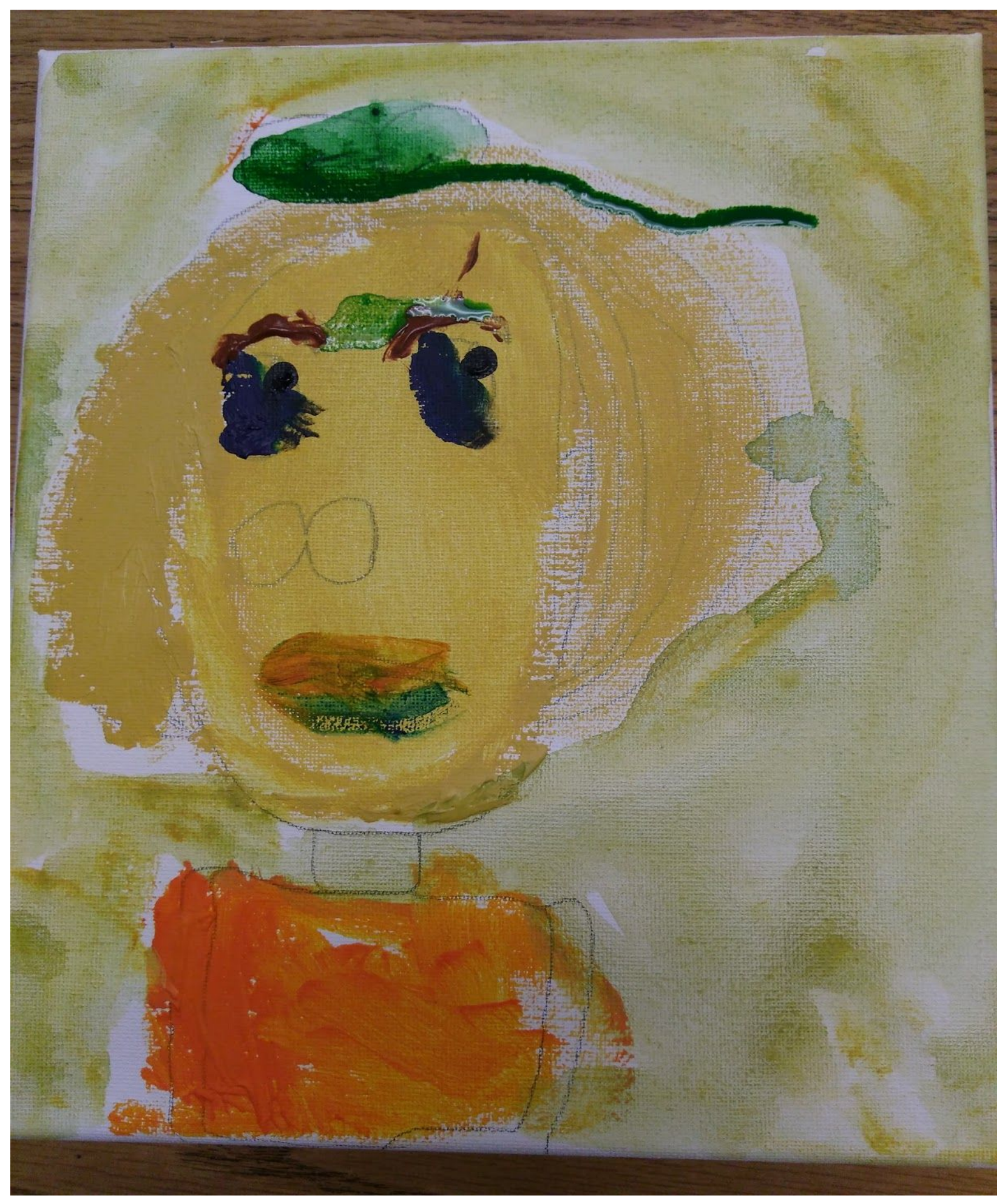

Figure 24. Student A completed Van Gogh Self Portrait 


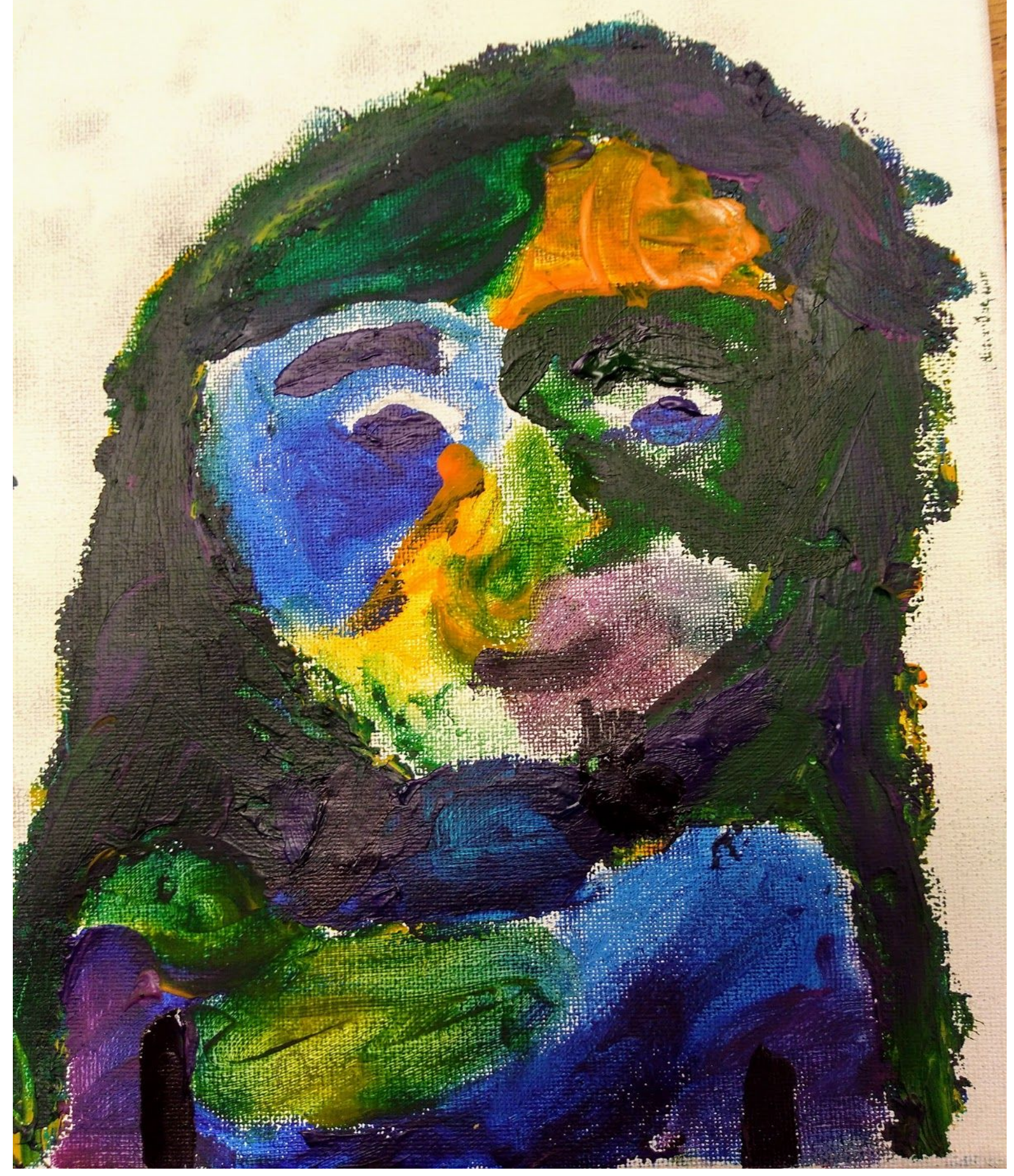

Figure 25. Student C Van Gogh Self- Portrait completed 


\subsection{Frida Self-Portrait Collage}

The symbol that I chose to incorporate in my artwork from Frida Kahlo was the hummingbird from the Frida Kahlo piece titled, Self- Portrait with Thorn Necklace and Hummingbird into my self portrait collage. I choose this specific image to incorporate into my piece to reflect the hummingbird image that I included in my personal pizza pie chart (Figure 26). Hummingbirds have a strong connection to me because they were my grandmother's favorite animal.

Once I had established the image I was taking from the artwork we looked at. I then moved on to start and create the other drawings I was going to include in the collage. I created the markers in the primary colors, color wheel flower and paint brush to show my love of art. The Van Gogh style moon was done to tie into the previous project and create a visual link between the two artists. The heart was added to show my love of Halloween and horror movies. The cut out dragon wing was added next along with the flowers coming out of the heart as a representation my fascination and love of fantasy and the Renaissance time period. The last element that I added was the words teacher and artist in sticker letter.

The fifth grade participation group did very well with this project. The painting, My Dress Hangs There, was the painting that most of them identified with the most. The connection seemed to happen more with this painting versus the other one, perhaps for the simple fact that this painting contains the most objects together, allowing all the students more variety and objects to choose from. The students picked different objects that they liked out of the piece as they began to create. The materials that were provided, with the magazines that I had on hand, allowed a wide variety of 
choices for them to work with. The fifth grade participation group worked very diligently cutting out found images, along with creating drawings to cut and incorporate into the pieces. At the end of the first day, the participants ask if they were allowed to draw some of the personal images at home or cut out pictures from magazines at home and bring them in, which I allowed.

Fourth grade participants were a bit more literal with their collages. Students in this group did more realistic portrait based images and ideas as their icon and symbols as a whole over their fifth grade counterpart.

Student A struggled with the idea and use of symbols and icons that represented her (Figure 27). She began the project by asking if she was allowed to use words in her collage. The small cut squares were the first pieces glued to her collage. Student A then choose a letter K sticker to add above the smaller squares. The last thing that she added was a sketch portrait of herself, not necessarily a icon or a symbol but more of a realistic depiction. Once Student A was completed I was able to photograph a closer detail of her collage (Figure 28). With Student A I became more aware that her use of icons and symbolism varied compared to the other participants in the group. She was able to convey the idea of the emotions that she had chosen based more on the use of color psychology, than by using the icons and symbols.

Twin A has shown many improvements through his artwork and abilities over the sessions (Figure 29). Twin A started his collage by drawing and shading an apple, centered on the page. Twin A loves apples and that is why he incorporated it into his collage. The next step was Twin A getting a children's book out of the box of books to cut images out of. Twin A chose cow images. As he cut he slipped with the scissors and cut the ear and corner of the cows face off (Figure 30). Twin A solved this by angling the cows head behind the apple before gluing it down. Twin A 
showed a huge jump in problem solving by doing this. He was able to add depth to his collage by fixing a mistake in cutting.

Twin B used multiple different animals to describe his true inner self (Figure 31). The main animal that he focused on discussing in session was the large cheetah image that was added to the upper right corner. Twin B described the cheetah as a fierce and strong creature. He them went on to add the snake along the bottom of the collage and the small animated character above that. Twin B did not get as far with the collage as Student A or Twin A.

"Passion is the bridge that takes you from pain to change."

-Frida Kahlo.

This quote summarizes the advantages that art education and art therapy have for students in the school system. Art can act as an expression of their most inner thoughts and can also act as a release of emotions that have no other place to go. 


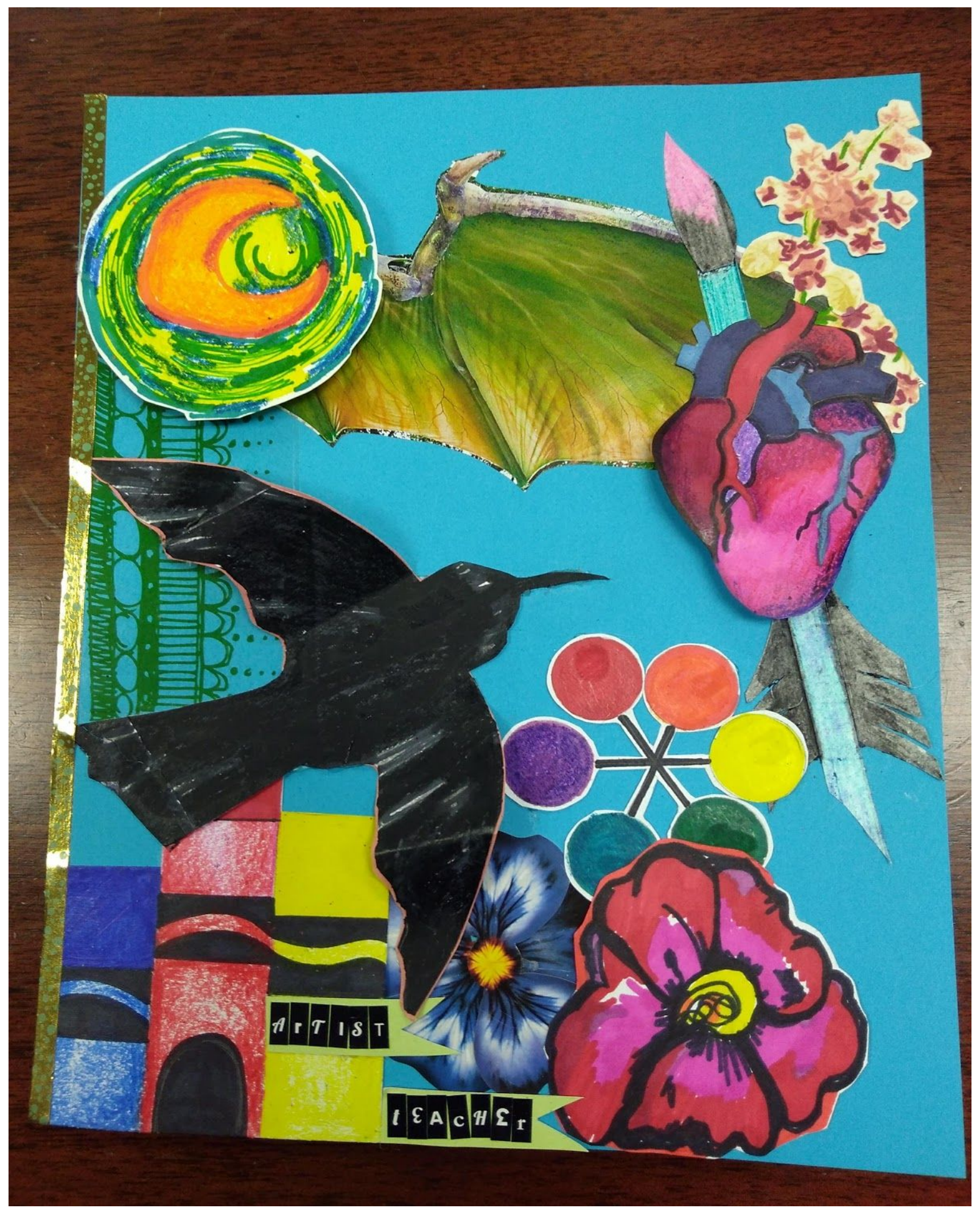

Figure 26. Teacher Example Frida Kahlo Collage 


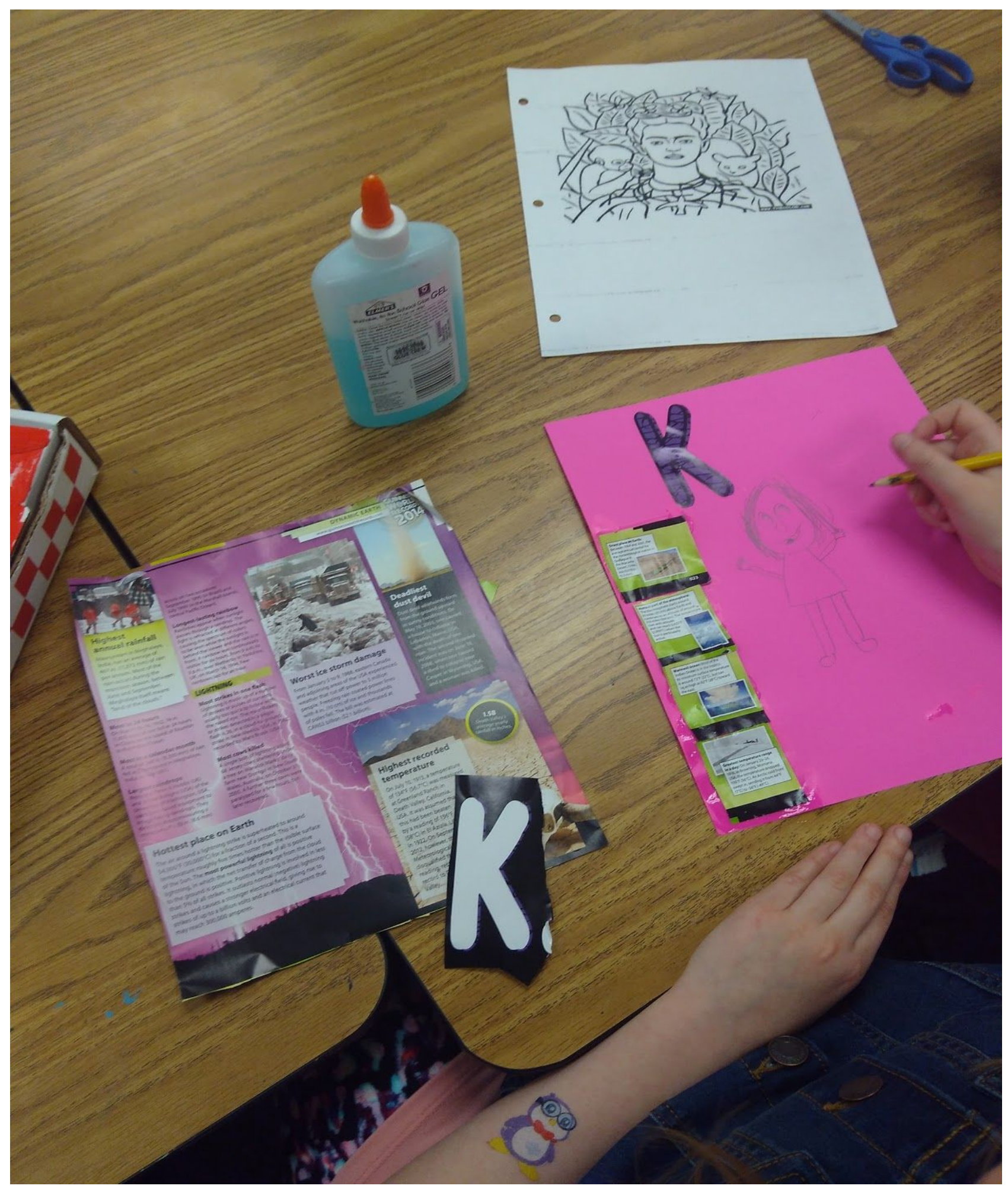

Figure 27. Student A Frida Kahlo Collage working image 


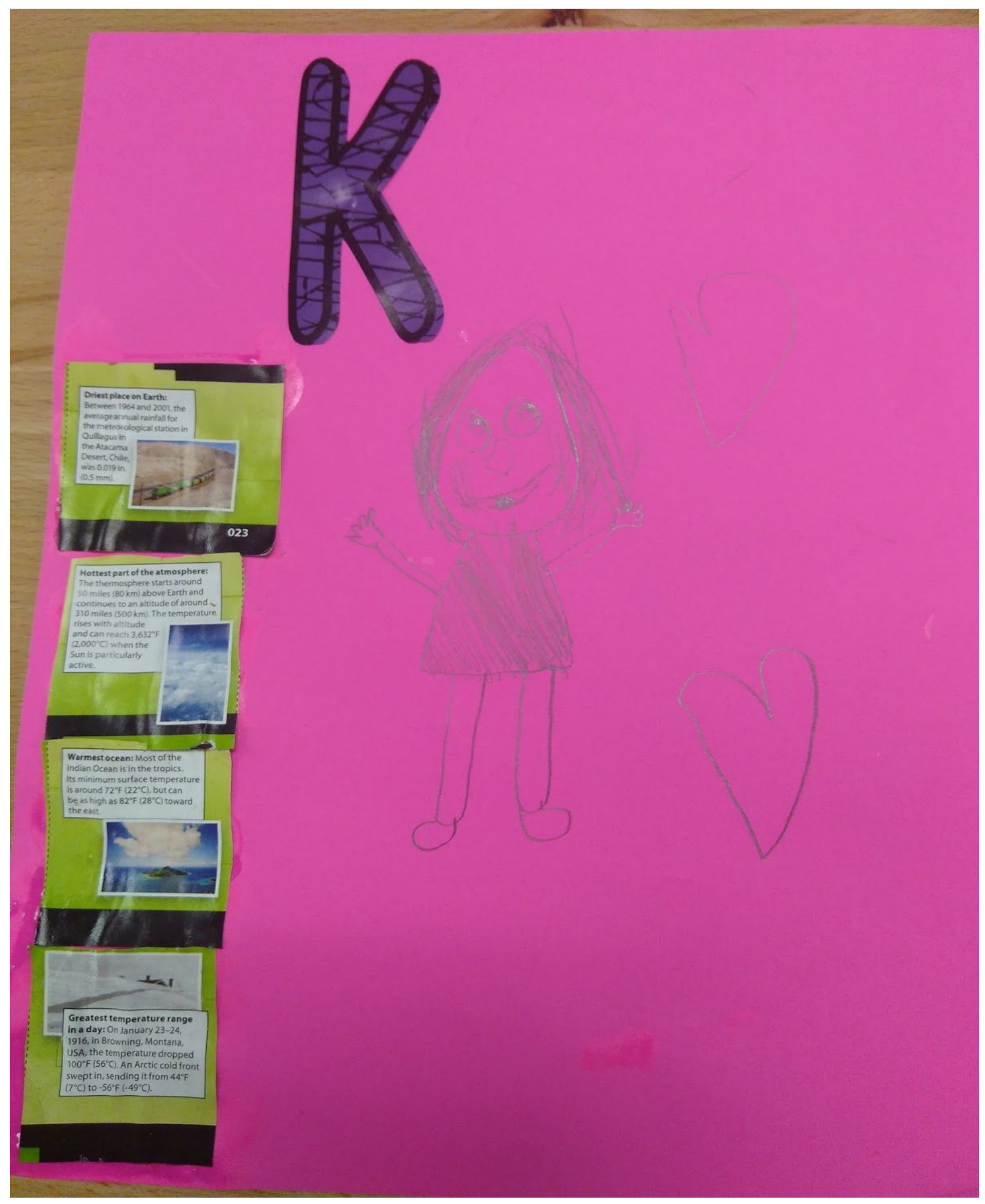

Figure 28. Student A Frida Kahlo Collage completed 


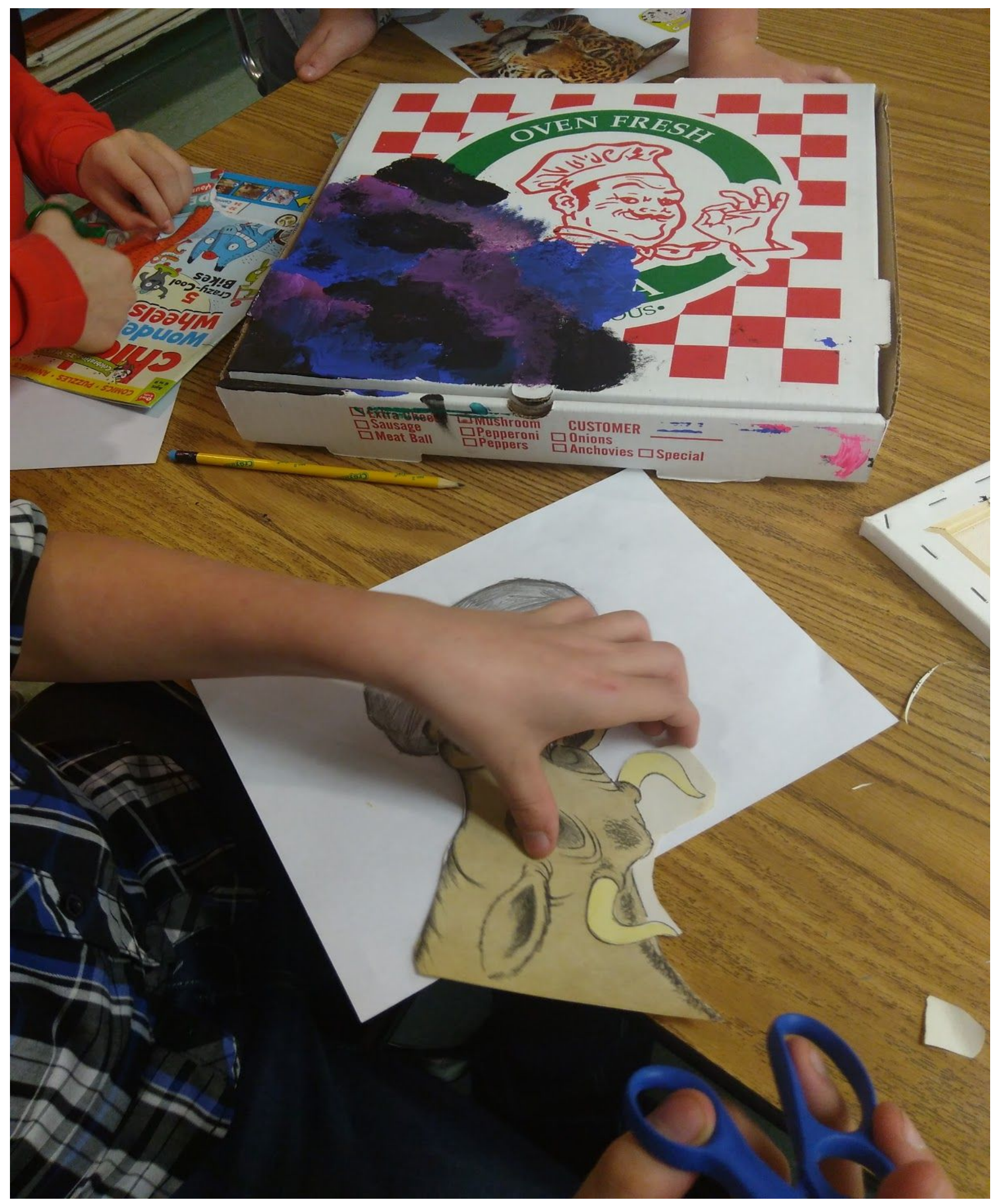

Figure 29. Twin A Frida Kahlo Collage working image 


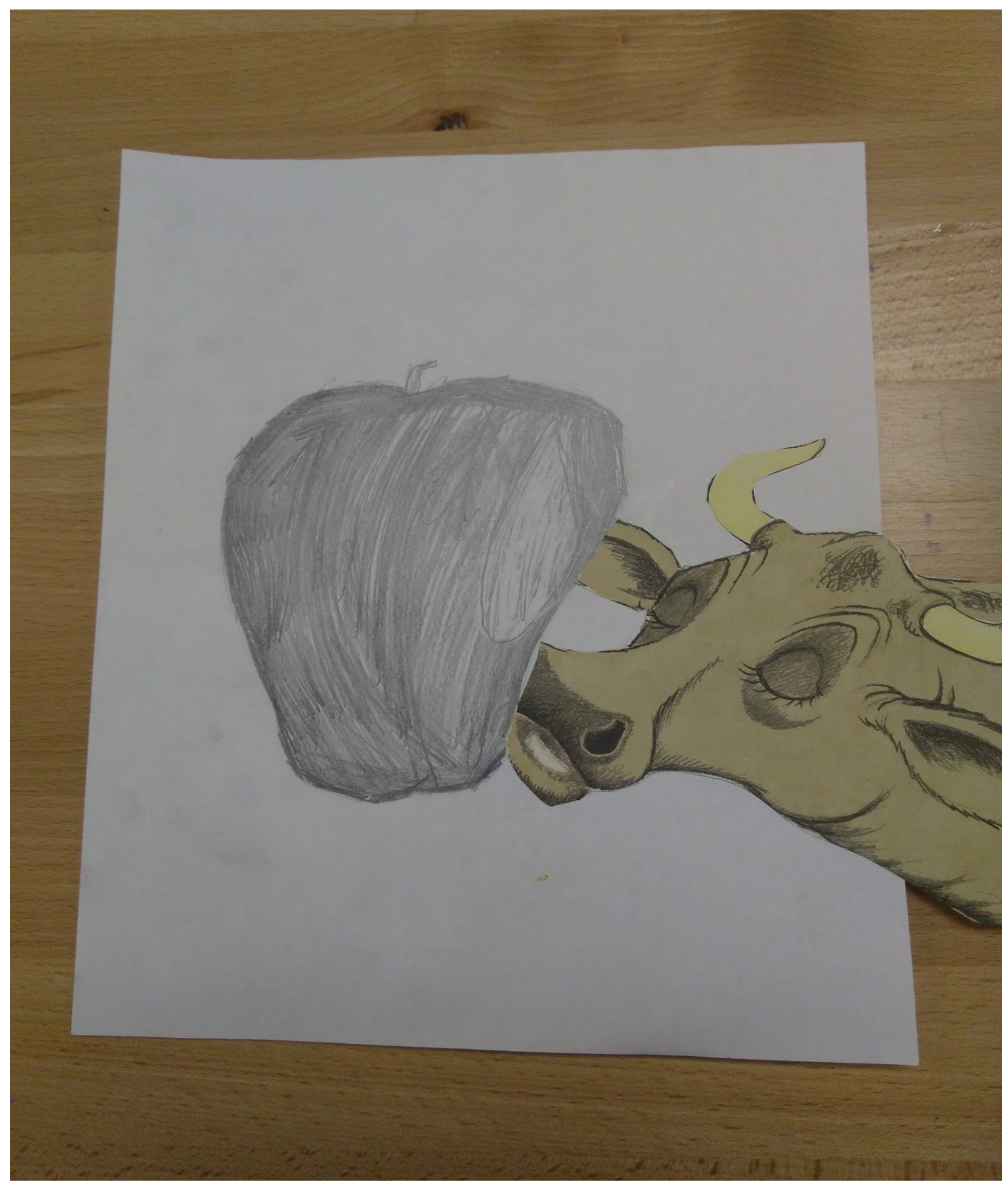

Figure 30. Twin A completed collage 


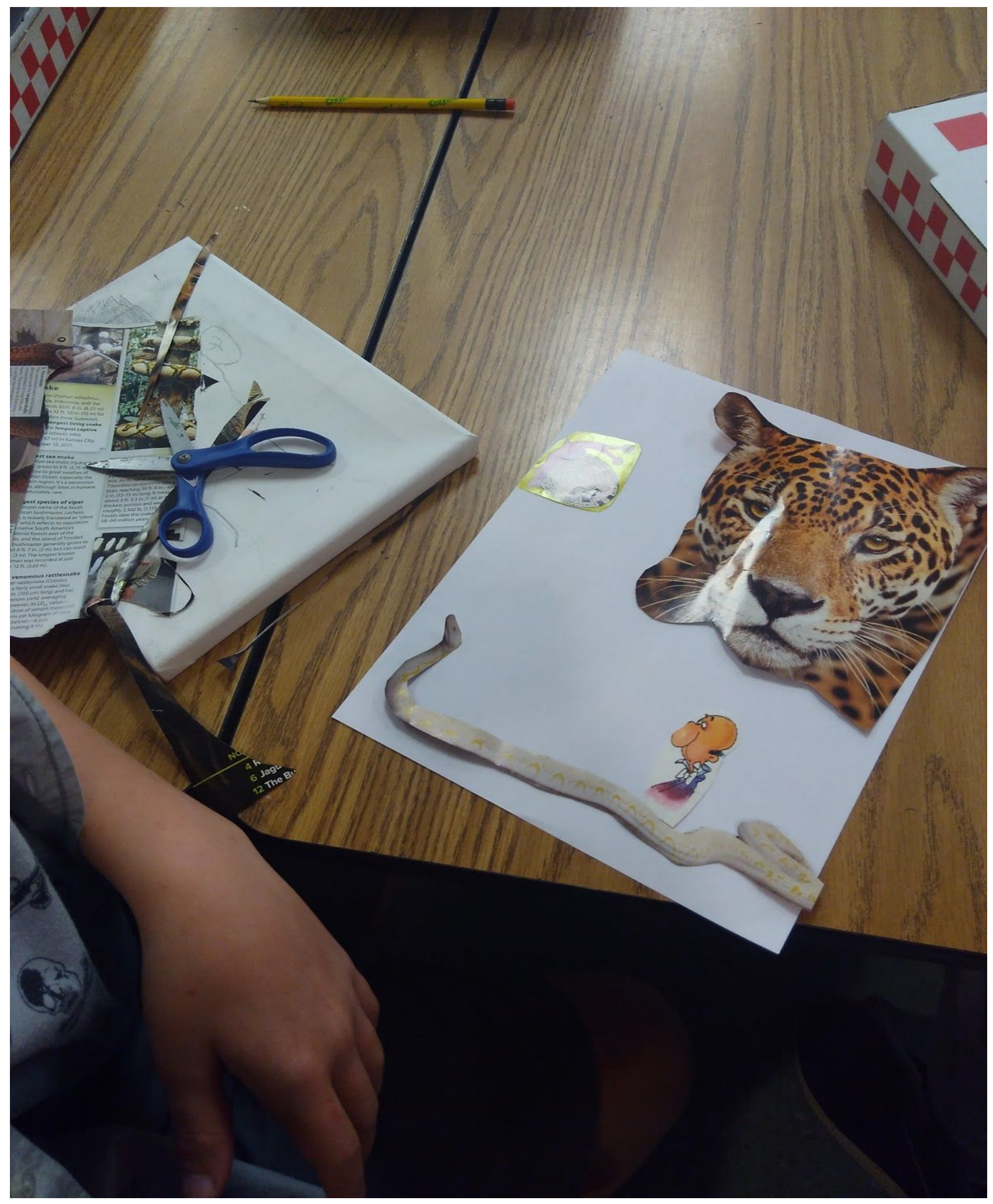

Figure 31. Twin B Frida Kahlo Collage completed 


\subsection{Materials}

Contour drawing- Robert Ault

- Elmo Camera

- 8 x 11 Paper

- colored pencil

- Mirrors

- Prismacolor blenders

Journals

- White folder

- Pre printed handouts for reflections (Figure 32)

Pizza Box

- Paintbrush (multiple sizes)

- Paint Pallets

- Various colors of Acrylic Paint

9 inch construction paper circle (Pizza Pie Chart)

- scrapbooking materials

- Stickers

- magazine clippings

- Glue- hot / sticks

- Three- dimensional objects; toys, game pieces, buttons, beads

Van Gogh Portrait

- Vincent Reflection Sheet (Figure 33) 
- Face handout \#1-3 (Figure 34-36)

- 8 x 10 canvas

- Pencil

- Mirrors

- Various colors of Acrylic Paint

- paint pallet

- Brushes (Various sizes)

- pallet knives (different sizes)

Frida Kahlo Collage

- Frida Reflection Sheet (Figure 37)

- $8.5 \times 11$ paper

- Pencils

- colored pencils

- Markers

- Crayons

- Two- dimensional objects; scrapbooking paper, magazine clippings 
Name

Date

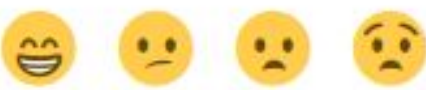

Project Title

Figure 32. Journal reflection 


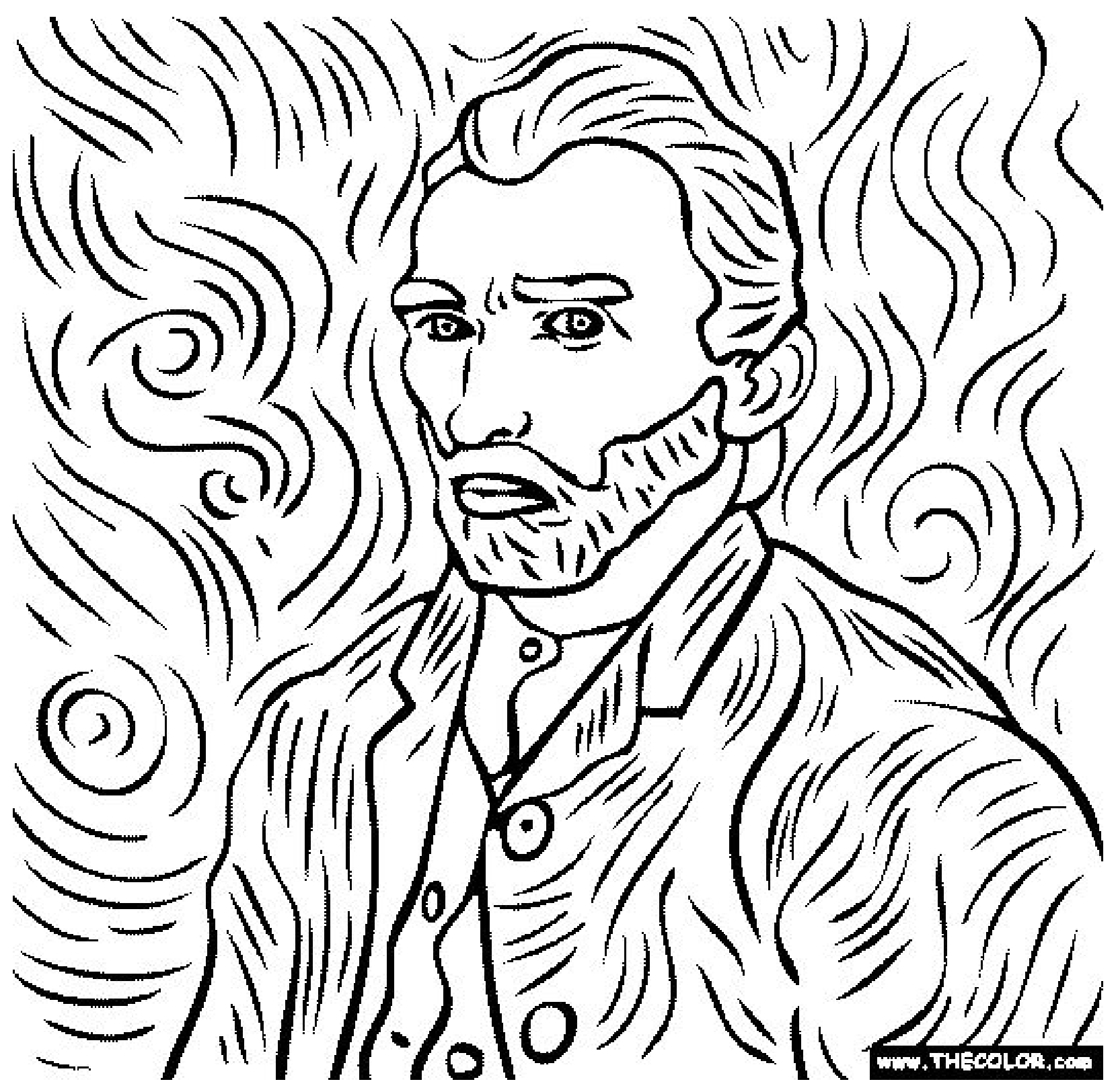

Figure 33. Vincent Reflection Sheet 


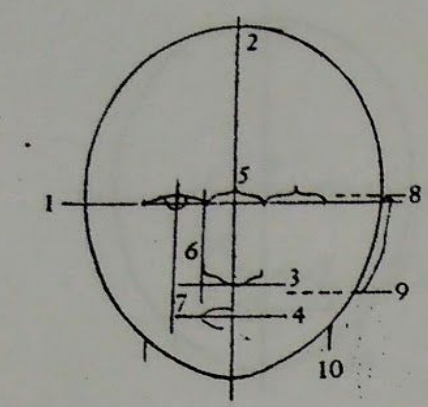

PROPORTIONS OF THE HUMAN HEAD

Fig. 9-12. General proportions of the human head.

1. This line represents the middle of the head, the location of the eyes.

2. This line represents the vertical center or the head.

3. Fnd of nose. Located slightly less than halfway between the eyes and bottom of the chin.

4. Where the lips meet. Located about a third of the way down from the nose to the chin.

5. There is the space of an eye between the eyes. There is also the space of an eye between the outer edge of the eye and the side of the head.

6. The outer edges of the nostrils are located directly below the inner corners of the eyes.

7. The outside corners of the mouth are located directly below the pupils of the eyes.

8.-9. The ears are located between the eyebrows and the bottom of the nose.

10. The neck starts just under the ears and is almost as wide as the widest part of the jaw. In some men it is as wide or
wider.

Figure 34. Face Handout \#1 
Name

Date

\section{Drawing: Portraits}

1 Fold your paper. The folds will be guidelines for drawing.
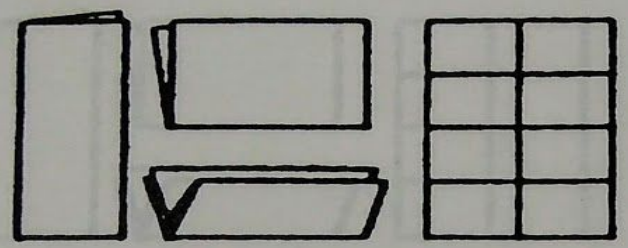

2 Observe and draw the shape of the head. Draw large. Leave space for the ears, neck, and hair.
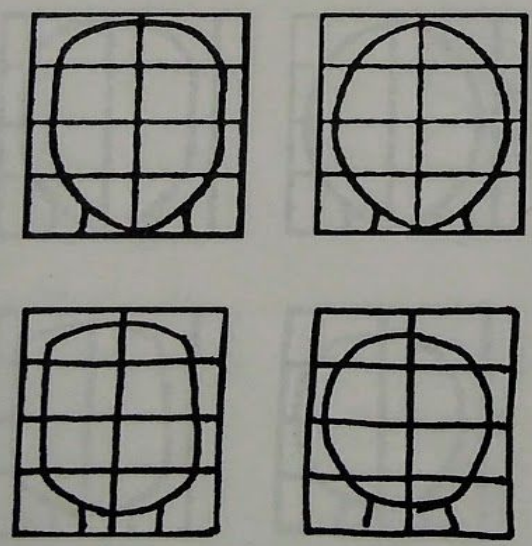

3 Draw the eyes, nose, and mouth near your guidelines.

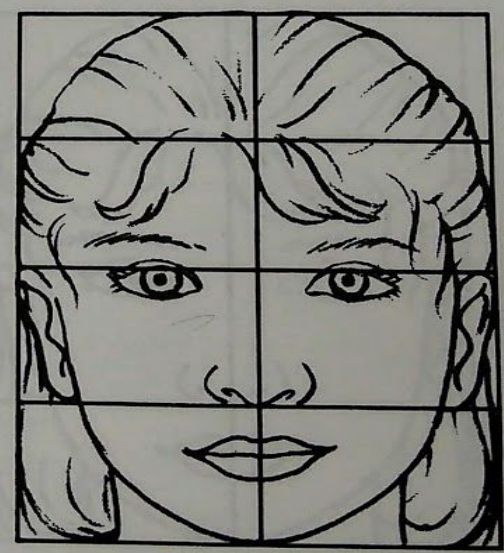

4 Look closely. Draw details.

5 Reflect: How did the guidelines help you?

Adventures in Art, Lessons 25, 26

Figure 35. Face Handout \#2 


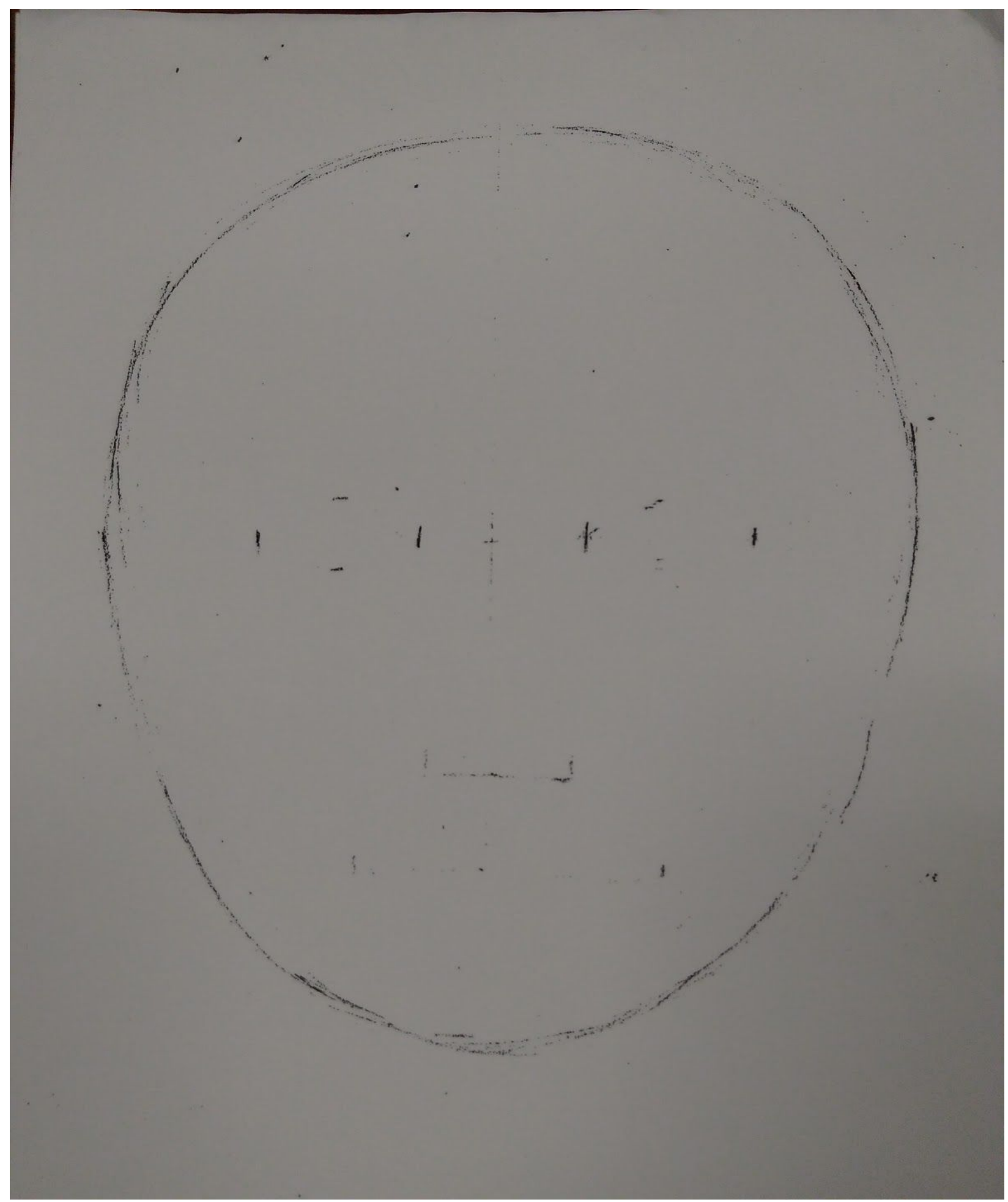

Figure 36. Face Handout \#3 


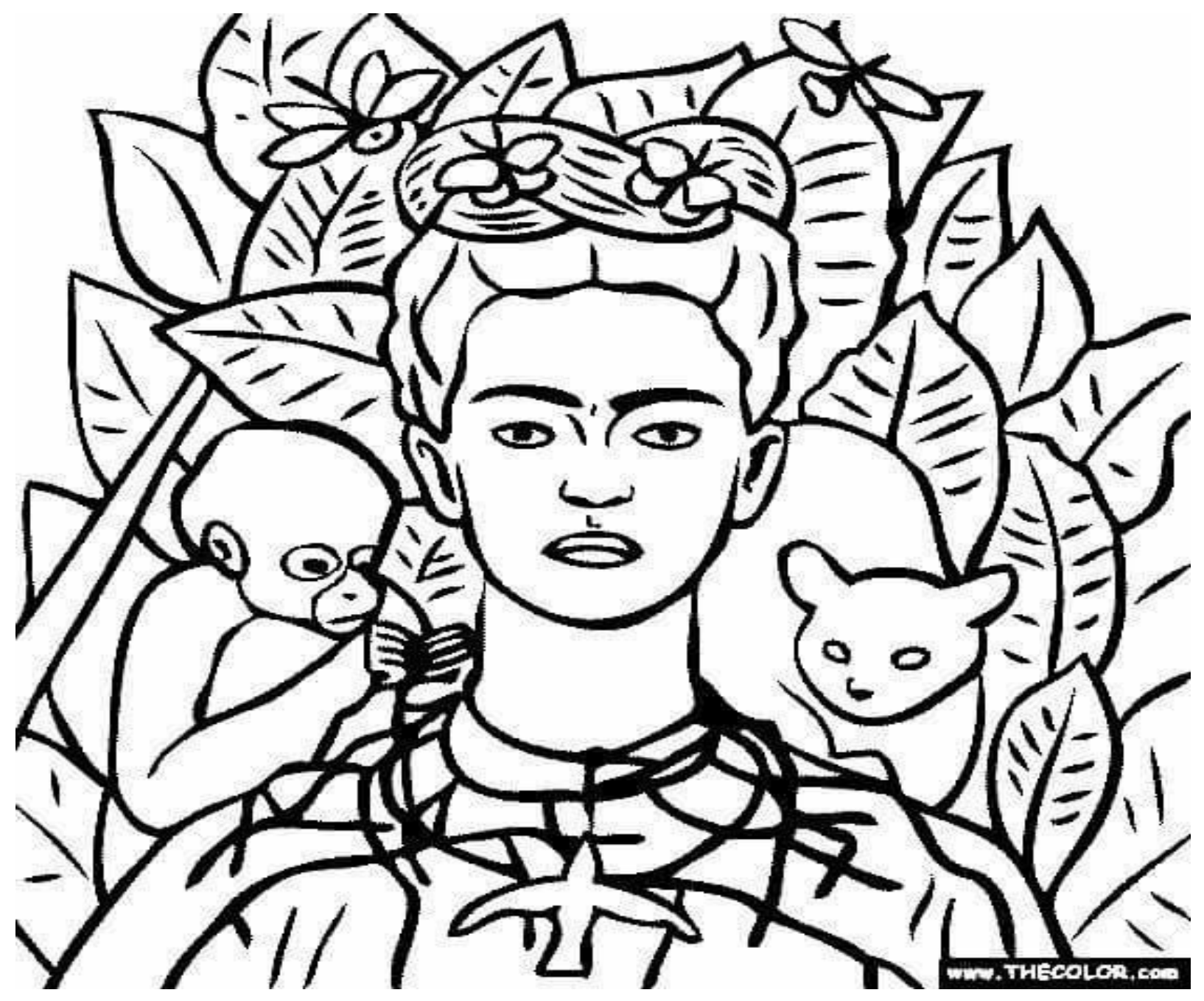

Figure 37. Frida Reflection Sheet 


\subsection{Teacher Responses}

Student D, a fifth grade student considered to be an introvert who does not interact much with peers her own age. Student D is an average education level student. She has no special education label. As I interviewed her teacher she began to explain that art and art making has opened up a lot of things for her in the last few months. She was able to make new friends through drawing, showing an improvement in social peer relationships. Her educational levels have also improved since her regular education teacher allowed her to draw and doodle on her test as a thinking processing tool (Figure 38-40). The doodles are contained to the negative spaces in between the questions not interfering with the test itself. The three images I have included were from Student $\mathrm{D}$ the tests show how the images are contained to a few areas but also that the questions are checked off as correct. This allowance of extra space for art allows her to think by performing a small action that clears her mind enough to find the correct answers in her art doodle.

During the interviews I was able to talk to the behavioral teacher for two of my students who participated in the additional art sessions. The two students are twins that are both diagnosed as $\mathrm{BD}$ with additional learning disabilities that affect their core education classes.

Twin A has made great improvements in Math and Science. In addition his reading levels have raised so much that he has reached grade level in just the last few months. Twin B has improved also in his core education classes but not as much as Twin A. Twin B also still struggles with outbursts of behavioral issues but less frequently then before the sessions started. Even though 
Twin A has made more improvements than Twin B they both have gained some additional skills after the additional art classes with art therapy fundamentals incorporated. 


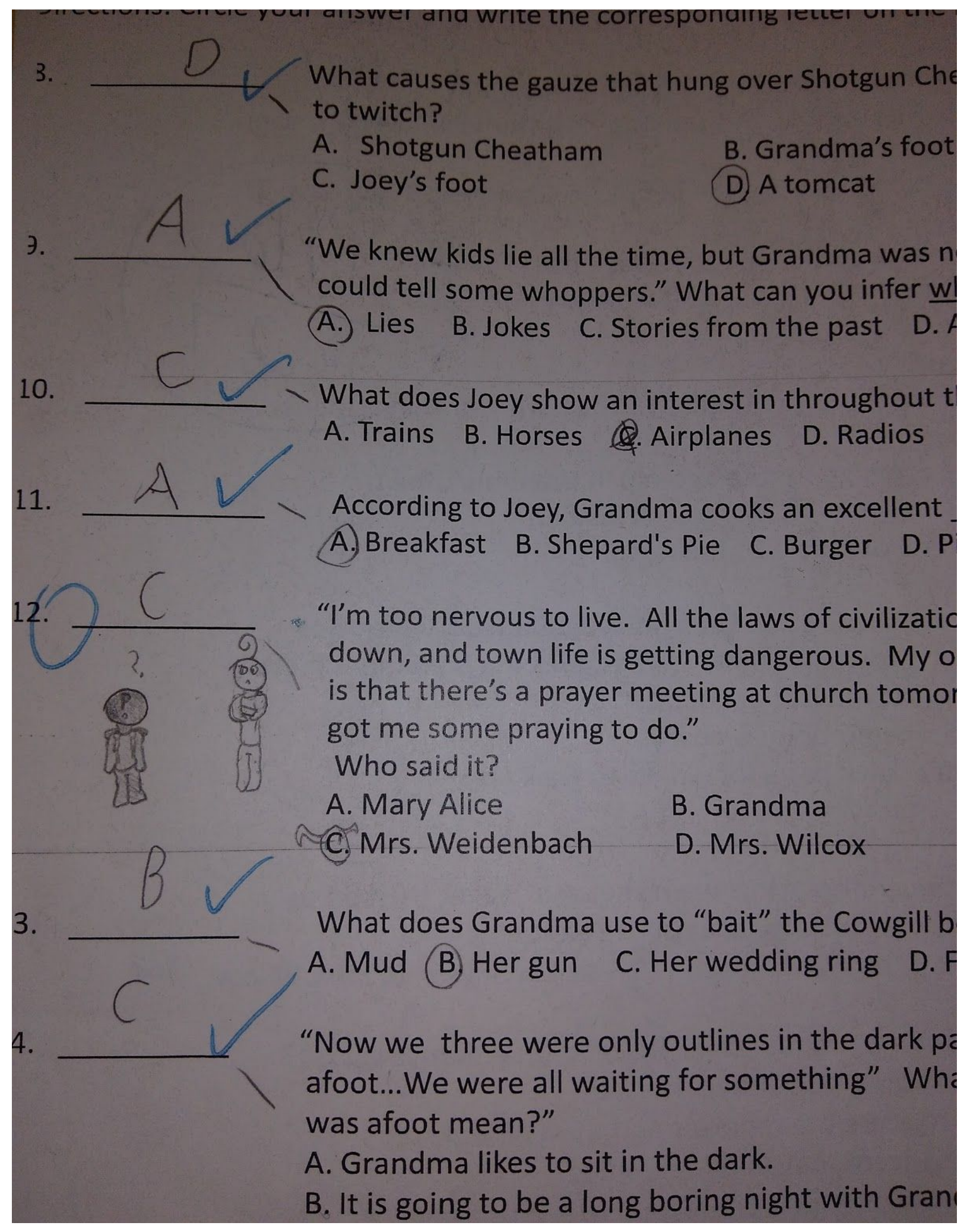

Figure 38. Student D Test page \#1 


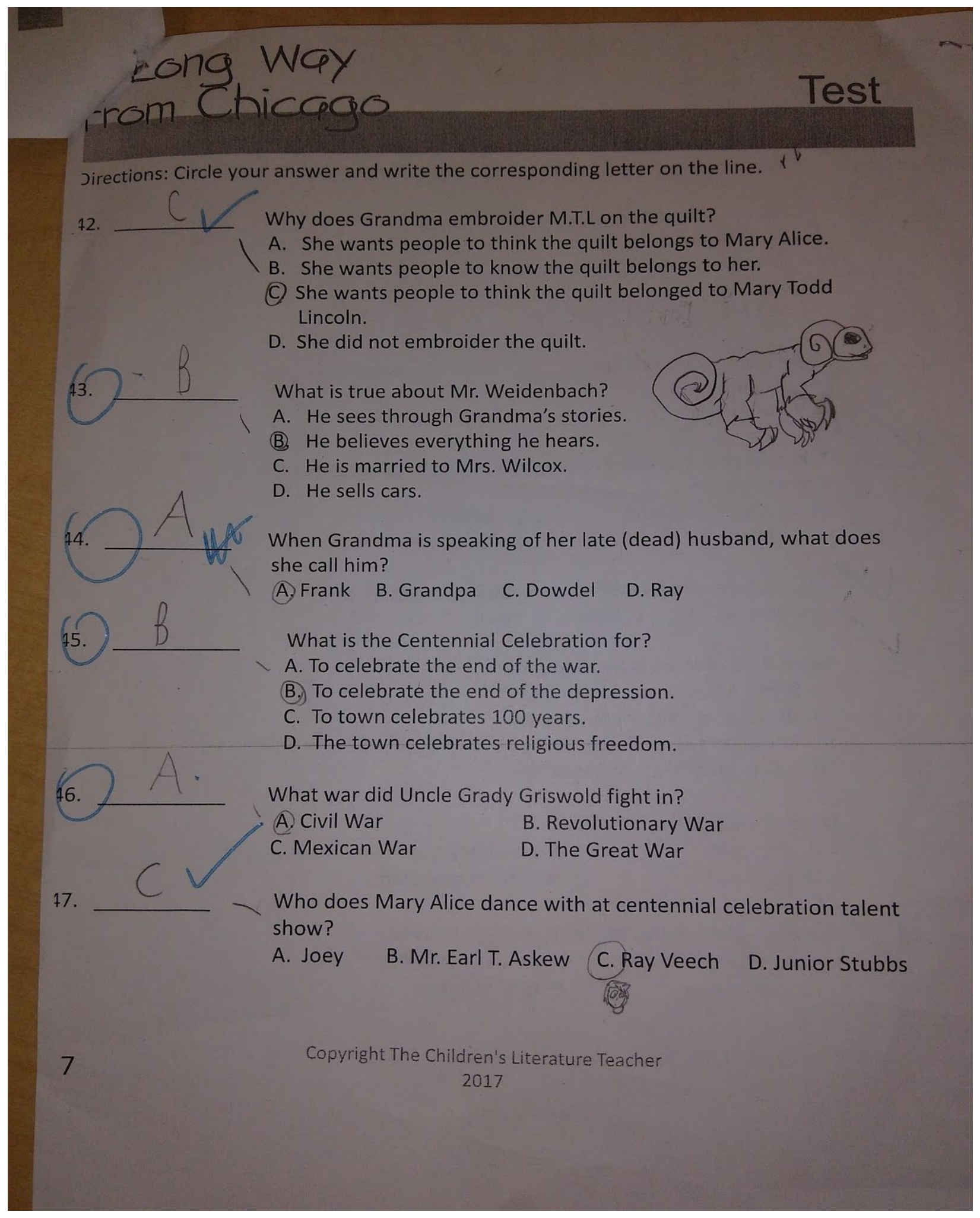

Figure 39. Student D Test page \#2 


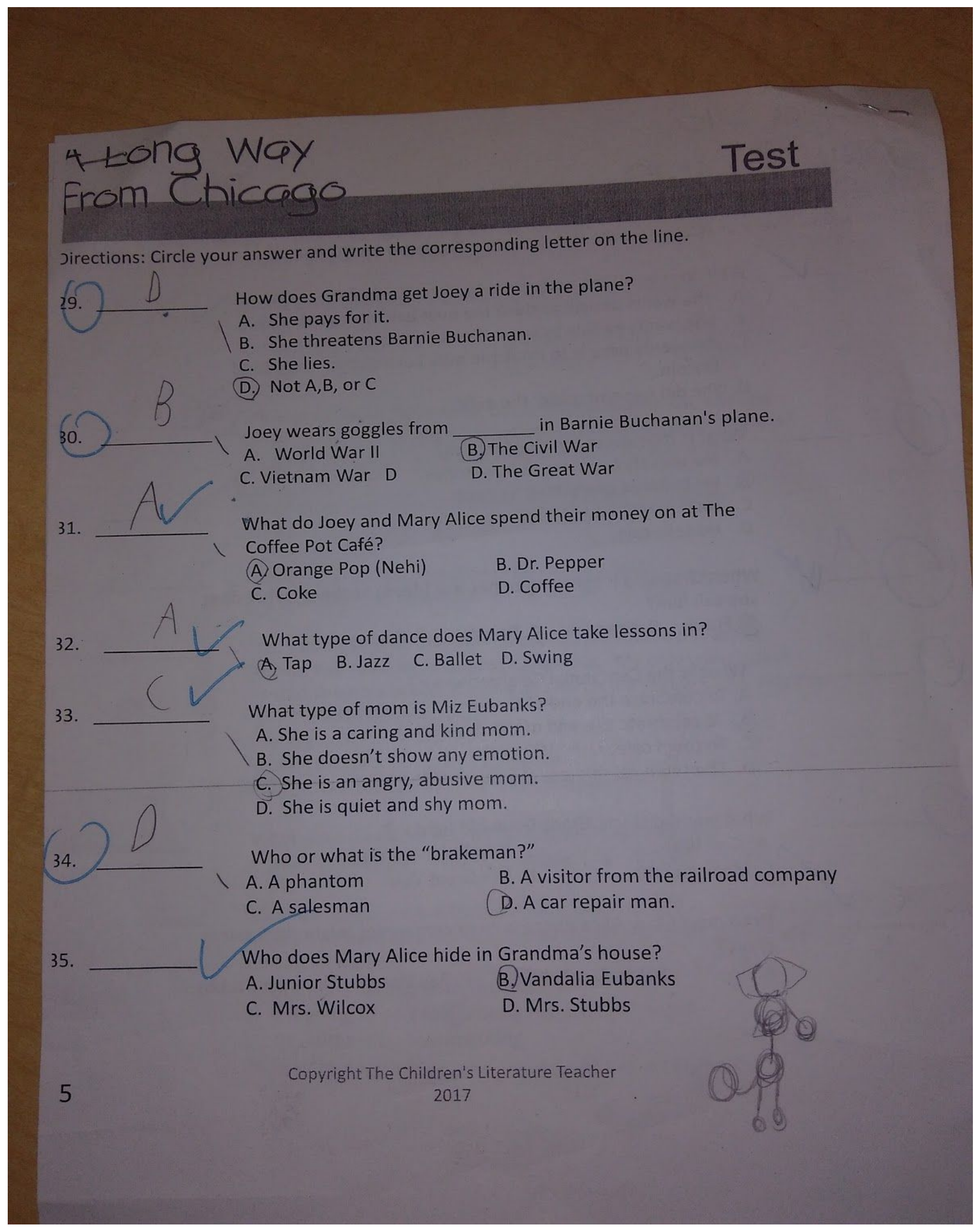

\section{Figure 40. Student D Test page \#3}




\section{Chapter 5: Discussions and Findings}

\subsection{Introduction}

The research may provide new instruction strategies and art activities for art educators to use that will improve students learning outcomes for students with AS and BD. The purpose of this paper was to discuss how art therapy, when integrated into an art education classroom, could benefit students diagnosed with Autism Spectrum or Behavioral Disabilities. The findings appear to suggest that when certain art therapy approaches are used with students with AS and BD, there is noticeable improvement in student behaviors, student learning outcomes and student creativity. A summary of these findings, interpretation of the findings, implications for educational practice and suggestions for further research are presented in this chapter.

From my research questions, the following themes emerged:

Throughout the process students were able to reflect and create outward expressions of themselves using new and exciting tools, techniques, and media. Through the use of contour drawings, students were able to use unrefined lines and full body motions to express any stress or build up anxiety. Through introspective self portraits, in the style of Van Gogh, students were able to express what their inner self would look like verses their outer appearance. This allowed for their more internal emotions to shine outwards, showing their deeper personal self. This idea was paired with new tools and familiar more child-like approaches, like finger painting, to allow everyone the opportunity to step out of the expected bubble of society. 
Students were able to use objects and cultural references to show interests, likes and dreams that improved learning outcomes. When working with symbolism and icons the students were able to use objects and cultural references to show interests, their likes and dreams, allowing the self portrait idea to be created in a new form than the more traditional facial portrait style. All these tools paired together, and the many variety of styles combined, was a good base for participants to flourish in.

Students were able to use different tools during this project that helped them improve creativity. The students were introduced to artists that use more complex levels of thinking to create artwork. During the pre-project activity, based on Robert Ault, the students were able to freely draw themselves as curved free flowing lines. The artwork that was introduced from Grandma Layton bordered between dreams and doodles, an artform that the students had never experienced with me. When looking at Van Gogh's' self portraits the students were introduced to the idea that self portraits do not have to be clean and defined details. The students could express their personal self portrait image more as what they felt and how they saw their internal self. During the Frida Kahlo section the artwork required more of a higher level of thinking, using icons and symbols as a way to represent yourself. The use of collage and layer objects is a advanced idea in itself, let alone paired with the new idea of personal self representation.

Students used advanced cognitive thought to understand the depth and higher level of thinking associated to these artists that showed student growth. The new and advanced ideas that fed into the students' creativity and the process were instrumental in helping them reach their full human potential. The ideas that can come from these new tools are endless. By opening up to these ideas, the students, now armed with a higher level of thought, can go forward into other educational 
core subjects and see more complex, more abstract ideas than before. The overall benefits to not only the AS and BD students, but also the general population as a whole, was a wonderful discovery.

\subsection{Suggestions for Future Implementation}

Time management seemed to be an overall concern and constant struggle throughout all of these projects. For future lessons, I would allocate more time to each of the individual projects. For the contour drawing lesson, I would add a powerpoint to the beginning of day 1 instead of having it on day 2. Looking back, I am not sure why I did not initially think to add this to day 1 before beginning any groups into this project. When the powerpoint was added the students responded better to the project once they were able to see what a final piece, other than my example, would look like. The addition of her real photograph into the first slide was a huge contributor to successful understanding. The photo allowed the students to see an actual real image of her and see the differences between the real and the contour drawing.

For journals, I would suggest to allot additional time to fill them out during the sessions. I noticed as the sessions went along the students became melancholy about filling out the journals. They responded more positively to the additional reflection sheets, the print outs of the artists portrait, more than the original one. I think that by adding more variety the students would not become as melancholy to the process.

For the pizza box project, I would make sure that the pizza box exterior was all white, no identifications printed on the pizza box. An all white pizza box would probably serve as a better canvas for any future attempts of this project. The students did a great job at painting and 
expressing themselves on the cover of their boxes but some students allowed some of the pre-printed surface to show. Either because they like the design or pizza itself, but did distract a bit from the overall goal of the exterior of the box. Another suggestion I would give is to allow additional time to paint, longer than one class time. I was amazed at what they were able to accomplish but wonder if one additional day was added what the end results would look like.

For the pizza pie chart project, I would make the following suggestions to improve the process. I would request that the students bring in drawings and objects in, from home, to incorporate into their pizza pie chart. I had made it a suggested option during this process but if it was strongly requested the process may have gone faster. The main discovery I observed during this project was the very obvious difference between male and female participants in the fifth grade group, specifically. The females in this group seemed to be more aware of their cognitive emotions and were able to process the more complex emotions being asked of them than their male counterparts.

When given specific tools and media were used to work with, some students were more successful creatively and the craftsmanship improved. For the Van Gogh project, I would make mirrors readily available to all students who wanted one. As i did this project I noticed some students in particular were more successful when given a mirror to draw. I noticed that when given this tool to use specifically, they paid more attention to themselves and their drawings and added more details and had more form incorporated into them. When talking to the mentor assistant, she expressed that one student in particular loved to look at herself in mirrors, probably contributing to her overall success when given one as a drawing tool. I think the love of looking at herself, to form a sketch that she was able to paint the following week played on this student's self-efficacy. By 
playing on her strengths, and using a mirror to draw, some students were able to have a more successful project.

There was noted improvement among students with specific art therapy approaches. By the end of week five I was able to conduct an informal interview with the special education teacher of Student A. Have you seen an improvement with Student A since the beginning of January? If yes, what have you noticed different? She responded by saying Student A has experienced less crisis within the given time of January to beginning of March. Student A has also improved her focus while working on tasks in her educational core classes. Student A has also been less self stimulating (STIM) within this time. Self-stimulatory behavior, also known as stimming and self-stimulation, is the repetition of physical movements, sounds, or words, or the repetitive movement of objects common in individuals with developmental disabilities and most prevalent in people on the autism spectrum. These actions include flapping, rocking, spinning, or repetition of words and phrases. With all these findings and developments within the first five weeks, I will be interested to see how and what will change in the last few remaining weeks of the experience. The fact that Student A tried all the materials and tools given to her during this project paired with the outcome shows growth from the beginning of these sessions to now.

Students who used outside class time, to make additional pieces for their personal collages, showed noticeable improvement. After this project was completed I reflected on a few different ideas. I think that by having the students draw outside of the sessions settings, along with collaging during the sessions the results turned out more beneficial. Not all participants did this step, but if I were to redo it again I would request this as a requirement to all involved. The students that did draw outside of class were able to be specific, making their piece more personal to them, than those 
who just used the available magazines and allotted class time. It also was beneficial because the students who took longer and were more detailed with their drawings were able to get the time that they needed, verses rushing in the 30 minutes given to them in sessions.

Students were able to show improvements in their core education courses along with peer to peer relationships. After the projects were all completed I was able to interview the students' teachers about improvements that they had seen over the course of the sessions.

Student A, as listed in the above sections, had improved from the beginning of the sessions to the halfway point when I did the first interview with her teachers. Student A's self stimulating behavior has improved throughout the entire additional art session process. On the days that the sessions had to be cancelled due to additional things happening at the school, Student A would become aggravated by the inability to receive the additional art class time. This could be due to two factors; the destruction in her planned schedule and need for routine with consistency, and/or her added enjoyment from getting to participate in the additional art sessions.

I was able to conduct other interviews after the sessions were completed. The teachers were asked the following questions; Did you see any improvement in, insert students name, from January to now? If so what were the changes that you saw? Would you like to add anything else additionally about the students along with this? All the teachers interviewed responded positively to the questions about the students that participate in the sessions.

\subsection{Closing}

Art has a way of helping people of all ages, especial children, show ideas and emotions that can sometimes be hard to express verbally and student projects showed art appeared to help them 
deal with some of these issues. The proof that the students were able to show improvements in their core education courses along with peer to peer relationships was great news. The fifth grade group had a greater understanding of the more difficult, more abstract thoughts, compared to the fourth grade participation group. The overall benefits to not only the AS and BD students, but also the general population as a whole, was a wonderful discovery.

Time management seemed to be an overall concern and constant struggle throughout all of these projects. The students are used to having additional allotted time, in art class, that was not possible during these projects. If they were given additional time the students would be able to get more products done in a more affectent way, but that idea is based more in the art education realm and less in art therapy. After doing these projects I can see that the border line between the two is very fuzzy and can waver back and forth more than I had originally expected. Part of that could be because of the students participating in the group having had me in an art education setting verses shorter art therapy based setting. 


\section{Conclusion}

"Great things are done by a series of small things brought together"

-Vincent Van Gogh

Art education paired with selected art therapy approaches has the ability to impact students diagnosed as Autism Spectrum (AS) and Behavioral Disabilities (BD) by giving them skills that will help them throughout their lives. The idea of visual arts paired with art therapy fundamentals allows all elementary age students a creative outlet to express themselves and grow as individuals, helping them reach their own personal human potential. Visual arts encourage academic growth, but also cognitive and interpersonal growth as well. The above Vincent Van Gogh quote speaks volumes in this situation: The small action of art making can impact and change a student in many positive ways, giving them the tools needed to achieve great things throughout their lives. 


\section{Bibliography}

Autism Facts and Figures. (2019). Retrieved February, 2019, from

https://www.autismspeaks.org/autism-facts-and-figures

Benefits of expressive art therapy for children. (2016, August).

Retrieved September, 2019, from

https://www.georgetownbehavioral.com/expressive-art-therapy-for-children

Bergland, C. (2013). Cortisol: Why the "Stress Hormone" is public enemy no. 1. Psychology

Today. Retrieved September, 2018, from

https://www.psychologytoday.com/us/blog/the-athletes-way/201301/cortisol-why-the

-stress-hormone-is-public-enemy-no-1

Blumberg, N. (n.d.). Arthur Wesley Dow american artist and educator.

In Encyclopedia Britannica. Retrieved Fall, 2018, from

https://www.britannica.com/biography/Arthur-Wesley-Dow

Bolin, Paul E. (1990). The Massachusetts Drawing Act of 1870: Industrial Mandate or Democratic Maneuver? In Soucy, D. E., \& Stankiewicz, M. A. (1990). Framing the Past Essays on Art Education. National Art Education Association. doi:10.2307/368385

Caldwell, S. F. Ph. D. (1975). The Human Potential Movement: Forms of body/movement/nonverbal experiment (paper presented at the forty-second annual conference of - the California association for health, physical education, and recreation (42nd Los Angeles, California, March 21-24, 1975)). 
California State University, Northridge. Retrieved March 26, 2019.

Cherry, K., (2018, September). Can color affect your mood and behavior?

Retrieved February, 2019, from

https://www.verywellmind.com/color-psychology-2795824

Corrington, D. R. (1970, January 01). Art Therapy: Sharing directives [Web Blog post].

Retrieved January, 2019, from

http://arttherapydirectives.blogspot.com/2012/07/self-portrait-contourdrawings-this.h

$\underline{\mathrm{tml}}$

Cox, J. (2016). STEM vs STEAM: What's Better?

Retrieved February, 2019, from

http://www.teachhub.com/stem-vs-steam-what-is-better

Dewey, J. (1934). Art as Experience. New York, NY: Minton, Balch \& Company.

Drachnik, C. (1976, November). A historical relationship between art therapy and art education and the possibilities for future integration. Art Education

Vol. 29, No. 7, 16-19. doi: 10.2307/3192142

Edelson, S. M., Ph.D. (n.d.). An overview of Autism. Retrieved March 14, 2019, from https://www.autism.com/symptoms self-stim

Edudemic Staff (2015, January 21). STEM vs. STEAM: why the "A" makes a difference". Retrieved October, 2018, from http://www.edudemic.com/stem-vs-steam-why-the-a-makes-all-the-difference/

Falk, L. (2017, June 28). Art projects helps students with emotional and behavioral 
challenges. Retrieved February 18, 2019, from

https://www.thewatsoninstitute.org/art-project-helps-students-emotional-behavioral-ch

allenges/

Feen-Calligan, H. (2008). Remembering Robert E. Ault (1936-2008). Art Therapy, 25(2), 85-89.

doi:10.1080/07421656.2008.10129419

Freedman, C. (2019). Frida Kahlo paints "My Dress Hangs There".

Retrieved February 14, 2019, from

https://worldhistoryproject.org/1933/3/frida-kahlo-paints-my-dress-hangs-there

Kahlo, F. (1937). Memory, the Heart, [Painting].

Retrieved October, 2018, from https://www.fridakahlo.org/memory-the-heart.jsp

Kahlo, F. (1933) My Dress Hangs There, [Painting].

Retrieved October, 2018, from https://www.fridakahlo.org/my-dress-hangs-there.jsp

Kahlo, F. (1940). Self- Portrait with Thorn Necklace and Hummingbird, [Painting].

Retrieved October, 2018, from

https://www.fridakahlo.org/self-portrait-with-thorn-necklace-and-hummingbird.jsp

[Frida Kahlo Coloring sheet]. (2007-2018). Retrieved December, 2018, from

https://i.pinimg.com/originals/6c/83/40/6c8340c74decfb44a379d9b3538b

Kahlo, F. (n.d.). Retrieved January, 2019, from

https:/quotefancy.com/quote/807768/Frida-Kahlo-Passion-is-the-bridge-that-takes-you-fro

$\underline{\mathrm{m}}$

-pain-to-change

Kaimal, G., Ray, K., \& Muniz, J. (2016). Reduction of Cortisol Levels and Participants Responses 
Following Art Making. Art Therapy, 33(2), 74-80. doi:10.1080/07421656.2016.1166832

Katz-Buonincontro, J. (2018). Creativity for whom? art education in the age of creative agency, decreased resources, and unequal art achievement outcomes. Art Education, 71(6), 34-37. doi:10.1080/00043125.2018.1505388

Gale Encyclopedia of Medicine. (2008). Retrieved Fall, 2018, from https://medical-dictionary.thefreedictionary.com/Human-Potential Movement Gogh, V. V. (1888). Bedroom in Arles [Painting].

Gogh, V. V. (1889). Starry Night [Painting].

Gogh, V. V. (1886-1889). The eyes of Vincent Van Gogh:Self Portraits [Image]. Retrieved September, 2018, from http://blog-de-beaux-arts.tumblr.com/post/104233348521/caravaggista-the-eyes-of-vi ncent-van-goghself(December 3, 2014)

Gogh, V. V. (1886-1889). Self Portraits [Image]. Retrieved September, 2018, from https://i.pinimg.com/564x/8a/b7/50/8ab75061d0644b9884ad8e24147ae48c.jpg

Goulding, Ellie. (2018, February 19). Vincent [Video file]. Retrieved November, 2018, from https://www.youtube.com/watch?v=bw8zr1n-MF

Keane, C. (2018, December 12). An expert on school-based art therapy explains how art therapy helps children make sense of the insensible.

Retrieved December, 2018, from https://arttherapy.org/art-therapy-helps-children-make-sense-of-the-insensible/ 
Keating, M. (2007, November 13). A place to hide and heal. Retrieved October, 2018, from https://www.theguardian.com/education/2007/nov/13/schools.uk3

Lachman, R. (2018, October 30). STEAM not STEM: Why scientists need arts training. Retrieved February, 2019, from https://theconversation.com/steam-not-stem-why-scientists-need-arts-training-8978 $\underline{8}$

Lacour, K. (2018, October 01). The value of art therapy for those on the autism spectrum. The Art of

Autism. Retrieved November, 2018, from https://the-art-of-autism.com/the-value-of-art-therapy-for-those-on-the-autism-spectrum/

Lambert, D. KCAC Forum Magazine November 1980. Kansas City Artists Coalition. Retrieved January, 2019, from http://kansascityartistscoalition.org/artists/throwback-thursday-kcac-forum-45/

Layton, E. (n.d.). Layton Contour. Retrieved January, 2019, from https://www.picswe.com/pics/layton-contour-bb.html

Layton, E. (1986) 327: pencil signed lithograph. Retrieved January, 2019, from http://www.liveauctioneers.com/item/8279087

Loveless, B. (2019). Emotional and behavioral disorders in the classroom. Retrieved January, 2019, from https://www.educationcorner.com/behavioral-disorders-in-the-classroom.html Malley, S. M. (2017, December 14). Collaboration between special education and arts 
education. Retrieved January, 2019, from

https://www.routledgehandbooks.com/doi/10.4324/9781315618135-4

Martin, N. (2009). Art Therapy and Autism: Overview and recommendations.

Art Therapy, 26(4), 187-190. doi:10.1080/07421656.2009.10129616

Mayo Clinic Staff (2018, January 06). Retrieved January, 2019, from

https://www.mayoclinic.org/diseases-conditions/autism-spectrum-disorder/symptoms-cause $\underline{\mathrm{S}}$

/syc-20352928

Mcleod, S. (2018, May 21). Maslow's hierarchy of needs. Retrieved April 2, 2019, from https://www.simplypsychology.org/maslow.html

Morrell, M. (2011). Signs and Symbols: Art and language in art therapy. Journal of

Clinical Art Therapy, 1(1), 25-32, retrieved from:

http://digitalcommons.lmu.edu/jcat/vol1/iss $1 / 8$

MotionMagic. (2016, November 28). Retrieved November, 2018,

from https://www.youtube.com/watch?v=G7Dt9ziemYA

Naumburg, M. (1966). Dynamically oriented art therapy: Its principles and practices. New York, NY: Grune \& Stratton.

Robinson, K. (2006, February). Do schools kill creativity? Retrieved October, 2018, from https://www.ted.com/talks/ken_robinson_says_schools_kill_creativity?language $=$ en $\#$ t-1148557

Rubin, J. A. (1999). Art therapy: An introduction. Philadelphia (PA): Brunner/Mazel. 
Ryff, C. D. (2018). Well-being with soul: Science in pursuit of Human Potential.

Perspectives on Psychological Science, 13(2), 242-248.

doi:10.1177/1745691617699836

Schweizer, C., Spreen, M., \& Knorth, E. J. (2017). Exploring what works in art therapy

with children with Autism: Tacit knowledge of art therapists. Art Therapy, 34(4),

183-191. doi:10.1080/07421656.2017.1392760

Shultis, J. (2018). 20 Art therapy activities you can try at home to destress.

Retrieved Fall, 2018, from

https://cdn.lifehack.org/wp-content/uploads/2014/11/Chart.jpg

Snow, C.P. (1959). The two cultures. London: Cambridge University Press.

Stout, V. T. (1995). Integrating art education and art therapy in the public schools

(Honor Master's Thesis). Southern Illinois University Carbondale. https://opensiuc.lib.siu.edu/cgi/viewcontent.cgi?article $=1116 \&$ context $=$ uhp theses

Tobin, M. (May 2015). A brief history of art therapy: From Freud to Naumburg and

Kramer. A Brief History of Art Therapy: From Freud to Naumburg and Kramer. doi:10.13140/RG.2.1.4211.6003/1

TopekaLibrary. (2010, December 19). 52 for 150: What's so special About Elizabeth "Grandma" Layton? Retrieved Fall, 2018, from https://www.youtube.com/watch?v=Zz kCQ $562 \mathrm{k} \&$ feature=youtu.be

Valentin, K. (2018, February 19). Benefits of art therapy. Retrieved January, from https://www.myautism.org/benefits-art-therapy/ 
[Vincent Van Gogh coloring sheet]. (2007-2018). Retrieved December, 2018, from

https://www.thecolor.com/Print/PrintPicture2 k4gzihlgthhqqk4sjbc5avri vincent-van -gogh-selfportrait.aspx

Wade-Leeuwen, B., Vovers, J., Silk, M., \& Chemical. (2018, November 26). Explainer:

What's the difference between STEM and STEAM? Retrieved January, 2019, from http://theconversation.com/explainer-whats-the-difference-between-stem-and-steam-95713

West Virginia Policy 2419 Regulations for the Education of Students with Exceptionalities. (2017, July). Retrieved March 28, 2019, from https://wvde.state.wv.us/osp/Policy2419 2017.pdf

Wiste, M. (2016, June 09). Awakening your inner Artist: Why art teachers should make art. Retrieved September, 2018, from https://www.theartofed.com/2016/06/23/awakening-inner-artist-art-teachers-make-a $\underline{\mathrm{rt} /}$

Wysty67. Don Mclean- Vincent [Video file]. (2009, August 27). Retrieved November, 2018, from https://www.youtube.com/watch?v=oxHnRfhDmrk 
Additional Library (reference books for the students to use)

Appel, Julie and Amy Guglielmo, (2006). Touch the art making Van Gogh's Bed. New York, NY: Sterling Publishing Co.

Brown, Monica. (2017). Frida Kahlo and her animalitos. New York, NY: North South Books.

Cabanne, Pierre, (1963). Van Gogh the man and his work, New Jersey: Prentice-Hall Inc. Englewood Cliffs.

Fabiny, Sarah. (2013). Who was Frida Kahlo?, New York, NY: Grosset and Dunlap .

Frith, Margaret. (2003). Frida Kahlo The artist who painted herself, New York, NY: Grosset and Dunlap .

Hughes, Andrew, (1993). Famous Artists Van Gogh, An Introduction to the Artist's Life and Work, Aladdin Books, Barron's Educational Series Inc.

Second grade students at East Washington Academy in Muncie, Indiana. (2010). Vincent Van Gogh's Cat, New York,NY: Scholastic Inc.

Van Gogh Museum Guide, (1996). Amsterdam: Van Gogh Museum.

Venezia, Mike. (1999). Getting to know the World's Artist, Frida Kahlo. New York, NY: Children's Press.

Venezia, Mike. (1999). Getting to know the World's Artist, Vincent Van Gogh. New York, NY: Children's Press.

Vergara, Ma Isabel Sanchez. (2016). Little People, BIG DREAMS, New York, NY: Frances Lincoln Children's Books. 